Florida International University FIU Digital Commons

9-14-2010

\title{
Sales Tax Enforcement: An Empirical Analysis of Compliance Enforcement Methodologies and Pathologies
}

Philip C. Christian

Florida International University, pcc2220@gmail.com

DOI: $10.25148 /$ etd.FI10120308

Follow this and additional works at: https://digitalcommons.fiu.edu/etd

\section{Recommended Citation}

Christian, Philip C., "Sales Tax Enforcement: An Empirical Analysis of Compliance Enforcement Methodologies and Pathologies" (2010). FIU Electronic Theses and Dissertations. 335.

https://digitalcommons.fiu.edu/etd/335 


\section{FLORIDA INTERNATIONAL UNIVERSITY}

Miami, Florida

\section{SALES TAX ENFORCEMENT: AN EMPIRICAL ANALYSIS OF COMPLIANCE ENFORCEMENT METHODOLOGIES AND PATHOLOGIES.}

A dissertation submitted in partial fulfillment of the

requirements for the degree of

DOCTOR OF PHILOSOPHY

in

PUBLIC AFFAIRS

by

Philip Cary Christian

2010 
To: Dean Kenneth Furton

College of Arts and Sciences

This dissertation, written by Philip Cary Christian, and entitled Sales Tax Enforcement: An Empirical Analysis of Compliance Enforcement Methodologies and Pathologies, having been approved in respect to style and intellectual content, is referred to you for judgment.

We have read this dissertation and recommend that it be approved.

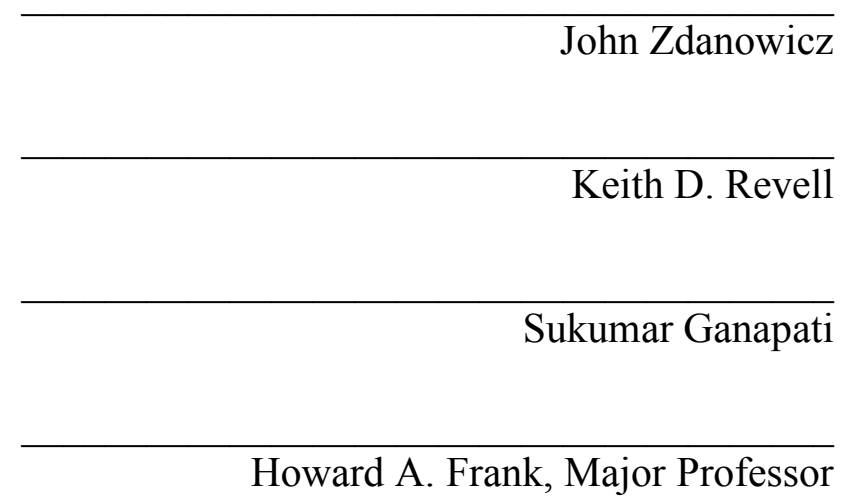

Date of Defense: September 14, 2010

The dissertation of Philip Cary Christian is approved.

Dean Kenneth Furton
College of Arts and Sciences

Interim Dean Kevin O'Shea University Graduate School

Florida International University, 2010 
(C) Copyright 2010 by Philip Cary Christian

All rights reserved. 


\section{DEDICATION}

This dissertation is dedicated to my mother, Mildred Ann Christian, for her

incredible strength of character and unflinching support and belief in my potential, and to my late father, Hollis Tracy Christian, whose quiet humility and grace showed me the path to be a better man. 


\section{ACKNOWLEDGMENTS}

I would like to thank the members of my dissertation committee for their time and effort in assisting me in this dissertation effort. I am in their debt for the clarity of the guidance provided and their assistance in identifying important results of my work that I might have otherwise failed to give appropriate weight. I would like to especially thank Dr. Howard Frank, not only for his guidance with respect to this dissertation, but for his interest, encouragement and invaluable counsel throughout my years at Florida International University, and for helping to craft an experience that has been truly lifechanging for me. I owe a particular debt of gratitude to Dr. Keith Revell for pointing out the relevance of further developing the evader typology presented herein and for his considered and studied advice regarding the application of theory to my study. I thank Dr. Sukumar Ganapati for his calm reassurance and for his suggestions and discussions with me regarding the application of the principal-agent model to my study. Dr. Ganapati is always ready with helpful advice and willing to travel that extra mile to help a student. I would like to thank Dr. John Zdanowicz for bringing a business-directed perspective to my study and reminding me that marginal costing is important in the evaluation of compliance enforcement methodologies even though politicians frequently seem to find that concept somewhat foreign when considering budget dollars for tax enforcement efforts.

I would also like to thank the management of the Florida Department of Revenue for their graciousness in allowing me to study sales tax enforcement from within the organization. I also thank the staff and employees of the Department for their candid responses to my questions and willingness to help me understand the complexities of the 
environments in which they struggle. The people of Florida should be grateful that these individuals strive daily to serve to the best of their abilities, often with less than adequate resources, and nearly always without appreciation commensurate with the effort they put forth.

And finally I would like to thank Suzanne Kong, a 19-year veteran of the Department of Revenue, for reviewing, commenting, and assisting with editing this document, and for invaluable first-hand insight into local-level discovery operations and campaigns. 
ABSTRACT OF THE DISSERTATION

SALES TAX ENFORCEMENT: AN EMPIRICAL ANALYSIS OF COMPLIANCE ENFORCEMENT METHODOLOGIES AND PATHOLOGIES

\author{
by \\ Philip Cary Christian \\ Florida International University, 2010 \\ Miami, Florida \\ Professor Howard Frank, Major Professor
}

Most research on tax evasion has focused on the income tax. Sales tax evasion has been largely ignored and dismissed as immaterial. This paper explored the differences between income tax and sales tax evasion and demonstrated that sales tax enforcement is deserving of and requires the use of different tools to achieve compliance. Specifically, the major enforcement problem with sales tax is not evasion: it is theft perpetrated by companies that act as collection agents for the state. Companies engage in a principal-agent relationship with the state and many retain funds collected as an agent of the state for private use. As such, the act of sales tax theft bears more resemblance to embezzlement than to income tax evasion. It has long been assumed that the sales tax is nearly evasion free, and state revenue departments report voluntary compliance in a manner that perpetuates this myth. Current sales tax compliance enforcement methodologies are similar in form to income tax compliance enforcement methodologies and are based largely on trust. The primary focus is on delinquent filers with a very small percentage of businesses subject to audit. As a result, there is a very large group of 
noncompliant businesses who file on time and fly below the radar while stealing millions of taxpayer dollars.

The author utilized a variety of statistical methods with actual field data derived from operations of the Southern Region Criminal Investigations Unit of the Florida Department of Revenue to evaluate current and proposed sales tax compliance enforcement methodologies in a quasi-experimental, time series research design and to set forth a typology of sales tax evaders. This study showed that current estimates of voluntary compliance in sales tax systems are seriously and significantly overstated and that current enforcement methodologies are inadequate to identify the majority of violators and enforce compliance. Sales tax evasion is modeled using the theory of planned behavior and Cressey's fraud triangle and it is demonstrated that proactive enforcement activities, characterized by substantial contact with non-delinquent taxpayers, results in superior ability to identify noncompliance and provides a structure through which noncompliant businesses can be rehabilitated. 


\section{TABLE OF CONTENTS}

CHAPTER

PAGE

1. INTRODUCTION

Objectives and Study Focus $\quad 2$

Research Questions 4

Significance of this Study 5

Outline of the Chapters 9

2. LITERATURE REVIEW 12

$\begin{array}{ll}\text { The Deterrence Model } & 12\end{array}$

$\begin{array}{ll}\text { Competing Theories } & 14\end{array}$

The Theory of Planned Behavior $\quad 17$

$\begin{array}{ll}\text { Opportunity to Evade } & 19\end{array}$

Differences between the Income Tax and the Retail Sales Tax 20

Fraud Theories $\quad 23$

Agency Theory 25

3. THEORETICAL FRAMEWORK OF THIS STUDY 31

Sales Tax Evader Typology $\quad 39$

Enforcement Tools $\quad 47$

Why People Evade $\quad 49$

Importance of This Study $\quad 52$

4. TAXATION IN FLORIDA $\quad 55$

The Florida Department of Revenue $\quad 55$

$\begin{array}{ll}\text { Technology } & 62\end{array}$

Business Strategies $\quad 63$

The Compliance Enforcement Environment 65

$\begin{array}{ll}\text { Knowledge-Based Enforcement } & 68\end{array}$

5. $\quad$ RESEARCH METHODOLOGY 77

Baseline Activities $\quad 81$

Analysis of the Effectiveness of Task Force Utilization 81

Tax Evasion Predictors from Industry Samples $\quad 82$

Targeted Industry Enforcement Program Analysis $\quad 84$

Reliability and Validity $\quad 91$

6. TASK FORCE UTILIZATION: FINDINGS AND ANALYSIS 94

7. PREDICTORS OF TAX EVASION: FINDINGS AND ANALYSIS 104 
8. TARGETED INDUSTRY ENFORCEMENT PROGRAMS:

FINDINGS AND ANALYSIS

The Interventions

Tests of Compliance after Interventions

127

The Indirect Impact of the Interventions

131

Enforcement and the Major Case Dealers

133

Summary of the Impact of the Targeted Interventions

9. EXPLAINING SALES TAX THEFT THROUGH THE

THEORY OF PLANNED BEHAVIOR AND CRESSEY'S

FRAUD TRIANGLE

10. MAKING ENFORCEMENT WORK

11. CONCLUSION AND DIRECTIONS FOR FUTURE RESEARCH 
2.1 Percentages of Individual Income Tax Income and Deduction Items Subject to Third-Party Verification

$\begin{array}{lll}3.1 & \text { Sales Tax Evader Typology } & 40\end{array}$

3.2 Enforcement Tools by Evasion Type 48

4.1 Prepaid Calling Card Sales Including Chain Stores 70

4.2 Prepaid Calling Card Sales Excluding Chain Stores 71

6.1 Summary of DOR Criminal Prosecution Cases 2003-2009 98

6.2 Breakout and Analysis of Region 5 Task Force Cases and

Comparison to Means for Regions 1 through 4

6.3 Summary of Region 5 Criminal Prosecution Cases 2003-2009

With Proforma Results Excluding Task Force Cases

7.1 Survey Questions and Observations

7.2 Classification Table for Survey Fraud Flags to Theft Comparisons 113

7.3 Results of Logistic Regression - Tax Evasion Prediction 113

$\begin{array}{lll}7.4 & \text { Correlations among Theft and Fraud Flag Variables } & 114\end{array}$

7.5 Results of Logistic Regression - Tax Evasion Prediction Flags and Amnesty

8.1 Classification of Dealers with Potential Sales Tax Theft 122

8.2 Resolutions from First Mailing - Wave 1 124

8.3 Resolutions from Second Mailing - Wave 2 126

8.4 Average Sales Tax Theft for Wave 1 Companies at Future Measurement Dates

8.5 Wave 1 Pairwise Comparisons of Average Sales Tax Theft at Measurement Dates 
8.6 Wave 2 Monthly Sales Tax Theft Means and Standard Deviations before the Interventions and at the Five-Month Measurement Date

8.7 Comparison of Mean Sales Tax Theft per Month between Waves 1 and 2

8.8 Monthly Sales Tax Theft Means and Standard Deviations for Indirect Effects of Interventions

8.9 Summary of the Impact of Interventions

8.10 Means and Standard Deviations of Sales Tax Theft Identified and Recoverable With and Without Interventions 


\section{LIST OF FIGURES}

$\begin{array}{ll}\text { FIGURE } & \text { PAGE }\end{array}$

3.1 Sales Tax Theft Model 36

4.1 DOR Partial Organizational Structure 56

5.1 Focus of Sales Tax Enforcement Efforts in Florida 77

5.2 Proposed Enforcement Design for Closing the Tax Gap 78

5.3 The Auto Dealer Tax Return to Title Application Comparison
Process

8.1 Intervention Mailing and Measurement Timeline 128 


\section{CHAPTER 1}

\section{INTRODUCTION}

Tax evasion is widely recognized as a significant problem. Estimates of federal tax revenue lost to evasion, known as the tax gap, exceeded $\$ 290$ billion for tax year 2001 not including evasion of taxes on illegal activities (Internal Revenue Service, 2006). State governments publish little information regarding state tax gaps, but indications are that states have multi-billion dollar tax gaps of their own. For example, California estimates their tax gap related to the state income tax at $\$ 6.5$ billion based on the IRS tax gap (State of California Franchise Tax Board, 2007). Most states that levy an income tax use federal taxable income as a starting point in the calculation of state taxable income and the related state income tax liability. Therefore, almost every state that has a corporate and/or individual income tax will have a tax gap equal to a percentage of the federal gap. ${ }^{1}$ The tax gap related to other taxes, such as the sales tax, is much more difficult to estimate and such estimates are rarely published. Access to raw sales tax data for purposes of research is exceedingly rare and the sparse research that exists holds the assumption that the sales tax is nearly evasion free. I have been granted the opportunity to study sales tax evasion in the field which not only allows access to raw data, but more importantly, enables the ability to match tax data to other informational sources. This level of access allows the development of a typology of sales tax evaders; a clearer understanding of the true nature of sales tax evasion; the impact of current enforcement methodologies; and the gaps in enforcement capabilities that can be filled with innovative new approaches to enforcement.

\footnotetext{
${ }^{1}$ That percentage will generally be state income tax rate adjusted for allocation and apportionment of income to other states by multi-state tax filers.
} 


\section{Objectives and Study Focus}

The primary objective of my study is to identify improvements in tax compliance enforcement methodologies with respect to the sales tax. My study indicates that the amount of sales tax evasion is, contrary to popular belief, large and much greater than current accounts allow. The existence of this larger tax gap is testament to the partial failure of existing compliance enforcement methodologies. The scope of the problem is cloaked by compliance measurement based only on known delinquent taxes ${ }^{2}$ and audit assessments. Political expediency may drive continued focus on these factors at the expense of acknowledging and addressing the full impact of evasion. While important, political issues are not the focus of this study. I believe that evasion is a political problem for the enforcement agency only to the extent the agency ceases to innovate and improve. If agencies are better able to identify evasion, they may be able to turn potential political liabilities into assets. Witness now the practice of publicizing arrests and prosecutions of those caught evading a tax. Such activities are considered successes of the agency because the illegal activity was discovered and punished. If the agency is able to catch evasion activities earlier to minimize the impact, or arrest and prosecute more flagrant evaders, the political impact is positive. So it is not the amount of evasion exposed that becomes a political issue, but evasion that remains undiscovered that becomes a potential political vulnerability. It may be perceived that political danger for an agency lies in the improvement being seen as an indictment of previous policy, but if goals and policies are geared toward continuous improvement, as many believe they should be, then a need to

2 "Delinquent taxes" means tax that has been reported by the taxpayer but not yet paid or estimated taxes due on returns that have not been filed and are past the due date. In this respect, delinquent taxes represent taxes that are known to be due based either on taxpayer reporting or estimates based on previous taxpayer reporting. 
constantly improve is communicated to stakeholders and improvements will be seen as the fruits of the positive enforcement culture created by the leadership of the agency. As a result, research to improve enforcement methodologies becomes politically neutral to an agency that is constantly striving to improve and that rewards creative approaches and solutions. My work during this study took place within such an environment. I use a mix of quantitative and qualitative techniques to evaluate existing enforcement processes and to test new processes and approaches as they are being implemented.

The Florida Department of Revenue was chosen for this study because Florida is a large state that has no individual income tax and, therefore, depends heavily on the sales tax for state revenues. The Florida Department of Revenue is considered a progressive and well-managed revenue agency. This is demonstrated by the agency receipt of the Governor's Sterling Award for Performance Excellence and the implementation of the Malcolm Baldrige Criteria for Performance Excellence in each of its business processes. The American Society for Quality notes that representatives from other state and foreign governments visit the agency each year to learn more about Florida Department of Revenue quality programs (American Society for Quality Research Committee, 2003). Agency leadership is amenable and interested in knowledge-based efforts to improve enforcement and has provided unparalleled access with respect to this study, limited only by Florida law related to the confidentiality of tax data. It must be stressed, however, that the Florida Department of Revenue is in no way responsible for this study and has insisted that this study not be identified as a study undertaken by the Department. Any conclusions and interpretations of data are strictly those of the author and the Department of Revenue may not officially agree with the 
conclusions and interpretations contained herein. This study is rather narrowly focused on intelligence, data analysis operations, and field techniques that may be employed at the local level and may lead to improved compliance enforcement outcomes, and does not purport to present or evaluate all of the Department of Revenue's methodologies and tools currently used for enforcement purposes.

\section{Research Questions}

This study addresses the following major questions:

- How effective are traditional sales tax compliance enforcement efforts, especially in controlling sales tax theft?

- What types of innovative enforcement methodologies can be utilized to improve compliance?

Secondary but potentially very important questions relate to the implications for the potential implementation of a national sales tax and calls within Florida to replace local property taxes with an expanded sales tax. Current proposals for the national sales tax call for the replacement of all federal income and payroll-based taxes and cite the elimination of the Internal Revenue Service as a benefit of the change process (Americans for Fair Taxation, 2010) reflecting the conviction that retail consumption taxes are evasion free. In Florida, replacement of the property tax, which is legitimately nearly evasion free, with the sales tax could be enormously expensive if the true nature of sales tax evasion and theft is not properly understood. 


\section{Significance of this Study}

One of the more important tasks in this study was to demonstrate that general assumptions regarding the sales tax being nearly evasion free are unrealistic. To determine voluntary compliance, state revenue agencies generally focus on accounts receivable, which is derived from estimates of delinquent taxes, reported but unpaid taxes, and amounts found due as the result of audit and discovery campaigns. In other words, only known delinquent taxes and audit results are considered. These estimates do not include tax losses from evasion, unidentified unregistered taxpayers, or sales in the underground economy ${ }^{3}$ that the revenue agency cannot estimate.

To illustrate, assume a revenue agent is responsible for 100 taxpayers, and each taxpayer files a monthly sales tax return reporting $\$ 1,000$ in sales tax collected, for a total of $\$ 100,000$ in sales tax. All but one of the taxpayers submits a check with their return paying the full $\$ 1,000$ owed. So out of $\$ 100,000$ in self assessed and reported sales tax on monthly sales tax returns, only $\$ 1,000$ is delinquent. An audit is performed on one of the other taxpayers (representing a one percent audit rate), and that taxpayer is found to owe an additional $\$ 500$. Therefore, the receivables identified total $\$ 1,500$. The state will represent a 98.5 percent voluntary compliance rate with respect to those taxpayers ( $\$ 99,000$ properly reported and remitted divided by $\$ 100,500$ total sales tax collected that should have been remitted).

Imagine now that, in reality, 50 of the 100 businesses actually collected $\$ 10,000$ in sales tax $(\$ 500,000$ total), but reported and remitted only $\$ 1,000$ each $(\$ 50,000)$, and

\footnotetext{
${ }^{3}$ Underground economy refers to businesses that deal in cash or barter or who use other methods to conceal their true tax liabilities from the government. The term encompasses both legal and illegal business activities.
} 
have thus evaded or stolen $\$ 450,000$ in sales tax collections. The state has no way of knowing this unless those 50 companies are audited or investigated. Otherwise, their self-assessments are accepted. So we see that in reality the amount due is $\$ 451,500$, not $\$ 1,500$, and the compliance rate is only 18 percent, not 98.5 percent. While these demonstration numbers may appear to have been designed merely for shock value, the present study shows that the ratio of actual tax theft to delinquencies is this large or larger in at least one large industry, and likely so in many others on the basis of information and documentation reviewed during the course of this study. The goal of the agency reporting compliance based on delinquencies and assessments is not to mislead, but merely to measure what is readily measureable, and to provide information that is available and verifiable. There is no generally acceptable basis to estimate the total sales tax gap derived from audit and investigative results because such a tiny percentage of businesses collecting the sales tax are audited or investigated. Since audits are strategic in nature rather than random, there is also no basis to generalize audit results to the entire population. Even the process of estimating delinquencies involves a certain amount of guesswork. Prior filing history provides an estimation tool that is useful provided the filer has not historically engaged in evasion behavior beyond delinquencies. The fact that evasion behavior can distort delinquency and receivable analyses that are generally viewed as trustworthy is yet another indication of the difficulty in estimating the tax gap for the sales tax. The significant amounts of tax revenue being lost every year at both the federal and state levels could balance budgets, reduce overall tax rates, and make funds available for important programs that currently go begging. An assumption in this study is that rather than noncompliance rates of two to five percent ( $\$ 4.8$ billion to $\$ 12$ billion 
nationwide), the actual noncompliance rates for sales tax are a minimum of ten percent and may be as high as 28 percent. ${ }^{4}$ This represents a range of $\$ 24$ billion to $\$ 67$ billion for sales tax theft in the 45 states that administer a sales tax. Full compliance would not only balance budgets, but it would allow the reduction of tax rates.

The assumption that sales tax is nearly evasion free causes states to focus enforcement efforts on managing delinquencies rather than catching evaders, resulting in an allocation of maximum resources to efforts with the lowest yield in terms of additional revenue. Amounts devoted to combating tax evasion are not insubstantial, but pale in comparison to resources devoted to resolution of delinquencies and assessments. The large amounts of tax dollars that are being lost would appear to indicate that devoting even more resources to enforcement would be worthwhile. It is well established that audit and investigative activities have a significant direct impact on compliance, and also generate significant "spillover" effects as taxpayers witness the punitive actions taken against evaders (Dubin, 2007). Some argue that devoting additional resources to the problem of tax evasion has been found to be subject to diminishing returns (Alm J. , 1999) (Mikesell \& Birskyte, 2006). While this is undoubtedly true, the real question concerns where the line of diminishing returns is crossed. Consider that in the example above, doubling audit and investigative resources might mean auditing two of the 100 companies instead of one. In that example, the improvement might be substantial but not nearly sufficient. If the size of the problem is as large as the results of this study indicate, state governments are a long way from reaching the point of diminishing returns with respect to adding sales tax enforcement resources. An analysis of marginal revenue

\footnotetext{
${ }^{4}$ This assumption is supported by calculations made by the author in a separate study of compliance rates in Florida, by industry, which is ongoing.
} 
compared to marginal costs can and should be used to guide the expansion of enforcement resources to optimal levels. Rather than simply increasing traditional compliance enforcement capabilities to optimal levels, governments must seek to improve tax compliance in an ever more cost-effective manner by employing innovative compliance enforcement solutions that produce better results than traditional methods without requiring large increases in the overall level of resource dedication. Such solutions may involve reallocating and refocusing certain existing resources and greater investments in technology.

The current study demonstrates that current methodologies task 80 percent of compliance personnel to delinquency management and only 20 percent of compliance personnel to audit and investigations, resulting in extremely low audit rates and reliance on reporting honesty alone for compliance with respect to 99.53 percent of all the businesses in Florida. A level of reporting honesty greater than 99 percent is impossible even in a tax system with the built-in verification of income and deductions of an income tax system, or the multiple reporting steps and cross-checks available in a value added tax system. Such heavy dependence on natural honesty in a retail sales tax system is without merit and results in much larger levels of evasion than previously thought specifically because of the lack of verification and cross-checks. Some view the collection of the sales tax by businesses as the essential third-party participation and reporting that makes the sales tax nearly evasion free. In the present study it is made clear that the issue with sales tax is not evasion by the taxpayer, but theft of the sales tax collected by the business collecting the tax, the collection agent for the state, which is more similar to embezzlement than evasion. 
In order to better understand evasion in a retail sales tax environment, I advance a typology of sales tax evaders that is useful in understanding how and why people evade and the tools that are best suited to enforcement efforts for a particular type of evader. Upon examination of the typology, it becomes clear that existing enforcement tools are too narrowly focused and are ineffective in identifying most types of evader. Contrary to existing beliefs, this study shows that delinquency status is a poor predictor of evasion in the sales tax environment.

In the current study I introduce a proactive methodology for addressing the enforcement gap that exists between delinquency management and audit and that addresses enforcement with respect to evader types that remain outside the influence of current methodologies. This approach is the targeted industry enforcement program that is built on the foundation of current enforcement efforts known as lead development, discovery operations and campaigns. This enforcement methodology is proactive; is based on employee expertise and the use of multiple data sources to effectively target evaders; and does not rely to any extent on the delinquency status of a particular company.

\section{Outline of the Chapters}

The documentation of this study and the results obtained are presented in this paper as described in the following paragraphs.

In Chapter 2 the existing tax evasion literature is examined, which is heavily focused on the income tax, and the impact of third-party reporting on compliance in an income tax system is demonstrated. Through an analysis of the Principal Agent Model 
my study shows that high levels of sales tax theft should not be surprising, but rather ought to be expected because of the structure of the sales tax; heavy dependence on honesty; lack of incentives for the agent; and inability of states to properly manage the principle agent relationship because of the number of agents involved and the inability to control adverse selection.

Chapter 3 advances a theoretical framework that is based on Cressey's Fraud Triangle for understanding the environment conducive to theft of the sales tax collected by the agent; and on the theory of planned behavior to understand the individual decision to steal a portion of the sales taxes collected. This framework suggests appropriate enforcement approaches that include activities designed to affect the evader's degree of perceived behavioral control over the decision to evade without discovery. Chapter 3 also includes my typology of sales tax evaders and a discussion of the appropriate enforcement tools for each type of evader.

Chapter 4 is an introduction to the environment for the study: sales tax enforcement within the State of Florida by the Florida Department of Revenue. Chapter 4 provides a description of Florida's approach to enforcement, the resources dedicated to enforcement, and a summary of the results of enforcement activities.

Chapter 5 provides the methodologies and statistical tools utilized in the quasiexperimental analysis of the targeted industry enforcement program in Chapter 8 and related processes covered in Chapters 6 and 7.

Chapter 6 covers an evaluation of the Department of Revenue's Criminal Investigations Process task force participation and its impact on enforcement results. The 
review in Chapter 6 is preparatory to the introduction of alternative task force structures utilized in the targeted industry enforcement program.

Chapter 7 offers an evaluation of revenue agent observation and intuition as a tool in the identification of fraud indicators within an industry. Utilizing a sample of 369 used car dealers, the ability to identify sales tax evaders based on the completion of an observational survey and review of filing history is tested.

Chapter 8 provides an analysis of a complete cycle of a targeted industry enforcement program as it was executed with respect to 192 used car dealers in MiamiDade County, Florida, who were identified as likely evaders during the data analysis portion of the project. These 192 dealers were responsible for more than $\$ 21$ million in sales tax theft yet had only $\$ 302,000$ in delinquent sales tax identified and outstanding.

Chapter 9 provides a qualitative analysis of the project and how the results comport with the theoretical framework and typology of sales tax evaders advanced by this study.

Chapter 10 offers a discussion of how enforcement efforts can be strengthened through the addition of targeted industry enforcement programs to the arsenal of enforcement tools and its integration with existing tools and methodologies. Also provided is an estimate of the marginal cost and estimated marginal revenues associated with such programs.

Chapter 11 contains concluding comments and directions for future research. 


\section{CHAPTER 2}

\section{LITERATURE REVIEW}

\section{The Deterrence Model}

One of the most enduring theories of tax evasion was set forth by Allingham and Sandmo (1972) and is known as the deterrence model, criminal deterrence model, or the economics of crime argument (hereafter, "deterrence model") and is based on expected utility theory. Allingham and Sandmo theorized that the choice by a rational person to evade taxes is based on the expected gains or losses associated with the decision to evade, an argument that sets forth the objective of the evading taxpayer as maximization of utility through the decision to evade. In the deterrence model the gain is represented by the money saved through evasion and the loss is the penalty attached to getting caught. If the probability of getting caught is high and the penalties are severe, the utility maximizing taxpayer will not attempt to evade taxes. The deterrence model is an extension of the theory set forth by Becker (1968) with respect to crime in general, and presents a simplified and straightforward approach to tax evasion. The deterrence model became the underlying premise for nearly all approaches to tax evasion for decades and remains in wide use in practice even though it has been somewhat discredited in theory consistent with general criticisms leveled against expected utility theory with respect to rationality. People generally do not behave as rationally as the deterrence model would predict in that taxpayers do not fully understand their alternatives or the related consequences of their actions (Tanzi \& Shome, 1993). Taxpayers do not know the probabilities of getting caught and generally do not know the penalties involved. The deterrence model also ignores non-pecuniary costs of evasion activities such as loss of 
self-esteem, embarrassment, and loss of reputation and social status (King \& Sheffrin, 2002). Perhaps the most important criticism is that the deterrence model would predict much lower rates of compliance than presently achieved given low audit levels and the very small probability of getting caught evading taxes. For this reason, the deterrence model is deemed a very poor predictor of evasion activities (Jones, 2003; Mikesell \& Birskyte, 2006; Korobow, Johnson, \& Axtell, 2007). Results of surveys and experiments suggest that most taxpayers would never consider tax evasion even though the probabilities of audit are tiny (Long \& Swinjen, 1991). Varma and Doob (1998) found that penalties are ineffective in controlling tax evasion and the size of legal sanctions is not important if people believe they will not get caught. However, they found that deterrence had an impact if people could be convinced that the probability of getting caught was high. They also found that whether the consequences of evasion were criminal or not clearly matters and that compliance may have more to do with individual personal beliefs such as a moral obligation to be honest.

Sociological models of deterrence, as opposed to the economic model, begin to add psychological and sociological considerations, particularly ethical considerations, to the deterrence equation and contemplate a taxpayer's attitudes toward social obligations and self-image to be important factors in deterrence. In the sociological model of deterrence, ethical considerations act to set bounds on the choices available to the taxpayer (Reckers, Sanders, \& Roark, 1994) and account somewhat for compliance above the levels that would be predicted by the econcomic deterrence model. 


\section{Competing Theories}

To address the perceived shortcomings in concepts of tax evasion based on the deterrence model, researchers have proposed alternative theories to guide evasion research efforts. Equity theory posits that when the system of taxation is considered fair, compliance will be high, or at least higher than when the system is considered unfair (Thibalt, Fredland, \& Walker, 1974; Smith \& Kinsey, 1987). Equity theory looks to the horizontal equity of the tax system and presumes the taxpayer will be satisfied as long as his burden is fair when compared to other taxpayers. Exchange equity theory moves the equitable comparison from other taxpayers to the mode of what the taxpayer receives in return for their tax dollars and holds that individuals evaluate the fairness of their tax burdens based on the benefits they receive from the government. Exchange equity theory also posits a link with the popularity of the public goods purchased with taxpayer's tax dollars (Kinsey, Grasmick, \& Smith, 1991).

Prospect theory models evasion decision making in terms of gains and losses similarly to deterrence theory. However, the framing of the tax evasion decision becomes more important than under the deterrence model, equity theory, or exchange equity theory (Chang, Nichols, \& Schultz, 1987; Robben, et al., 1990). Under prospect theory, a decision to evade is framed in terms of gains and losses with respect to a particular reference point, such as the taxpayer's withholding position, rather than an overall decision to evade tax as in the deterrence model/expected utility theory. Prospect theory predicts that when individuals are faced with a loss, they will be encouraged to adopt more risk-seeking, noncompliant behavior. For example, when taxpayers are in a situation where their withholding is insufficient and tax is due with the return, taxpayers 
will be more noncompliant than when they find themselves in a refund position. The withholding position becomes the referent point in the taxpayers framing activities (Blanthorne, 2000).

King and Sheffrin (2002) experimentally compared evasion under equity theory using a framework of prospect theory with the deterrence model and found that criticisms of expected utility theory were valid, but that prospect theory was not superior in terms of predictive value in a scenario of inequity. They instead found support for expected utility theory in scenarios depicting inequity. Results were generally not consistent with equity theory. They found that responses to control questions were consistent with prospect theory but the responses to framed questions were not. They noted that none of these theories were particularly robust and none faired any better than the others in their testing.

Nwogugu (2005) criticizes both prospect theory and expected utility theory for failure to address the real process of decision making. He posits that decision making involves the evaluation of many factors and is a multi-dimensional process that cannot be accurately portrayed by imposing rigid models on the process. Instead, he recommends studying decision making through the analysis of completed real life decisions on issues that have several dimensions, such as situation contexts and risk/loss management capabilities, and over several time frames. In his opinion, expected utility theory and prospect theory are derived from questionable experiments, limited in dimension and the nature of the questions asked.

In the continuing search for a robust theory of tax evasion, researchers have built upon the deterrence model and evaluated cultural, administrative, and individual factors 
that act as potential determinants of evasion behavior. Among these factors are the quality of services provided by the government, the existence of high tax rates, the complexity of tax laws, social norms, morality, tax amnesty policy, income levels, size of businesses, tax ethics, and source of income (Madeo, Schepanski, \& Uecker, 1987; Reckers, Sanders, \& Roark, 1994; Alm J. , 1999; Cummings, Martinez-Vazquez, McKee, \& Torgler, 2004; Torgler \& Murphey, 2004; Christian \& Frank, 2006; Hyun, 2006). These determinants can be thought of as contributors to tax morale, defined by Torgler and Murphy (2004, p. 4) as "the intrinsic motivation one has to pay their tax." All of these determinants have been empirically shown to have a statistically significant impact on tax evasion.

Alm (1991) stated that theoretical models of individual choice are too simple to adequately address the decision to evade taxes. He notes that the Internal Revenue Service had, at that time, listed 64 factors that may affect the reporting decisions of taxpayers, but theoretical models are not capable of including very many of these factors in a single analysis, which limits their explanatory power. Many other factors have been added to the list of potential determinants since then, as noted in the previous paragraph. Alm's calls for broader, theory-based approaches to the problem obviously were not a deterrent to investigating every conceivable factor for its impact on the evasion decision process.

Behavioral decision theory examines how decisions related to compliance are affected by the way in which the risks of noncompliance are presented or are otherwise perceived. Behavioral studies focus on the way people subjectively evaluate and choose among risks but reject the rational choice methodology in favor of a more boundedly 
rational approach. In an application of behavioral decision theory in an experimental setting, Casey and Scholtz (1991) found that the design of compliance strategies to provide for variation in the probability of getting caught adds ambiguity to taxpayer assessments of audit chances and increases compliance. Greater confusion about detection activities leads to more compliance in situations where deterrence is actually relatively weak, but to less compliance where deterrence is relatively strong. Sheffrin and Triest (1992) found evidence that taxpayers who perceive a higher probability of detection are less likely to evade taxes and that the perceived probability of detection may be more important than the actual probability of detection. Collins and Plumlee (1991) note that theoretical models of compliance generally assume that individuals face a fixed random probability of audit, whereas the Internal Revenue Service determines audit leads

partially based on the information supplied by the taxpayer on their tax returns. As such, audits are not fixed or random, but rather are strategic, and studies have shown that strategic audits significantly affect individual taxpayer behavior and lead to more compliance with reporting requirements. Therefore, strategic audit schemes can have the capability of creating within the taxpayer a belief in a higher probability of audit than actually exists.

\section{The Theory of Planned Behavior}

The theory of planned behavior evolved from the theory of reasoned action developed by Ajzen and Fishbein (Fishbein \& Ajzen, 1975; Ajzen \& Fishbein, 1980) and posits that intentions to engage in behaviors of different kinds can be predicted with accuracy from attitudes toward the behavior, subjective norms, and perceived behavioral 
control (Ajzen, 1985; Ajzen, 1988; Ajzen, 1991). In an investigation of the application of the theory of planned behavior to tax evasion, Bobek and Hatfield (2003) equated the beliefs held by the taxpayer about what would occur if they engaged in evasion as the attitude; the influence of referent groups or individuals as the subjective norms; and the degree of control an individual perceives he or she has to engage in the evasion activity as the perceived behavioral control. An additional variable was added for the impact of moral obligation, which the authors thought would be a moderating influence. Control beliefs relate to the individual's beliefs about the presence or absence of resources and opportunities, or obstacles and impediments to their performance of the specific behavior, in this case evasion. The authors note that this includes perceptions regarding income visibility and the probability of detection. They found that moral obligation alone was not sufficient to reduce evasion behaviors to zero but that subjective norms and perceived behavioral control were consistently significant. Bobek and Hatfield note that the theory of planned behavior does not refer to how easy it is to cheat in general, but applies to specific behavioral choices and how much control an individual has to carry out that choice, such as taking an unauthorized deduction. More importantly, they note that perceived behavioral control must exist before any other construct can exert influence on behavior. If an individual does not believe that the behavior is within their control, then subjective norms, attitudes, morality, and ethics are immaterial. An individual who believes the government is unfair; believes taxation is unconstitutional; has friends and relatives who perpetually cheat on their taxes; and who is generally immoral and unethical; will satisfy the subjective norms and attitude constructs but still will not engage in tax evasion if he or she believes they do not have enough control of the activity 
and ability to engage in the behavior without getting caught. Therefore, it would appear that an individual's perceived behavioral control would be a primary target in the taxing authority's efforts to enforce compliance.

In another study utilizing the theory of planned behavior, Blanthorne (2000) found that taxpayers that have the opportunity to underreport income actually underreported more income than taxpayers lacking such an opportunity, affirming the impact of perceived behavioral control but finding that subjective norms were not significant. The author also used an ethical beliefs component in the study which was found to be the strongest indicator of the intention to underreport income and the actual underreporting behavior.

\section{Opportunity to Evade}

Madeo, Schepanski, and Uecker (1987) found that taxpayers were three times more likely to evade taxes with respect to income not reported to the Internal Revenue Service. Klepper, Mazur, and Nagin (1991) found that tax compliance increases with respect to items of income that are unambiguously defined, such as wages, and decreases with more ambiguously defined items such as employee business expenses. Work by Erard (1993) provided further support for the correlation between the opportunity to evade taxes and the act of evasion, finding that tax compliance was not dependent on the level of income but on the source of income. According to King and Sheffrin (2002), the Internal Revenue Service estimates that 99 percent of wage income is correctly reported 
but less than 70 percent of income from unincorporated businesses is properly reported. ${ }^{5}$ It is exceptionally difficult to evade taxes on income reported to the tax authorities by third parties, since mismatches between income reported by the third party and income reported on the individual's tax return are electronically matched and flagged for review without human intervention. Taxpayers understand that attempts to evade tax on income reported by third parties yields a high probability of detection and are much more likely not to report income they believe cannot be traced (Madeo, Schepanski, \& Uecker, 1987).

\section{Differences between the Income Tax and the Retail Sales Tax}

The preceding discussion highlights a critical point about sales tax evasion: sales taxes are not subject to third-party verification of amounts collected. Third parties collect as agents of the state and are trusted to remit. Thus, the potential to evade sales taxes relative to income taxes is much greater. In fact, the issue is not evasion at all, but rather theft of the sales tax collected by the agent from the actual taxpayer. The question must be asked whether research on income tax evasion provides any basis at all for understanding sales tax evasion. Watrin and Ullmann (2008) found significantly lower compliance rates with respect to consumption taxes versus income taxes, and noted significant differences in reactions towards changes in detection probabilities based on the results obtained from an experimental multi-stage game. Specifically they found that individuals react more strongly when detection probabilities are increased with respect to

\footnotetext{
${ }^{5}$ A portion of the income of unincorporated businesses is also subject to third-party reporting on Form 1099 , so the actual amount of unreported income from unincorporated businesses that is not subject to third-party verification is likely even higher.
} 
consumption taxes than when the detection probabilities are increased with respect to the income tax.

It was previously noted that the deterrence model has lost much of its credibility because most people appear to be honest and, if the theory underlying the deterrence model were correct, evasion would be far more common than it actually is. However, when it is considered that most work on tax evasion has been with respect to the income tax, and that it is extremely difficult to evade taxes on income that is subject to thirdparty verification, compliance might not be nearly as universal as some studies might claim.

A review of the data contained in the Internal Revenue Service Source of Income Bulletin for each filing year provides insight into the impact of third-party reporting on tax compliance. Utilizing the data from 2007 (Internal Revenue Service, 2007), the following analysis was performed to demonstrate the percentage of taxable income that was subject to third-party verification and the results obtained are summarized in Table 2.1. The details of the analysis are included in Appendix 1.

Table 2.1 Percentages of Individual Income Tax Income and Deduction Items Subject to Third-Party Verification

\begin{tabular}{|l|r|r|r|}
\hline \multicolumn{1}{|c|}{ Category } & \multicolumn{1}{c|}{ Total } & \multicolumn{1}{c|}{ Verifiable } & \multicolumn{1}{c|}{ Percentage } \\
\hline Income items & $\$ 8,793,560,693,000$ & $\$ 7,262,331,438,000$ & $82.59 \%$ \\
\hline $\begin{array}{l}\text { Deductions for } \\
\text { AGI }\end{array}$ & $\$ 122,922,183,000$ & $\$ 89,313,528,000$ & $72.66 \%$ \\
\hline Other deductions & $\$ 2,930,389,570,000$ & $\$ 1,597,353,028,000$ & $54.51 \%$ \\
\hline
\end{tabular}

The analysis of Internal Revenue Service data demonstrates that a large majority of the items that compose adjusted gross income, the "income items" and "deductions for 
AGI" in the table, are subject to third-party verification. Further, since a substantial number of returns utilize the standard deduction rather than itemizing deductions, more than half of the amounts claimed as deductions are also not at issue and not subject to evasion because they are statutorily defined.

Other research bears out the theory that compliance may be less than universal. It has been found that there is a positive correlation between under-withholding of income tax and a subsequent underreporting of the tax liability based on the 1982 Taxpayer Compliance Measurement Program (TCMP) audit data (Chang \& Schultz, 1990). Martinez-Vazquez, Harwood, and Larkins (1992) observed that people with liquidity problems were less likely to pay commercial debts and theorized that liquidity problems may have the same effect on the behavior of taxpayers. In two sets of experiments they found that if the possibility of evading taxes in a safe manner existed, a near-majority of people would take that chance, and the proportion of individuals choosing to evade who were in an illiquid position was significantly larger. Blanthorne (2000) found that taxpayers who have the opportunity to underreport income actually underreported more, in both frequency of underreporting and in the amount underreported, and had lower tax reporting ethics than taxpayers who did not have the opportunity to underreport. Carnes and Englebrecht (1995) found that tax compliance increases as the visibility of income to the taxing authority increases. Antonides and Robben (1995) found that the probability of tax evasion was related to the opportunity available to the taxpayer to conceal income. Given that the sales tax is not subject to any third-party verification, these preceding findings portend dire consequences for compliance under a sales tax regime. Yet Watrin and Ullman (2008) note that their work is the first to explicitly focus on the behavioral 
differences between compliance in the realm of income tax versus compliance related to consumption taxes. The lack of specific research related to tax evasion in a consumption tax environment is surprising given the core differences between how income taxes and consumption taxes are administered and given the lack of third-party controls in a consumption tax system. It should also be noted that Watrin and Ullman (2008) found that in their review of the literature, none of the models developed for the analysis of the usefulness of consumption taxes and optimal mixes of taxation regimes have even allowed for the possibility of tax evasion in a consumption tax setting, and there has never been a model that allows for evasion in income tax and consumption tax regimes at the same time. To set this glaring omission in its proper context, it must also be understood that research related to evasion in value-added consumption taxes (VAT) are inapplicable to this study since VAT regimes are more easily enforced because the tax is collected at multiple stages during the production process. If the tax is not collected at one stage, it can still be collected at a subsequent stage of production. Additionally, the VAT calculations at each stage of production leave a paper trail that makes it easier to find and prove evasion, and provides an incentive for proper reporting because of the built-in credit structure (Garner, 2005). This verification and incentive structure does not exist with a retail sales tax.

\section{Fraud Theories}

Donald Cressey (1953) developed a conceptual context known as the "fraud triangle" on the basis of research findings from the study of several hundred instances of internal fraud. Three factors were present in each case he studied: the perpetrators felt 
perceived pressure from financial needs; they had access to funds; and they had the ability to rationalize their illegal behavior. While tax evasion is not internal theft or embezzlement in the traditional sense of the crime, the theft of sales tax is virtually identical to embezzlement. As mentioned earlier, with respect to the sales tax, the taxpayers are not the businesses that collect and report the tax, but the customers of these businesses. It is not the taxpayers per se who evade the tax, it is rather the agent of the state, the business that collects the tax, which retains the funds for their personal use and thereby commits the crime. It is literally the same as embezzlement, skimming, or any other of a number of frauds employees perpetrate on their employers by taking money before their employers realize it has been collected. In fact, in 1978 the Florida Statutes addressed theft of sales tax by providing that then Section 812.10 , relating to embezzlement by state, county, or municipal officers, would apply to every person who collected sales tax on behalf of the state. ${ }^{6}$ The statute was amended in 1979 to provide separate specific penalties for theft of state funds by those who collect sales tax on behalf of the state. With respect to the sales tax, the business collecting the tax has access to and control of the funds, so all that is needed is a reason to take the money (the perceived financial pressure) and a rationalization to do so for the fraud triangle framework to be applicable.

A portion of Cressey’s (1953) study dealt with "independent businessmen" who were in business for themselves and received and converted deposits entrusted to them by customers or others to their personal use. These businessmen typically explained and excused their conversion of funds by asserting that they were merely "borrowing" the

\footnotetext{
${ }^{6}$ Florida Statutes Section 212.15(1), Fla. St. 1978, Supp.
} 
money, or that the funds were really theirs and they could not steal from themselves (Wells, 2005). The situation described and the excuses provided mirror the situation of the businessman caught stealing tax dollars collected as an agent of the state.

The fraud triangle concept was formally adopted by the auditing profession in Statement on Auditing Standards No. 99: Consideration of Fraud in a Financial Statement Audit (American Institute of Certified Public Accountants, 2002). This pronouncement was issued after the accounting scandals at Enron, Worldcom, Tyco, and Adelphia and the levying of criminal charges against the accounting firm Arthur Andersen \& Co. that increased pressure on the accounting profession to identify fraud in the corporate financial statements they audit. The fraud triangle is generally recognized as a useful tool in indentifying potential fraud by the accounting profession and fraud examiners (Albrecht \& Wernz, 1993; Wolfe \& Hermanson, 2004; Sacchetti, 2005; DeFatta, 2005; Murdock, 2008; McNeal, 2009; Association of Certified Fraud Examiners, 2009).

\section{Agency Theory}

Since the sales tax is administered by utilizing retail businesses as collection agents for the state, agency theory yields additional important insights in the analysis of sales tax compliance enforcement. Two concerns addressed by agency theory are the problems of adverse selection and moral hazard (Droege \& Spiller, 2009). Adverse selection occurs when a principal selects an inappropriate agent because of false or inaccurate information. Moral hazard refers to the situation where the agent does not provide appropriate effort to achieve the goals of the principal. Agency theory assumes adverse selection can be controlled if the principal has access to all available information, 
and that the required information can be obtained for a price. The principal must balance the cost of acquiring the information needed with the potential gain from selecting an appropriate agent. Moral hazard can be controlled through either behavioral contracts designed to control the activities of the agent, or through outcome-based contracts which are designed to align the goals of the principal and agent and allow the principal to monitor specific outcomes produced by the agent rather than the agent's activities (Droege \& Spiller, 2009).

Both adverse selection and moral hazard are problems encountered by the state in its dealings with its collection agents, but the state has several unique problems that must be addressed:

First, the state cannot choose the collection agents it wishes to work with. If a business meets the minimal requirements to obtain a sales tax license, they become an agent of the state. There are few reasons for disqualification and even new businesses owned by known tax cheats or their family members cannot be denied a license. As a result, the state is guaranteed an adverse selection problem regardless of the information available to it.

Second, agency theory assumes a direct relationship between the principal and the agent that makes it possible to either monitor the agent's activities, or require specified results based on contract specifications. Since all retail businesses engaged in the sale of tangible personal property become agents, there are too many agents for the state to devote direct monitoring to each one. Outcomes cannot be predicted or planned for with respect to sales taxes since sales tax collected will be proportional to the sales the business is able to make and the mix of taxable and exempt items sold. Setting quotas for 
tax collected would be poor public policy given such a policy's similarity to organized crime protection schemes. The agent's duty is simple: collect the tax on all sales of taxable items, and account for and remit the total amount of sales taxes collected on sales of taxable goods. To ensure that the agent carries out this duty, the state must either allocate the resources required for direct monitoring, or develop methodologies for predicting outcomes at the single-business level for use in direct monitoring by exception.

Third, agency theory assumes that the agent will perform well for the principal based on incentives provided by the principal. In Florida there is a minor collection allowance given to the sales tax collection agent for his efforts that is a small percentage of the tax collected and is capped at $\$ 30$ per month. The result of this provision is that the agent has no incentive at all. In fact, the payment of the collection allowance may be counterproductive and contribute an inducement to skim. Gneezy and Rustichini (2000) found that adding compensation for an activity that has a motivation of its own, such as a sense of duty to the community, may replace and reduce the intrinsic motivation associated with the activity. In experiments designed to test this hypothesis, they found that where money was offered, higher monetary rewards resulted in greater efforts, but that overall, subjects offered monetary rewards did not perform as well as those offered no reward. They did acknowledge that subjects paid a small fixed amount regardless of performance did not show a reduction in intrinsic motivation, which suggests the use of a collection allowance may do no harm, but it is certain that the collection allowance does not provide an incentive to the agent to do a better job. Additionally, Miller and Whitford (2006) point out that incentives large enough to induce an appropriate level of 
effort in the agent are prohibitively expensive for public agencies, who rely more on coercive monitoring and sanctions.

Fourth, agency theory presumes that the principal is risk neutral and the agent is risk averse, which speaks to a dynamic that does not exist in the sales tax principal-agent relationship. The risk presumptions of agency theory assume the agent is being incentivized under the contract in a manner that takes into account the fact that the risk of failure in the subject matter of the contract is borne by the principal, who has a wide enough portfolio to absorb the risk of failure. In the sales tax collection contract, the agent has no incentive at all, other than possibly the incentive to steal as much tax money as possible. The agent bears no risk from subpar sales tax collections and only encounters risk in any form if the agent decides to steal tax monies. That risk, of course, is the risk of civil or criminal sanctions. The principal is not risk neutral because, especially in Florida, the sales tax collection process is the life blood of the state. The state has few other sources that are capable of replacing lost sales tax revenue.

Finally, the premise that information is a commodity where all information can be known and purchased is simply unrealistic in the sales tax collection principal-agent contract since the state must deal with nearly a million separate retail establishments. The cost of acquiring the level of information required to effectively monitor every agent would be cost prohibitive as is indicated by the reliance of tax agencies on audit regimens rather than contract management activities to enforce compliance.

These problems might be interpreted to mean that agency theory is only contingently valid in the case of the sales tax collection principal-agent relationship, and it is apparent that major presumptions of the theory are, indeed, invalid in this 
relationship. But agency theory is instructive nonetheless in that agency theory will predict very poor results for the state as principal for the reasons discussed above.

Indeed, an analysis of the state's position in the sales tax collection principalagent relationship using agency theory provides ample reasons why compliance is significantly lower with respect to retail consumption taxes versus income taxes, where third-party verification removes the opportunity to evade with respect to a large portion of taxable income. Agency theory is designed to assist the principal in the design of contracts that control adverse selection and moral hazard, but in the instant case, it is impossible for the principal to follow that guidance. Agency theory provides the warning that in the sales tax collection process, the agency must find alternative means to monitor and enforce compliance because standard methods of controlling adverse selection and moral hazard will be of little use.

The Principal Agent Model (PAM) has been criticized because of its implicit assumption that the agent is dishonest, but this assumption contributes to the theory's power to predict poor results for the principal when the principal's control over agent dishonesty is not perfected (Bohren, 1998). It is difficult to acknowledge that so many people will choose to evade or steal tax monies when faced with the opportunity to do so, but the research on evasion presented in this chapter continually points to the fact that this is so regardless of the theory or determinant of evasion under study. The corporate world takes a more realistic view of opportunistic crime and commits vast sums of money each year on internal controls, corporate security, employee screening, and outside consultants in an attempt to control employee theft or embezzlement. In spite of these efforts U. S. organizations still lose almost five percent of their revenues to fraud, an 
estimated \$652 billion in 2006 (Ramamoorti, 2007). In the private sector it is deemed reasonable to assume that many will choose to steal and to be forthright in accepting that premise and take steps to minimize the damage from theft. For unknown reasons we expect our citizens, who are the same individuals corporations pay to protect against, to be much more ethical and honest in their dealings with the government. In government, we audit less than one percent of accounts each year for compliance, and at the state level, audit activity is so low that it is almost nonexistent. How can government agencies assume that fraud will not occur? In an environment where there are no third-party controls to help enforce remittance of sales taxes collected, how can we assume that theft will not be rampant? It is my hypothesis that we cannot. 


\section{CHAPTER 3}

\section{THEORETICAL FRAMEWORK OF THIS STUDY}

The theoretical framework for this study of sales tax evasion has been derived from Cressey's fraud triangle and the theory of planned behavior, a blending of components to form a complete model of the sales tax evasion process. The fraud triangle provides the overall structure of the theft process while the theory of planned behavior provides the understanding of the specific decision to steal sales tax funds in a given month, and perhaps the decision not to steal in another. The fraud triangle is particularly robust with respect to understanding sales tax theft because of the similarities between sales tax theft and embezzlement. Under the fraud triangle, sales tax theft by an agent of the state will exhibit three characteristics:

1. The individual or business committing sales tax evasion/theft will have access to the funds of the state. This is a physical truth with respect to sales tax since the agent collects the tax from the taxpayer as an agent of the state. Further, there is no third-party verification of the tax funds collected, so the state must rely on the honesty of the agent to remit the correct amount of sales tax collected ${ }^{7}$.

2. The individual or business will have a financial incentive to retain the state's funds and conceal the theft by underreporting their revenues and the amount of

\footnotetext{
${ }^{7}$ Third-party data can be obtained for use in verifying amounts reported as sales for sales tax purposes, but such records are obtained only if a taxpayer is selected for audit or investigation. These records, such as merchant account credit card sales data or purchases of items for resale from vendors, are not available unless requested or subpoenaed with respect to a particular taxpayer. Additionally, after such request or subpoena results in the production of such records, the process of compiling these voluminous records and comparing the results to reported data is extremely time consuming and can be carried out for only a small percentage of taxpayers. Contrast this with the 100 percent availability of a Form W-2 for every employee in the nation resulting in an ability to match data 100 percent without the need for a records request, subpoena, or labor-intensive compilations of data.
} 
sales tax collected. The financial incentive may be a financial strain such as needing money to pay bills, or it may be a social strain, such as needing more money to retain or improve social status, or as Cressey describes it, status-seeking or status-maintaining activities (Cressey, 1953).

3. The individual or business will have a rationalization or justification for retaining the sales tax and filing fraudulent returns to conceal the theft. Rationalizations will generally be internal, designed to deflect guilt, but may be voiced if the perpetrator is caught. For example, a business may rationalize the theft with the reasoning that it serves society for the business to remain open because it employs others or provides a valuable service, and if it did not retain the sales tax funds it would no longer be in business and society would suffer.

While the fraud triangle offers a framework for understanding sales tax theft, it does not immediately recommend a solution to fraud other than cutting off unrestricted access to funds, which is impossible in the sales tax principal-agent relationship. The theory of planned behavior works in complementary fashion with Cressey's fraud triangle. The fraud triangle describes the characteristics most universally associated with theft or embezzlement. The theory of planned behavior addresses an individual's intention to engage in a particular behavior, in this case theft, through three independent determinants of intention: attitude, social norms, and perception of behavioral control (Ajzen, 1991). The fraud triangle charts the beginning of the process by providing a "need" element not addressed by the theory of planned behavior. From that point, the theory of planned behavior's perception of behavioral control aligns with and strengthens the understanding of the fraud triangle's access to funds leg; and the theory of planned 
behavior's subjective norms and attitude components helps to illuminate the decision process and provide additional explanatory power to the fraud triangle's rationalization leg.

The "need" function in the fraud triangle is an important component not specifically addressed by the theory of planned behavior, where need might be assumed, but is not explicitly provided. A need can cause an otherwise honest and ethical person to steal available funds, and can increase the likelihood of "borrowing" funds to cover near term shortages. Sales taxes are collected monthly and remitted in the following month. When sales taxes collected become due, other liabilities may be more pressing, such as a mortgage payment, or payments to a vendor who is a major supplier to the business, or payroll. Since sales tax liabilities are reported on the honor system, amounts due to vendors and employees are much more difficult to avoid. A missed payroll means employees may walk out. A missed vendor payment may mean lost access to products to sell. A missed mortgage or rent payment, and the business premises may no longer be available. Furthermore, these results occur quickly. If the business underpays the sales tax liability it is highly probable that no one will notice since the audit rate is extremely low. Therefore, if funds are short, the sales tax is more likely to remain unremitted, or under-remitted, than other payments. B. F. Skinner (1953) would assert that this is an example of the theory of operant conditioning. The dire consequences of missing payroll, vendor, rent/mortgage payments and other expenses absolutely necessary to continued business operations condition the business owner to pay those expenses above all others. Likewise, the lack of consequences for underpayment of sales tax liabilities emboldens the business owner to continue that behavior when necessary. However, it is 
important to remember that "need" can mean many different things to different people. Need does not always mean deciding which bills not to pay, because some evaders have sufficient funds to pay them all. Need also arises from a desire to further improve one's lifestyle or social standing or, in some cases, just to increase profitability or horde money.

Many scholars have studied and written about the factors that influence tax evasion as discussed in Chapter 2. Many of the social and psychological factors identified, such as grievances against the government, for example, represent rationalizations in the fraud triangle and subjective norms and attitudes in the theory of planned behavior. There have always been ethical arguments in favor of tax evasion, from the extreme of "all government is illegitimate" to a milder view that evasion may or may not be ethical depending on the circumstances. For example, if government lies to the people, government has breached its contract with the people and the people no longer have the obligation to tell the truth to the government (McGee, 2006). Therefore, even generally honest people can find a rationalization for tax fraud or be negatively affected by subjective norms that subtly inform their attitudes toward evasion.

Some researchers have chosen to explicitly declare an additional component to the theory of planned behavior to account for ethics or moral obligation. Attitude and social norms probably can be conceived to include these determinants and this study assumes they do. Additionally, the rationalization leg of the fraud triangle represents consideration of an ethical or moral response to the issue, albeit a response to justify a departure from ethical or moral behavior. On the basis of the preceding analysis, the guiding theory for my study becomes the theory of planned behavior incorporated into 
the framework of Cressey's fraud triangle (See Figure 3.1). In this model, an agent of the state who chooses to steal state funds can be characterized as follows:

1. The agent develops an intention to retain state funds collected from taxpayers based on need.

2. The attitudes of the agent related to retaining state funds are favorable because of experience, views of government, perceptions of tax inequities, and other factors that have been empirically shown to influence tax evasion behaviors. Ethical and moral considerations are part of the agent's attitude toward evasion and are countered by rationalization that helps reduce tension and enable the act of theft.

3. The agent is under no pressure from social norms to avoid the illegal behavior. It is likely that members of his peer group, particularly those in the same industry, are also engaged in the illegal conversion of state funds. In some industries, members share information on how best to cover their theft of sales tax. Some accountants actively train businesses in the finer points of avoiding detection. These factors, too, have been empirically shown to impact tax evasion.

4. The agent perceives that he or she has the opportunity and resources necessary to successfully convert state funds to their use without discovery, i.e., they have behavioral control over the decision to retain state funds. They may have operated for years without interventions by the state; may have been successfully involved in sales tax theft for many years; and/or may have knowledge of others who are successfully engaging in sales tax theft. They perceive that they understand how to report and remit taxes in such a way as to "fly under the radar" and avoid detection. 
Figure 3.1 Sales Tax Theft Model

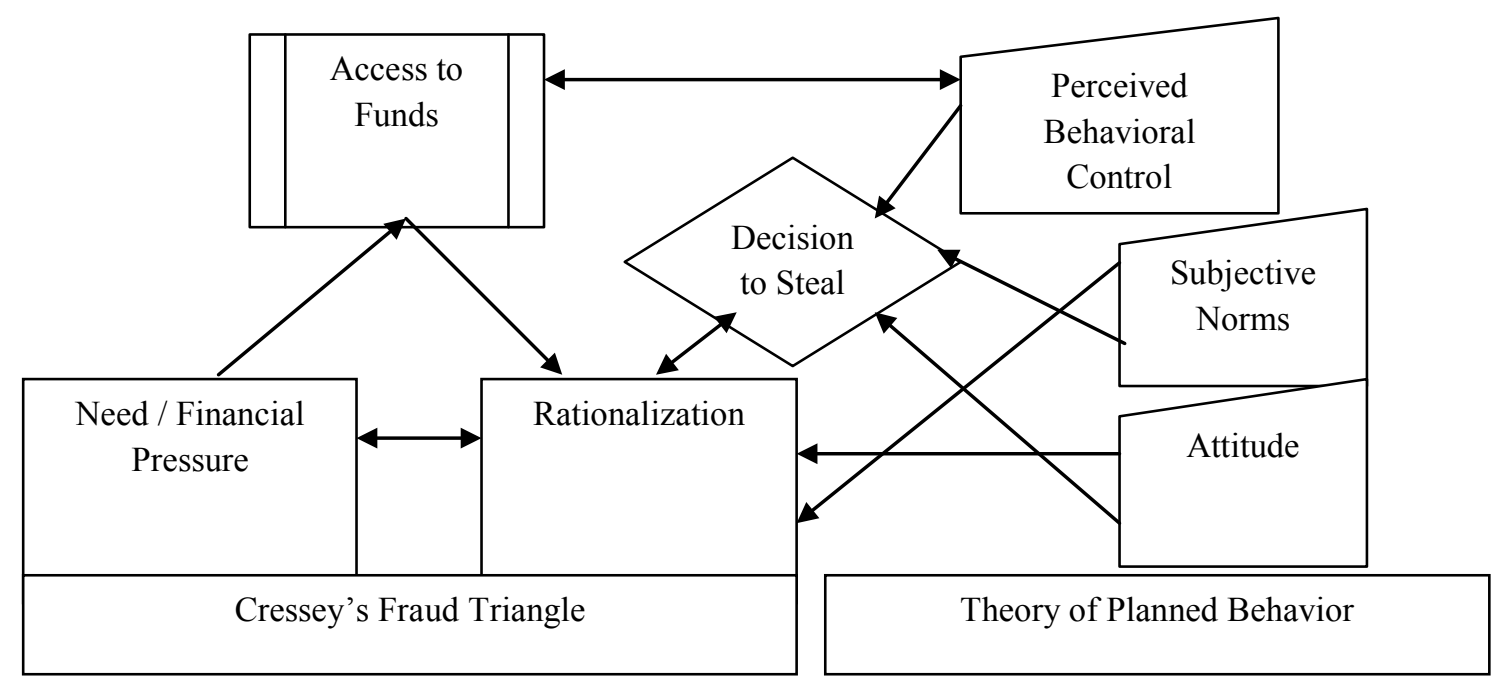

The model depicted in Figure 3.1 has the advantage of incorporating much of the existing research on the drivers of tax evasion into a decision model that comports with a well-accepted framework for understanding fraud found in Cressey's Fraud Triangle. When considering this model it becomes obvious that the access to funds, as viewed through the agent's perception of behavioral control, should be the primary target of enforcement efforts. While the business collecting the sales tax as an agent of the state does, in fact, have physical access to the funds, enforcement operations must be designed to cause the subject to perceive that behavioral control does not include the ability to retain those funds for their own use without discovery. Social norms and attitude can also be important targets of enforcement efforts because they not only help in explaining why a taxpayer might decide to steal tax funds and justify doing so, but can be targeted by taxpayer education initiatives that might help mold the attitudes and impact social norms in a more positive manner. Such education efforts should be a component of even the more punitive enforcement actions. This model responds to Alm's (1991) call for 
broader, theory-based approaches to the problem of tax evasion and compacts the too numerous identified drivers of evasion activity into the components of attitude and subjective norms.

The present study is not modeled after the deterrence model, but the explanatory power of that model cannot be dismissed. A greatly increased probability of detection of evasion is an important element in the effectiveness of deterrence policy, and of great use in impacting the subject's perception of behavioral control. Deterrence activities and schemes thus become a tool for use in managing the subject's perception of behavioral control and his or her choice to evade. Ben-Akiva, et. al. (1999) assert that choice behavior can be thought of as a decision process that is influenced by perceptions and beliefs and by emotional state, psychological tendencies, goals, and preferences. Compliance enforcement interventions must impact this decision process to be effective in reducing tax evasion. The present study shows that increasing taxpayer awareness of the certainty of detection, or alternatively increasing the perception that the probability of getting caught is high even when it is not, is a proper approach to compliance enforcement. Since deterrence activities are always limited by available resources, such activities should be highly visible and designed to appear as though the state has far more resources allocated than are actually available. The present study posits that one of the better ways to impact the subject's perception of behavioral control is the utilization of business intelligence by experienced enforcement personnel to strategically identify potential enforcement targets, and then increase contacts with those targets and require justification for identified weaknesses in reporting or explanations related to indicators of fraud. The increased contact also allows the agent to address attitudes and social norms 
by using the enforcement process as an opportunity to teach and influence. This yields two hypotheses which can be stated in the alternative form as:

$\mathbf{H}_{\mathbf{1}}$ : The effectiveness of compliance enforcement efforts will be improved if active, well-informed enforcement activities characterized by substantial contact initiated by the agents of the state are substituted for passive or reactive activities. $\mathbf{H}_{2}$ : Agent intuition applied to intelligence data yields effective identification of candidates for targeted enforcement efforts beyond audits and general collection activities.

Increasing compliance enforcement activities, especially in times of budget crises, can be a costly proposition. Police and other law enforcement agencies are generally impacted less by budget constraints than regulatory agencies. ${ }^{8}$ To the extent other law enforcement agencies have interests in targets identified for tax enforcement activities, the pooling of efforts and resources can result in significant magnification of perceived enforcement capabilities on the part of the taxing authority. This becomes the third hypothesis which can be stated in the alternative form as:

$\mathbf{H}_{3}$ : Joint investigations with other federal, state, and local agencies result in improved enforcement outcomes, including greater restitution for the same level of resource output.

The development of a model that aids in understanding sales tax evasion and the identification of improvements in enforcement methodologies are both important goals and contributions of the present study. Perhaps of more importance is the use of

\footnotetext{
${ }^{8}$ While this premise is generally true under all conditions, it has become more so because of increased Homeland Security funding of first-responder agencies.
} 
qualitative data obtained through this study to gain more insight into why people seek to evade taxes and the characteristics shared by these people.

\section{Sales Tax Evader Typology}

Generalized theories of tax evasion, including adaptations of behavioral, decision, and rational choice theories, are often too simplistic to adequately address what enforcement officials encounter in the field. The quest for parsimony in the explanation of the multi-dimensional decision to evade taxes naturally results in this flaw upon application; a flaw that must necessarily be applicable to the theoretical framework of my study as set forth in the previous section. It is necessary to understand that evasion is not one-size-fits-all, and that people evade for different reasons and in different ways. Many are noncompliant with no overt intent to evade. It is necessary to expand the theory to understand that different tools are required to address different formulations of noncompliant activity. To address these theoretical shortcomings, I have devised a typology of sales tax evaders to guide the appropriate choice of enforcement measures that is based on the results of my study, on my previous personal experience in the field, and on communications with collectors, auditors, and investigators responsible for compliance enforcement. An analysis of this typology provides a basis from which a realistic evaluation of current and proposed methodologies can be based. A summary of this sales tax evader typology is presented in Table 3.1 and is followed by a discussion of each type of evader and the current methodologies and tools utilized with respect to each type of evasion. 
Table 3.1 Sales Tax Evader Typology

\begin{tabular}{|c|c|c|}
\hline Type & Subtype & Description \\
\hline Delinquents & & $\begin{array}{l}\text { The most recognized type. Delinquents are the current } \\
\text { referent group for calculations of voluntary compliance. }\end{array}$ \\
\hline \multirow[t]{3}{*}{ Incompetents } & $\begin{array}{l}\text { Inadequate } \\
\text { training }\end{array}$ & $\begin{array}{l}\text { These individuals exhibit a lack of understanding of at } \\
\text { least some portion of their responsibilities for sales tax } \\
\text { collection and remittance. }\end{array}$ \\
\hline & $\begin{array}{l}\text { Poor } \\
\text { business } \\
\text { skills }\end{array}$ & $\begin{array}{l}\text { These individuals run their business from a checkbook, } \\
\text { i.e., "if there is money in the account, I must be } \\
\text { profitable." They maintain no, or very poor, sales } \\
\text { records, resulting in poor reporting compliance and } \\
\text { under-remitted sales tax. }\end{array}$ \\
\hline & $\begin{array}{l}\text { Illness of } \\
\text { the owner }\end{array}$ & $\begin{array}{l}\text { Reporting and remitting of sales tax suffers because of } \\
\text { the extended medical problems of the primary } \\
\text { responsible party. }\end{array}$ \\
\hline Survivors & & $\begin{array}{l}\text { These individuals do not want to evade, but do so to } \\
\text { remain competitive with other companies who are } \\
\text { deriving economic benefits from evasion. This group is } \\
\text { a victim group in reality. }\end{array}$ \\
\hline \multirow[t]{2}{*}{$\begin{array}{l}\text { Negligent } \\
\text { Evaders }\end{array}$} & $\begin{array}{l}\text { Absentee } \\
\text { owners }\end{array}$ & $\begin{array}{l}\text { Those who trust others to manage their business but do } \\
\text { not institute adequate internal controls to prevent theft or } \\
\text { evasion. }\end{array}$ \\
\hline & $\begin{array}{l}\text { Poor } \\
\text { control } \\
\text { over } \\
\text { associates }\end{array}$ & $\begin{array}{l}\text { Those who allow others to use their business name, } \\
\text { licenses, and other resources for a fee, but do not } \\
\text { maintain required control over tax reporting. This group } \\
\text { essentially allows non-qualified people to operate a "sub- } \\
\text { business" from within their organization. }\end{array}$ \\
\hline Borrowers & & $\begin{array}{l}\text { These individuals do not intend to steal, but reduce } \\
\text { remittance of sales tax to "tide them over" until their } \\
\text { financial condition improves, at which point their intent } \\
\text { is to make up payments in arrears. }\end{array}$ \\
\hline $\begin{array}{l}\text { Hardcore } \\
\text { Evaders }\end{array}$ & & $\begin{array}{l}\text { This group has learned, through experience or } \\
\text { counseling, to "fly below the radar" to conceal their sales } \\
\text { tax theft. They conceal the theft by appearing to comply } \\
\text { by always filing a sales tax return and paying the reduced } \\
\text { tax reported. When caught, they will generally become } \\
\text { compliant for a time. }\end{array}$ \\
\hline $\begin{array}{l}\text { Proficient } \\
\text { Evaders }\end{array}$ & & $\begin{array}{l}\text { Similar to the hardcore group, this group makes every } \\
\text { effort to conceal their theft of state funds, and have } \\
\text { become quite proficient at eliminating all indicators of } \\
\text { fraud. This group is the most difficult to catch evading, } \\
\text { and when caught, will adjust their methods rather than } \\
\text { become compliant. }\end{array}$ \\
\hline
\end{tabular}




\section{Delinquents}

When a business fails to file a sales tax return, or files a return and does not remit the taxes reported with the return, they are termed delinquents, and failure to file or pay: a delinquency. These evaders are identified easily because they are registered businesses that are required to file periodic sales tax returns. The absence of a sales tax return, or absence of a payment accompanying a return, is instantly flagged. This type of evader is the most recognized and best understood, and is the only type generally considered by tax agencies when they calculate voluntary compliance with respect to the sales tax. Agency collections personnel are in constant contact with delinquent taxpayers until delinquencies are resolved through proper reporting and collection of the tax due or through the filing of tax liens to protect the interests of the state. More extreme action may be taken when required, including revocation of the license to collect sales tax, seizure of property to recover the tax, or referral for criminal prosecution.

Audit assessments that are not timely paid can also be considered delinquencies and are dealt with in similar fashion.

Current enforcement methodologies are adequate for addressing this type of evader and generally result in favorable outcomes.

\section{Incompetents}

There are several subtypes of incompetents. Some have inadequate training in maintenance of the records required to properly report and remit sales tax, or problems in determining what is taxable and what is exempt. Others have a far more basic problem, with little understanding of how to operate a business and no understanding of 
bookkeeping or tax reporting. Operating their business utilizing only a checkbook, sales records do not exist to allow adequate reporting of sales tax collected. Some suffer from incompetence as a result of medical issues that render the primary responsible party unable to properly account for the results of their business operations or sales tax collected.

Sales tax evasion because of incompetency is generally discovered only when delinquencies occur as a result of the incompetency or an audit is performed on the business. Agency educational initiatives properly applied can counteract evasion as a result of lack of knowledge of the sales tax rules and can, in some cases, provide enough information to the more generally incompetent business owners to allow them to at least maintain sales records that allow compliance with sales tax law even if they cannot perform simple bookkeeping. The major obstacle to the success of such initiatives is that they must be requested by the taxpayer and are generally not required as a condition of obtaining a sales tax license.

\section{Survivors}

Survivors do not necessarily set out to evade sales taxes. They do so to compete. A business stealing sales taxes in Florida gains a six to seven and a half percent profit advantage over their competitors. In many low profit margin business models this advantage results in doubling profit or better. Such increases can make it possible to force compliant competitors out of business. Business owners do engage in intelligence gathering and often know when these unfair situations exist and must decide whether to compete by becoming noncompliant themselves or by taking alternative action. In other 
situations, an unfair tax advantage may not be specifically identified by the compliant competitor, but the competition may nevertheless force the same choice. A complete example of such a situation is offered in Chapter 4.

The preferred tool for ensuring compliance among survivors is the fair application of the law to everyone. If it becomes impossible to fairly apply a specific statute, then it is imperative that the statute be changed so that it can be enforced. A lack of fair enforcement causes distortions in the market and damages the tax morale of compliant businesses, making them more likely to be noncompliant.

Additionally, compliant businesses should be encouraged to file complaints against businesses taking unfair advantage by retaining sales tax collections rather than becoming noncompliant themselves. For this strategy to work, the agency must be able to immediately take action against lawbreakers or risk further reducing tax morale and sending a message that the agency is powerless to enforce compliance.

\section{Negligent Evaders}

Negligent evaders are typically absentee business owners that do not institute appropriate internal controls to control sales tax theft by those hired to manage the company. Numerous cases have been reviewed where owners found themselves facing very large sales tax liabilities, penalties, and interest, as a result of managers operating a side business within the structure of the owner's enterprise. Because these additional sales that benefitted only the manager were consummated in the name of the owner's business, the owner remains liable unless positive proof can be provided to implicate the manager. In this scenario, the manager prepares a sales tax return reporting only sales the 
owner is aware of, and presents it to the owner who unknowingly signs and files a fraudulent return.

In some cases, the owner knows of the additional business activity taking place within the structure of the enterprise, and receives a fee or a profit share for allowing the associate to use his or her business resources. In some cases, the owner may actually report the sales taxes collected from the sub-business, if they are properly accounted for by the associate. In other cases, the owner ignores that aspect of the enterprise and likely understands that the associate is not reporting the sales tax. When caught, however, the owner is charged with the responsibility because evidence of the additional sales and tax collections will normally exist within his or her books and records. There was one arrangement identified during this study where a used car dealer allowed up to 48 individuals at any one time to use his Department of Highway Safety and Motor Vehicles dealer's license to purchase and sell cars. The owner received $\$ 250$ per car sold by these associates. None of the sales transactions or sales tax collected by these 48 individuals was reported.

The negligent evader is normally discovered only when an audit or criminal investigation is undertaken. Even if the negligent evader becomes delinquent, collections activity will generally not be sufficient to identify the additional tax due. When pressed to file a return or provide sales and tax information, the owner will provide information with respect to his sales only, not those of his associates, and those sales will likely be consistent with prior filings, ending any further inquiry on the part of collectors. 


\section{Borrowers}

Borrowers do not begin with the intent to steal sales taxes collected. They are usually confronted with severe cash flow problems that force them to make a decision between paying the rent, making payroll, or sending in the full amount of sales taxes collected during the previous month. They "borrow" the money from the state, mentally pledging to repay the taxes when financial conditions improve. In rare cases the borrower may actually repay the borrowed tax money. In most cases, if they are not caught they will simply keep the money. In the worst cases, they learn from not getting caught and begin "borrowing" some of the tax money every month, making the transformation from Borrower to Hardcore.

Borrowers keep only a portion of the sales tax collected and retain a portion of the sales tax collected only when financial pressures require. They continue to file a sales tax return every month reporting less sales tax collected than actual for those months where borrowing occurs, and send in a check or make an electronic payment equal to the amount of tax they report. There are no delinquencies to raise alarms. If analysis of the account is performed, it may be noted that sales tax collections decrease periodically, sometimes dramatically, which might contribute to selection for audit if other indications of potential fraud are also evident.

\section{Hardcore Evaders}

Some evaders have learned through experience or counseling that filing a return every month, reporting a reasonable amount of tax collected, and paying that tax with a check or electronic transfer that is not dishonored by the bank virtually guarantees that 
the business will escape scrutiny. They understand that delinquencies receive instant attention and should be avoided. They also understand that the majority of agency personnel are tasked with resolving delinquencies. These evaders are betting against being selected for audit as long as the amounts they report are relatively reasonable, i.e., they are playing the "audit lottery." Generally their theft is only discovered if they are selected for audit or criminal investigation based on other indications of fraud or a criminal complaint initiated by a third party. When caught, these evaders will likely become compliant for a period of time but will return to evasion activities when they perceive the agency's attention has been turned elsewhere.

\section{Proficient Evaders}

Proficient evaders are an advanced version of the hardcore evader, but are careful to cover every potential indication of fraud. In that respect, they are hardcore evaders who have become very adept at sales tax theft. They understand how to use the laws to their advantage and generally limit their exposure to misdemeanors rather than felonies by manipulating the types of evidence available if they are caught. For example, in many cases they will raise prices and refuse to charge sales tax, a misdemeanor, rather than charging the sales tax and retaining it, a felony. The company receives the same amount of money from the customer but structures the transaction to manage the risk. When caught, proficient evaders do not become compliant; they adjust their methods and continue to steal sales tax. Proficient evaders frequently close businesses that have been in operation for several years and open new business entities owned by relatives, understanding that closed corporations pose more difficult enforcement scenarios for tax 
authorities and helps to bury the audit trail. Many Proficient Evaders also operate businesses that deal with substantial amounts of cash, and use cash to pay bills rather than depositing cash into bank accounts that leave evidence of greater sales.

\section{Enforcement Tools}

The general enforcement tools available to state tax agencies can be summarized as follows:

1. Collections staff who instantly address failures to file returns or failure to pay amounts reported as due on returns received without payment.

2. Audits of companies identified via a strategic lead development operation that utilizes data from a variety of sources to identify potential fraud and evasion.

3. Criminal investigations of companies suspected of fraud or sales tax theft derived from referrals from collections, audit, and lead development processes, or derived from complaints received from outside the agency.

4. Discovery operations and campaigns designed to identify companies that are not registered with the agency for the tax obligations related to their business operations.

Collections efforts are adequate with respect to Delinquents and many Incompetents. Discovery operations are effective in identifying Delinquent evaders that fail to register. However, in most cases audit and criminal investigations resources are so limited that the chance of identifying Survivors, Negligents, Borrowers, Hardcore Evaders, and Proficient Evaders is extremely small. This gap in enforcement coverage is discussed more specifically in Chapter 4. The proactive methodologies introduced in the 
present study are designed to address these types of evaders. In the framework introduced here all strategic lead development activities will be directed into targeted industry enforcement programs. It is also recommended that a substantial portion of audit activities be redirected from strategically developed leads to a completely random audit process designed to identify those evaders who have been successful in eliminating outward signs of fraudulent activities that would result in identification utilizing other methods, primarily the Proficient evaders. Table 3.2 provides a summary of the recommended tools for each type of evader.

Table 3.2 Enforcement Tools by Evasion Type

\begin{tabular}{|l|l|l|}
\hline Evasion Type & Current Tools & Proposed Tools \\
\hline Delinquents & $\begin{array}{l}\text { Collection activity; } \\
\text { discovery operations }\end{array}$ & $\begin{array}{l}\text { Collection activity; } \\
\text { discovery operations }\end{array}$ \\
\hline Incompetents & $\begin{array}{l}\text { Collection activity; strategic } \\
\text { audits }\end{array}$ & $\begin{array}{l}\text { Collection activity; targeted } \\
\text { industry enforcement }\end{array}$ \\
\hline Survivors & $\begin{array}{l}\text { Strategic audit; criminal } \\
\text { investigations }\end{array}$ & $\begin{array}{l}\text { Law changes; successful } \\
\text { enforcement efforts against } \\
\text { other types of evaders; } \\
\text { targeted industry } \\
\text { enforcement }\end{array}$ \\
\hline Negligents & $\begin{array}{l}\text { Strategic audit; criminal } \\
\text { investigations }\end{array}$ & $\begin{array}{l}\text { Targeted industry } \\
\text { enforcement }\end{array}$ \\
\hline Borrowers & $\begin{array}{l}\text { Strategic audit; criminal } \\
\text { investigations }\end{array}$ & $\begin{array}{l}\text { Targeted industry } \\
\text { enforcement }\end{array}$ \\
\hline Hardcore & $\begin{array}{l}\text { Strategic audit; criminal } \\
\text { investigations }\end{array}$ & $\begin{array}{l}\text { Targeted industry } \\
\text { enforcement }\end{array}$ \\
\hline Proficient & $\begin{array}{l}\text { Strategic audit; criminal } \\
\text { investigations }\end{array}$ & $\begin{array}{l}\text { Random audit; criminal } \\
\text { investigations }\end{array}$ \\
\hline
\end{tabular}

The goal is to find an optimal mix of enforcement methodologies that produces the greatest gain in compliance with minimal increases in additional resources. The 
implementation of targeted industry enforcement programs accomplishes that goal. Targeted industry enforcement programs are similar to current discovery and campaign operations, but are planned and executed wholly at the local level by local employees, and represent a continuous process rather than an isolated compliance exercise that may not be repeated for several years. The employees given responsibility for a particular industry will not approach their responsibility as a linear process of research, target identification, and intervention, but as one of continuous research and target identification simultaneous with engagement. The approach is one of consistent compliance pressure on the industry utilizing a minimum amount of resources prepared with the maximum amount of knowledge and information. The key is activity informed by intelligence that is accurate and actionable.

\section{Why People Evade}

A large percentage of sales tax revenues are collected in spite of fairly large gaps in compliance enforcement capabilities. There are two primary reasons for this. First, larger companies tend to have strong internal controls that act to limit evasion activities. Evasion would require collusion among many employees from different departments within the organization and management would have to be convinced none would ever break ranks. Large companies utilize expensive legal and accounting services to exploit any loopholes or gray areas in the law, but outright evasion is rare because the potential impact on corporate reputation would be much more expensive than any state sanctions. 
Second, as noted in the literature review, there are a substantial number of business owners who would not evade taxes under any circumstance because of moral and ethical considerations.

Based on my review of existing research, previous experience, review of hundreds of case files, communications with enforcement agents in the field, and the results of this study, it is clear that, aside from these two groups, substantial numbers of small- to medium-sized businesses do engage in tax evasion and sales tax theft. The evidence indicates that Survivors, Negligents, Borrowers, Hardcore, and Proficient evaders ultimately steal sales tax collections simply because they can. In terms of the theory of planned behavior, they steal because they perceive that they have behavioral control in the decision process. The circumstances that lead them to the decision point are certainly different, and many times based on some form of need. Some need the money to survive; others to maintain a lifestyle. Regardless of the circumstances that lead them to the decision to evade or their original intent, they would not steal if they did not strongly believe that they can retain sales tax monies collected from their customers without suffering consequences. They understand the criteria currently used to identify tax cheats to varying degrees, but each type of evader understands it well enough to know their chances of getting caught are minimal. Many also understand that getting caught is not the end of the story; they may still be able to offer explanations that mitigate the consequences or hide evidence to confound investigations. Under present conditions, the risks associated with sales tax theft are acceptable and manageable, if not nearly irrelevant. 
While perceived behavioral control is a necessary precedent to sales tax theft, subjective norms and individual attitudes are no less important as targets for enforcement action. There exists substantial anger toward governmental institutions, and politicians often fan the flames for their own ends. Anger leads to rationalizations that sales tax theft is not immoral and peer groups tend to strengthen such beliefs. There needs to be a realization that government serves a fundamentally required function in society and that it must be properly financed to be effective. Tax agencies must address this anger with increased taxpayer education and more focus on less punitive measures to enforce compliance, at least in the case of first-time evaders who are not of the Hardcore or Proficient variety. It is my belief that an emphasis on proactive engagement with the taxpayer contributes to changing attitudes and subjective norms. It is important that noncompliant taxpayers are approached with an understanding and helpful attitude throughout the enforcement process as long as the taxpayer is cooperating and making an effort to become compliant and resolve prior obligations. My main critique of the specific application of the deterrence model in tax enforcement is that taxpayers are immediately subjected to harsh treatment (guilty until proven innocent) and massive penalties with few good options available for rehabilitation. The deterrence model does not require the immediate application of draconian punishment against offenders without first the application of more reasoned measures, but this concept seems to have been lost when deterrence theory was conceptually applied to taxation. Few deterrence model economists conclude that punishment is the single best social response to crime and instead view deterrence as only part of the model of society's response (Palmer, 1977). More often the not, the result of the application of the deterrence model in tax matters is 
personal ruin. If there is an opportunity to effectively rehabilitate the taxpayer, it lies in engagement rather than punishment. More severe penalties and punishment should be reserved for Hardcore and Proficient evaders who resist rehabilitation. An approach based on engagement should allow rehabilitation of nearly all Survivors, Negligents, and Borrowers.

The targeted industry enforcement program introduced and tested in my study provides a method of identifying evaders that escape detection under the current enforcement paradigm and engages them in a process designed not only to bring them into compliance with the tax laws, but to provide education and understanding of the tax law and agency enforcement efforts that may help change attitudes and prevent recidivism.

\section{Importance of This Study}

Existing tax evasion research is focused primarily on the income tax with international studies related to the value-added tax a step behind. There are, in fact, few studies that deal primarily with sales tax issues, and most of those do not address evasion. Evasion is never addressed in any fashion differently than evasion in the case of the income tax. One possible reason for this is an assumption that the study of tax evasion can be equally applied to different types of taxation, and this may be true to a certain extent, but the sales tax creates an agency relationship between government and business that is not present in income taxes. A second reason is that a number of researchers believe that there is less evasion with the sales tax than with the income tax even though there are no data to support this assumption. As noted previously, evasion is three times 
more likely when there is no third-party reporting of income (Madeo, Schepanski, \& Uecker, 1987). With sales tax there is no third-party reporting; the business collecting the tax has unrestricted access to the funds; and there is no structure or process to guarantee proper reporting and remittance other than honesty. As a senior tax administrator with the Department of Revenue admitted, it is estimated that up to 60 percent of small businesses in Florida engage in sales tax theft. The experiences of tax collectors, auditors, and criminal investigators in the field bear out that estimate. The aforementioned administrator drew an allegory to speeding: if you drive on the interstate in Florida at the speed limit, you will be the slowest car on the road by far. Unless there are state troopers positioned at regular intervals on the highway, everyone will speed (Anonymous, 2006). Department of Revenue agents must be just as visible as those state troopers on the roadway to prevent open season for sales tax theft. Sales tax evasion is fundamentally different from income tax evasion, represents a very large portion of lost state revenues, and deserves dedicated research.

In Florida, there has been much discussion of lowering, or even eliminating, property taxes and compensating with an increase in the sales tax. Ignoring the regressivity of such a proposal in an already regressive, narrow, and outdated tax structure, it must be noted that the property tax is truly nearly evasion free. Undoubtedly those who propose such a change do not understand the true cost of the proposal in terms of increased sales tax theft and rate increases far in excess of those envisioned if revenue is to remain stable.

Perhaps more importantly, at least one proposal for a national sales tax calls for an elimination of the Internal Revenue Service under an assumption that the sales tax is 
evasion free, even though, as mentioned previously, substantive research does not exist to support this assumption. Talk of eliminating the Internal Revenue Service is likely no more than rhetorical "red meat for the masses" but may be a political liability if consumption tax evasion assumptions are erroneous. Furthermore, under most economic theories, either rational or boundedly rational, the increase in the sales tax rate to a combined federal and state rate that exceeds 30 percent would increase the benefits related to evasion to the point where the risk of getting caught and the penalties involved would have to be enormous and especially serious to have any deterrence impact at all (Tait, 1988). Mikesell (1997) also notes that considerable enforcement resources would be required to supplement existing state administrative capacities because of the much higher evasion rewards that would exist with a high national sales tax rate. But even though Tait and Mikesell understand the issues with evasion as the sales tax rate rises, they still appear to believe, as most others do, that evasion at the lower rates levied by the American states is inconsequential. It is my hope that this study will cause researchers to reexamine that belief and begin to question some of the assertions made by state agencies regarding voluntary compliance rates ${ }^{9}$.

\footnotetext{
${ }^{9}$ Calculation of an evasion rate for sales tax is very difficult. Using the theory that large companies are generally compliant and the estimate of $60 \%$ noncompliance to some degree on the part of most small companies, an estimate of sales tax theft and evasion in Florida would be likely within a range of $\$ 2.1$ billion to $\$ 6$ billion annually ( $10 \%$ to $28 \%$ ). The size of the range is indicative of the difficulty in determining an appropriate cutoff between large and small companies, since the real issue is not size, but the extent to which appropriate internal controls exist. Even at the low end of the range, 10\%, the impact of evasion greatly exceeds the popular estimates of $2 \%$ to $5 \%$ and represents $\$ 24$ billion in annual sales tax theft nationwide.
} 


\section{CHAPTER 4}

\section{TAXATION IN FLORIDA}

\section{The Florida Department of Revenue}

The current study reviews and analyzes tax compliance enforcement activities within the Florida Department of Revenue ("DOR"). There are three major functional groups called Programs within DOR: Child Support Enforcement, Property Tax Oversight, and General Tax Administration (GTA). The GTA program is structured functionally into the following Core Processes: Account Management, Compliance Determination, Compliance Support, Receivables Management, Resource Management, Return and Revenue Processing, Taxpayer Aid, and Taxpayer Services. Each Core Process consists of Business Processes that focus on different functions. My study focuses on specific Business Processes within the Compliance Determination and Receivables Management Processes that relate directly to the enforcement of sales tax laws and identification of evasion, which can be generally and simply described as, and will be referred to throughout this study as audit, collections, and criminal investigations. Audit includes tax enforcement campaigns and lead development. Lead development involves the strategic analysis of data to identify taxpayers for audit. Campaigns are likewise derived from strategic data analysis but are focused on enforcement problems within a particular industry or with respect to a particular issue. The Collections Process includes enforcement operations, which include the filing of liens, property seizures, license revocations, and similar activities. A partial organization chart for the Florida Department of Revenue is presented in Figure 4.1. 
Figure 4.1 DOR Partial Organizational Structure

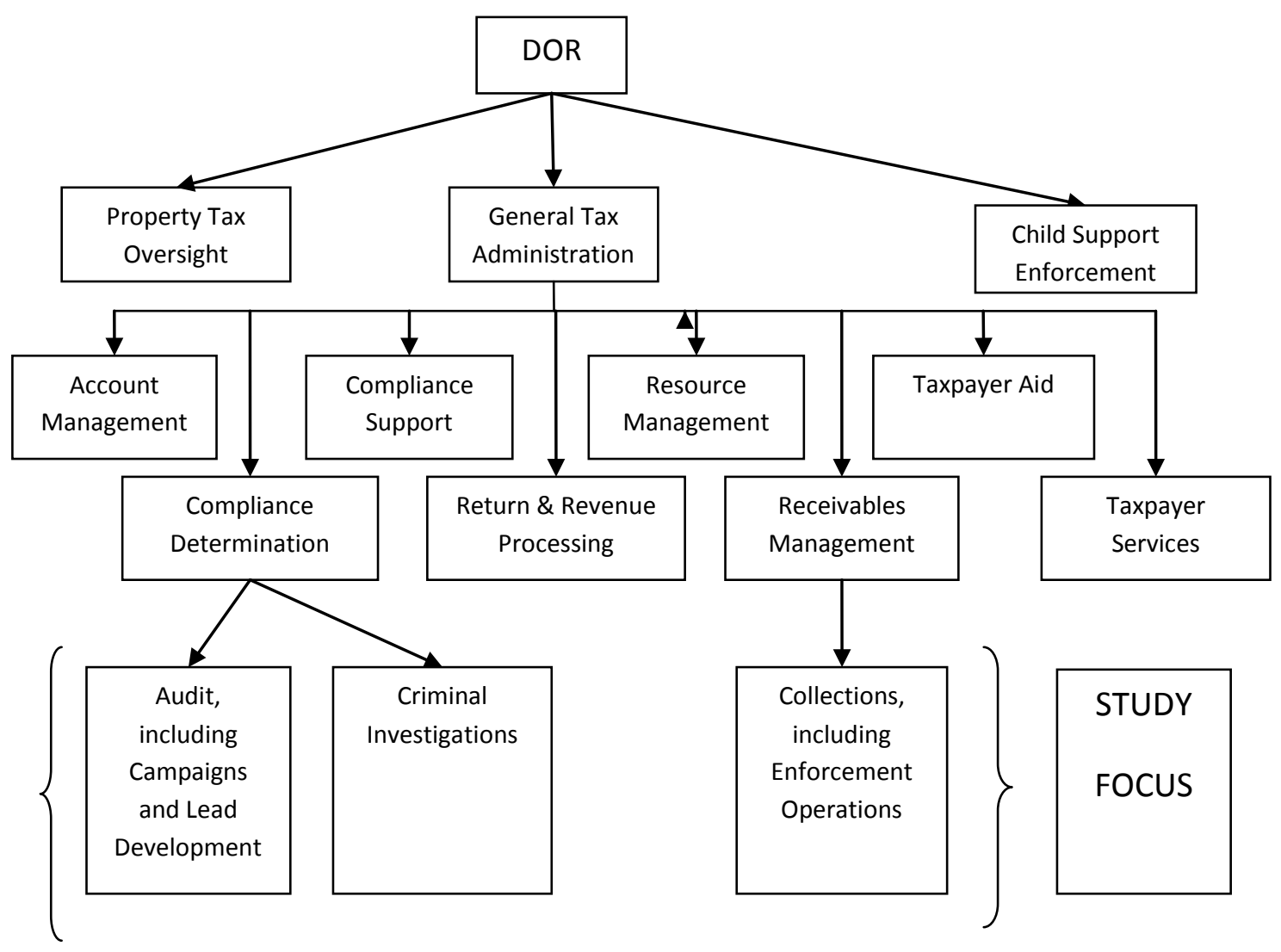

Source: Florida Department of Revenue (2010)

According to the 2006-2007 annual report (Florida Department of Revenue, 2007), GTA administers 33 taxes and fees, and more than $\$ 39$ billion in taxes annually, including almost $\$ 23$ billion in sales tax. Other major taxes and annual amounts are: fuel related taxes and fees, $\$ 3.2$ billion; documentary stamp taxes $\$ 3.1$ billion; corporate income and excise tax, $\$ 2.4$ billion; communications services tax, $\$ 2.4$ billion; and unemployment tax, $\$ 1$ billion. Florida has no state individual income tax.

At June 30, 2008, GTA had 2,278 employees, and this number has declined almost ten percent over the previous six-year period. The GTA program processed more than 9.4 million returns during the fiscal year ending June 30, 2008, and issued 11,580 
Notices of Proposed Assessment worth $\$ 421$ million, issued one million bills for $\$ 315$ million, and issued more than 900,000 delinquency notices. Enforced tax collections were more than $\$ 770$ million and 876 criminal cases were closed resulting in 137 prosecution referrals and 286 Tax Collection Enforcement Diversion Program referrals to State Attorney's Offices. There were 3,679 sales and use tax audits during the fiscal year carried out by 410 auditors resulting in an average assessment of $\$ 6,900$ (General Tax Administration, 2008).

In administering the sales tax, DOR relies on businesses that collect the tax from their customers. The taxpayers are the individuals who purchase from the businesses that collect the tax as agents for the State. Businesses file a Sales and Use Tax Return each month (generally) ${ }^{10}$ to report the amount of sales taxes collected and remitted with the return. The return for the previous month is due on the first day of the following month and is delinquent after the $20^{\text {th }}$ day of the month following the month during which the tax was collected. For example, sales taxes collected during May 2009 must be remitted with a return filed by June 20,2009 . If the $20^{\text {th }}$ day of the month falls on a holiday or weekend, the due date shifts to the next business day. So continuing the example, June 20, 2009 is a Saturday, so the return and payment are due by Monday June 22, 2009. Taxpayers are required to file and remit taxes electronically if their annual tax liability exceeds $\$ 30,000$.

Most businesses report and remit taxes on time. The percentage of unpaid taxes at June 30, 2008 was 1.63 percent. This percentage is the outstanding receivables divided by the total tax due as reported on returns filed plus estimated delinquent amounts and

\footnotetext{
${ }^{10}$ Companies collecting smaller amounts of sales tax on an annual basis are allowed to file quarterly, semiannually, or annually depending on the amount of sales tax collected in the previous year.
} 
amounts determined through audit and discovery activities. Even though the percentage is small, the amount exceeds $\$ 500$ million. It is important to note that this figure accounts only for self-reported sales tax that has not yet been paid, estimated delinquencies of businesses that file late, and audit assessments that have not been paid. Estimates are based on amounts generally reported by the business. The outstanding receivables used in this calculation do not include an estimate of tax evaded or stolen and, to the author's knowledge; no such estimate is produced by DOR.

When a business does not file their return and pay the taxes on time, collections personnel start the collection effort by contacting the delinquent taxpayer in an attempt to bring them into compliance with the law. In some cases, the taxpayer continues to be delinquent and may not file returns for an extended period of time. When taxes remain outstanding and collection efforts have failed, a tax warrant (lien) will be filed at the courthouse in the county in which the business operates, or in multiple counties if applicable. This lien works best if the business owns real property that cannot be sold with clear title until the lien is cleared. In those cases the buyer may insist on the lien being paid or modifications to the purchase contract, such as reserves held in escrow for the payment of the liability, before completing the purchase. Where the business does not own real property, the lien can attach to personal property but, from a practical standpoint, DOR would have to contact the buyer to inform them of the lien and potential levy and execution of the levy on the property. In practice, however, DOR will rarely be aware of any potential sale of personal property or the name of the potential buyer. The DOR has the authority to seize and sell personal property to satisfy the lien, but seizing and selling property is rarely done, except in the case of bank accounts, which are 
frequently frozen pending the levy and ultimate seizure of funds up to the amount of the tax liability, penalties, interest, and fees.

Except when real property is involved, tax warrants are generally not much of an incentive for delinquent filers to file and remit the taxes owed. In the fiscal year ending June 30,2008 , only $8.67 \%$ of tax warrants filed were cleared, paid in full, or subject to a payment agreement within 90 days of filing, and 39.52 percent were deemed uncollectible (Florida Department of Revenue, 2008). Taxes are deemed uncollectible when, for example, the business owing the tax has closed or declared bankruptcy and neither the business nor the shareholders have any assets that can be levied.

Collectors have a very heavy workload. In December 2008, the Service Centers around the state had 236,074 cases open representing more than $\$ 589$ million in receivables. In South Florida, where this study takes place, the workload is heavier than in other areas with 68,278 cases in Miami-Dade County alone out of a total of 152,852 registered businesses. This represents a staggering 44.67 percent of all businesses in delinquent status as opposed to an average of 20.46 percent for the rest of the state. The result is that collectors have very little time to spend on any given delinquency since the ratio of open delinquencies to collectors is 785 to one in Miami-Dade County.

Businesses that are chronically delinquent and show little interest in compliance may also be subjected to a revocation hearing. If their sales tax registration is revoked, they are essentially out of business since it is illegal to operate the business without a certificate of registration. Revocation is used as a last resort, after virtually all other civil collection efforts have failed. Specific guidelines exist and must be followed if a revocation is attempted. At the revocation conference, the business may present a case 
for why their registration should not be revoked; they may enter into an agreement to bring their business into compliance; or the result of the conference may be a recommendation that the certificate of registration be revoked.

Collectors and their supervisors may decide to refer a particular taxpayer for audit or for criminal investigation if the facts and circumstances warrant such a recommendation. Audit selection is performed centrally in Tallahassee and selected cases are assigned to the local Service Centers, so a referral for audit may or may not result in an actual audit being performed. Criminal investigation referrals are evaluated locally and accepted if there is probable cause that a crime has been committed. If probable cause exists and certain other policy requirements are met, the Criminal Investigation Process is required to open an investigation.

Auditing remains an efficient and effective means of discovering additional tax liabilities for DOR based on the return on investment of additional budget dollars allocated for audit. Currently, 76 percent of audits yield an assessment of additional taxes due to the state, a fact recognized by the Florida Legislature when they approved an additional 50 audit positions in the midst of deep cuts required to balance the fiscal 2009 budget. The problem with auditing in Florida is the same as it is at the federal level: there are so few auditors that the percentage of audits in a given year is very low. As noted previously, there were 3,679 sales and use tax audits in Florida during the fiscal year ended June 30, 2008. As of December 31, 2008, there were 972,977 registered businesses in the state. That represents an audit rate of .38 percent (.0038). While the literature states that there are diminishing returns to additional enforcement expenditures (see Alm, 1999 and Mikesell \& Birskyte, 2006), it would appear that Florida has much 
ground to cover before experiencing diminishing returns since the audit effort would need to almost triple to reach a one percent audit rate. The state has been doing the opposite with the number of auditors dropping from 585 to just over 400 over the past eight years. The decision in the current budget year to add 50 audit positions because of serious budget shortfalls is an indication that the cost effectiveness of auditing is recognized. It is also an indication that prior year reductions were based on ideology rather than a belief that additional audit resources would be a poor investment.

The Criminal Investigations Process has seen a drop in resources as well, though not as steep as the decline in audit resources because the process is smaller to begin with (34 investigators at December 2008). In Miami-Dade County there are four investigators with two support staff and the region's Investigations Manager is located there. A review of data from the Criminal Investigations Case Management System revealed that at month end December 2009 the four investigators had 154 criminal investigations in their case inventories. Assuming an average investigation requires 200 person hours, ${ }^{11}$ that case inventory represents approximately four person-years of work per investigator. An additional 15 to 30 criminal complaints are received each month that must be evaluated with an average of 14 of them qualifying for investigation. Even though the statute of limitations for sales tax theft is five years rather than the normal statute for civil enforcement of three years, these data mean there are legitimate criminal investigations that simply cannot be carried out within the statute of limitations period given current resource levels and current policies.

\footnotetext{
${ }^{11}$ In addition to cases averaging 200 investigative hours, investigators in Miami-Dade County are frequently involved in larger cases requiring 2,000 hours or more that span fiscal years.
} 


\section{Technology}

Resource limitations at all levels cause the DOR management team to be very interested in efficiency improvements, and particularly improvement spurred by technology. The implementation of SUNTAX (System for Unified Taxation) was begun by DOR in 2001 to replace the various antiquated mainframe programs accessed through DOS- or UNIX-based client systems in use at that time. The SUNTAX system is now integrated with web-enabled applications that allow taxpayers to register, file reports, and pay tax bills online. Additionally, electronic data interchange (EDI) and electronic funds transfer (EFT) capabilities are integrated that allow the Department to support electronic filing requirements mandated by the legislature. For employees, rather than consulting a separate computer program, with a separate login, for each tax administered by DOR, SUNTAX allows a DOR employee to review all taxes to which a business is obligated from one system, and receive a status overview of all the taxes on a single screen.

The Department has expanded the SUNTAX system to include the use of MySAP Customer Relationship Management in the call center and SAP Business Intelligence technology to identify gaps in compliance patterns across industries and regions. This data-warehousing technology has now been expanded to provide management staff with real time data reporting capability that enhances the management of day-to-day operations. As a result of this technology integration and reengineered administrative procedures, GTA has saved more than $\$ 96$ million in cumulative budget allocations during the past five years. It is further estimated that SUNTAX has produced $\$ 848$ million in increased revenue as a result of efficiency gains, improved audit and discovery leads, and identification of unregistered taxpayers (Florida Department of Revenue, 
2007). During the first six months after the data warehouse was brought online, DOR recovered more than $\$ 30$ million in unpaid taxes from unregistered commercial rental properties with a continuing impact of $\$ 10$ million per year.

The SUNTAX system is currently the nation's largest (in terms of dollars administered and the range of taxes involved) integrated tax-administration system based on enterprise resource planning software and was featured in an article published in eWeek Magazine (Chen, 2005). According to the article, the Department has hosted representatives from other states and 24 foreign governments who look to the Florida system as a model for their own technology efforts.

\section{Business Strategies}

The DOR has invested heavily not only in technology, but in the development of strategic initiatives and the restructuring of the organization along business process lines. Each strategic initiative is decomposed into specific goals and tasks. Each initiative is assigned to a team given the responsibility of evaluating the tasks required to accomplish strategic goals and to constantly monitor DOR's progress toward achievement of these goals. The strategic planning process is continual and fluid, with goals and objectives being updated as conditions dictate.

Performance accountability measures are monitored on a monthly basis and the annual results are shared with the legislature as part of DOR's negotiations for positions and funding. Performance accountability measures are coupled with quarterly strategic planning sessions to continuously evaluate organizational performance and develop strategies needed to achieve organization goals. The accountability process provides 
DOR's leaders with information that is used to deploy resources effectively and efficiently, and to select key strategic initiatives to make significant improvements to processes and performance.

The department has initiated a comprehensive leadership development system designed to recruit and hire talented people, train all managers in proven management techniques, provide cutting-edge feedback and evaluation tools, and make management decisions based on facts and organizational performance data. Feedback and evaluation is provided using 360-degree feedback surveys for supervisory employees, climate surveys to monitor employee beliefs and opinions regarding DOR, and Employee Evaluation and Development Plans (EE\&Ds).

Most DOR employees will tell you that their work is meaningful and satisfying. In the 2009 Climate Survey, almost 79 percent of employees stated they were proud to work for DOR, 77 percent were satisfied with their job, and more than 93 percent stated that their job was important to the success of DOR.

As in any successful organization, the people of DOR are one of its most important strengths. Its management team is sophisticated and technically capable measured in terms of the interest in DOR's quality programs on the part of other states and foreign countries and the awards garnered by the agency they manage. Management has developed and nurtured an excellent relationship and reputation with the Governor, the Cabinet, and the legislature over the last 20 years indicating the management team is politically savvy as well. The DOR won a Sterling Award in 1998 and used the Baldrige Criteria for Performance Excellence as the basis for development of DOR's vision, 
mission and core values statements, in the development of DOR strategic initiatives, and the restructuring of business processes within the organization.

As a group, the employees of DOR are dedicated to DOR's mission, vision and values, and are well-matched to the positions they fill. World-class technology and management accomplish little without the willing and committed participation of employees who understand the tasks assigned to them, have the training and abilities to perform efficiently and effectively, and believe in the goals and objectives enumerated by management.

\section{The Compliance Enforcement Environment}

The DOR is well organized and generally well-positioned to function as a truly world-class tax administration organization. But for all the technological advantage and human capital available to DOR, the probabilities are solidly stacked against DOR when it comes to stopping tax evasion and sales tax theft for one simple reason: the system is built on trust and has too few verification tools built in.

As noted in the discussion of theory, it is vital to understand that the sales tax functions differently from the income tax. The business remitting sales tax to DOR is not a taxpayer: it is an agent of the state in a principal-agent relationship. There are no thirdparties involved to supply information to DOR that could be used to verify the amounts of sales tax reported and remitted to DOR on any given monthly return. The DOR must rely on the filing business to honestly report and remit the tax. As long as a business does not become delinquent, they are generally left alone except for the .38 percent that is audited each year. Many business owners understand that if they file a return every 
month, on time, and pay the sales tax they report, they are unlikely to ever receive a call or notice from DOR. In 2005, DOR prosecuted an accountant who facilitated a $\$ 2.3$ million sales tax theft by a used car dealer. As part of his plea agreement the accountant spoke with members of the DOR Criminal Investigations Process frequently and admitted that he advised his clients to pay whatever they wanted to pay each month, but warned them to file on time and make sure the check did not bounce (the Hardcore Evaders in my typology). Criminal investigators have documented this same pattern on numerous occasions in investigations covering many different types of businesses. Small business owners and the accountants and bookkeepers who serve them are intimately familiar with the concept and benefits of "flying below the radar."

Accountants and tax preparers who coach their clients on how to evade taxes is not a problem isolated to Florida. In late 2007, the Criminal Investigations Division of the New York State Department of Taxation and Finance launched an initiative to determine to what extent tax professionals assisted their clients in the commission of tax fraud. Investigators were sent undercover posing as taxpayers who hired more than 170 tax preparers to prepare income or sales tax returns. The result was that 31 percent of the preparers, including some licensed Certified Public Accountants, engaged openly in fraud by coaching their new "clients" on how to evade state and federal taxes. Suggestions ranged from maintaining two sets of books to not keeping records of all cash receipts and skimming those proceeds not recorded. Part of the solution in New York will be a push to regulate all tax preparers and enact standards of conduct and continuing professional education requirements for all tax preparers (Commiskey, 2010). In a similar initiative to combat tax fraud perpetrated by tax preparers at the federal level, the Internal Revenue 
Service has just announced their intention to expand preparer regulation to those tax preparers who are not currently regulated (Internal Revenue Service, 2010).

In some cases the boldness of the evader is striking. In a detailed review of more than one thousand registered businesses, a significant number of them were found reporting exactly the same amount of sales tax collected every month, which is virtually impossible in a retail environment where customer purchasing patterns and customer mix are random. Numerous convenience stores were found reporting varying amounts of gross sales each month, but the exact same percentage of exempt sales every month carried to two decimal places. These examples are frequently noted and identified by those within DOR who develop audit and investigation leads, but the vast majority of the resources available to DOR are targeting delinquencies rather than analyzing reporting patterns that might indicate fraud.

It is my opinion that this problem is caused by the mindset that equates sales tax enforcement to income tax enforcement. Sales tax enforcement operations are administered and structured in the same manner as income tax compliance systems. The same trust placed in voluntary income tax reporting is erroneously granted in the setting of the sales tax, even though the sales tax does not enjoy the same reporting verification that exists, primarily through use of Forms W-2 and 1099, in an income tax system. Sales tax enforcement bears more resemblance to a contract management function than to income tax enforcement. Contract management-type enforcement efforts would mean more departmental contact with non-delinquent business filers and much more attention paid to the indicators and evidence of fraudulent reporting gleaned from intelligencegathering operations. Such a replacement of reactive responses to perceived 
noncompliance with proactive action would represent a sea change in how DOR and other state revenue agencies approach enforcement. The questions become whether such a change would be effective and, considering the current state of the budget, how could such a change actually be effected?

It is my opinion that the needed approach is relatively inexpensive in that it pays for itself and does not require the addition of a large number of personnel. Rather, it requires a change in focus to recognize and account for the boundaries of the sales tax gap. With respect to Florida, the change in focus takes the form of an expansion and modification of programs already in place that rely on the expertise and experience of the agency's employees supplemented by available technology.

\section{Knowledge-Based Enforcement}

Teaching its managers to use knowledge effectively in the performance of their assigned duties and to share that knowledge with their assigned personnel is an important priority for DOR. All managers are required to engage in formal Knowledge Based Learning (KBL) projects. I had the opportunity to assist in the KBL project carried out by the Investigations Manager of the Southern Region. The results of this study are illustrative of how field expertise can be applied to a problem to develop potential solutions. It is also an example of the difficulties involved in measuring compliance and how widespread noncompliance can be.

On the basis of an increasing number of business owner complaints, it became apparent that the sale of telephone calling cards represented a problem with respect to collection of the sales tax. Business owners complained that none of their competitors 
were charging tax on the sale of the calling cards. As a result, customers were refusing to buy the cards from these compliant businesses, accusing them of attempting to "rip them off" since "no one else charged tax" on the cards. It appeared that customers had become convinced that calling cards were nontaxable. A review of numerous investigation files confirmed that failure to collect tax on the cards was common.

On its face, it might appear that calling cards might represent an immaterial amount of tax revenue to the state. It is true that many stores sell only $\$ 100$ to $\$ 200$ worth of cards per month. However, DOR identified many thousands of stores statewide that were likely to sell the cards. Additionally, some stores sell a large quantity of cards. South Florida in particular is home to many people of foreign nationality who frequently call relatives outside the country, and rely on telephone calling cards to do so at discounted rates. There are also smaller stores that have developed a solid business by relying on sales of calling cards to the crews of cruise ships at ports throughout the state.

In an attempt to arrive at an estimate of phone card sales in South Florida, investigations personnel obtained the sales records for several major wholesalers in the area and sales were traced to their customers. Many of the customers were wholesalers themselves. The total wholesale cost of telephone calling cards sold in 2005 identified through this process was $\$ 323,425,517$, with a retail value of $\$ 404,281,896$. Not all sales of telephone calling cards in South Florida were identified through this process since the study focused on only a few wholesalers, but it did provide some perspective on the scope of the potential problem. The sales tax on these sales would be $\$ 24,256,913.76$ for the year 2005. The project was not conceptualized as a scientific endeavor with a representative sample of wholesale dealers for generalization of the results, but rather a 
selection of some of the larger independent dealers to arrive at a reasonable estimate based on volume. On its face, the amount of sales tax represented by the sales reviewed during this study is significant.

To estimate compliance, a representative sample of businesses was selected from those in Miami-Dade County that sell calling cards, concentrating on grocery stores, convenience stores, and gas stations with convenience stores. Investigators were dispatched to each location in the sample to answer two key questions:

1. Does the store sell prepaid calling cards?

2. If so, does the store collect sales tax on the sale of prepaid calling cards? Investigators visited each store in the sample and purchased a telephone calling card from each store that sold them, obtaining 127 usable responses after eliminating businesses that had closed and those with invalid addresses. The overall confidence interval for the sample results was $+/-8.41$ percent at the 95 percent confidence level. The actual confidence interval related to a specific response varies based on how skewed the response level is and is noted in the results below. The overall results of the survey were as follows:

Table 4.1 Prepaid Calling Card Sales Including Chain Stores

\begin{tabular}{|l|r|}
\hline Percentage of businesses selling prepaid calling cards $^{\text {a }}$ & 85.0 \\
\hline Percentage of businesses collecting tax on prepaid calling cards & b \\
\hline Percentage of businesses that were part of major store chains & 12.6 \\
\hline $\begin{array}{l}\text { a Confidence interval }+/-6.00 \text { percent } \\
\text { b Confidence interval }+/-6.77 \text { percent }\end{array}$ & \\
\hline
\end{tabular}


All of the major chain stores collected sales tax on prepaid calling cards. The estimation of the total sales of calling cards in South Florida was based on wholesalers who did not sell to major chain stores. Therefore, a separate analysis was performed on the responses of those stores that are not part of a major chain. There were 111 valid responses from stores not part of a major chain. The overall confidence interval for this group is $+/-9.03$ percent at the 95 percent confidence level. Again, the actual confidence interval related to a specific response varies based on how skewed the responses were and is presented below. The results of this analysis are as follows:

Table 4.2 Prepaid Calling Card Sales Excluding Chain Stores

\begin{tabular}{|l|r|}
\hline Percentage of businesses selling prepaid calling cards $^{\text {a }}$ & 82.9 \\
\hline Percentage of businesses collecting tax on prepaid calling cards ${ }^{b}$ & 6.5 \\
\hline $\begin{array}{l}\text { a Confidence interval }+/-6.80 \text { percent } \\
\text { b Confidence interval }+/-4.45 \text { percent }\end{array}$ & \\
\hline
\end{tabular}

The preliminary conclusions of the study were that major chain stores are properly collecting sales tax on the sale of prepaid telephone calling cards, and only a small percentage of independent stores are collecting tax on the sale of prepaid telephone calling cards.

When these results were combined with the estimate of the retail sales value of prepaid telephone calling cards sold in Miami-Dade County by the wholesalers reviewed, the study concluded that only $\$ 1,576,699$ of $\$ 24,256,913.76$ of potential annual sales tax on prepaid telephone calling cards sold in Miami-Dade County is being collected. It was conservatively inferred that total sales tax lost statewide on an annual basis is approaching the $\$ 80$ million to $\$ 90$ million range. 
The next step in the project was to evaluate potential responses to the problem identified. Florida Statutes Section 212.05(1)(e)(1)(a) makes it clear that prepaid calling arrangements, including recharge of a prepaid calling arrangement, is taxable at a rate of six percent. There are no gray areas, planning opportunities, or legal challenges related to this statute, yet it is routinely ignored by a large majority of businesses to which it applies. When confronted with the illegality of not charging the sales tax on prepaid calling cards, many business owners decided not to sell them at all, citing the fact that if they charge the tax, they will not make the sale. Businesses that have complained to DOR cite that not collecting the sales tax gives their competitors an unfair advantage over businesses that prefer to obey the law, and that is precisely what makes this situation so serious. When businesses begin competing by not collecting the tax to gain a pricing advantage and are not penalized for doing so, subsidizing their profit margins by keeping a portion of the taxes they do collect becomes attractive. The state loses credibility when it cannot enforce the law, so corrective action is critical, but what options are available?

Some business owners decided to sell the calling cards and pay the taxes themselves. However, Florida Statutes 212.07(2) and (4) require the tax be added to the purchase price and prohibits the dealer from holding out to the public, in any manner, that the dealer will absorb or pay the sales tax. While it may be admirable that certain dealers are honest enough to pay the tax themselves, it is poor public policy to count on dealers to break one law in order to comply with another.

In certain cases where it is not practicable for a dealer to add the amount of tax to the purchase amount, DOR is granted the authority by Florida Statutes 213.07(2) to establish an effective tax rate for that industry. Common examples are alcoholic drinks 
sold in a bar or goods sold through vending machines. Rather than calculate the tax and add it to the selling price, an effective tax rate is applied to the sale to determine the amount of tax collected that must be remitted. While this could be an option for the prepaid calling card industry, it would require adjustment of the cost and profit structure within the industry, and would probably result in either the tax being absorbed, which is against the law, or the tax being avoided by not reporting the sales, which is common under current law.

The legislature could decide to make prepaid calling cards exempt from tax. This would effectively forfeit the state's claim to the $\$ 80$ million to $\$ 90$ million in additional revenue that would result from these sales. Given that more than 60 percent of the dollar amount of transactions in Florida is already exempted from tax, with the amount exempted increasing annually, (Florida Department of Revenue, 2010) it could be argued that the state needs fewer exemptions, not more. However, it may be better to forgo the additional revenue than to maintain a law that cannot be enforced for reasons already discussed.

A logical question at this point is: why not just enforce the law? The answer is simple: the cost will exceed the benefit. In determining the estimated sales tax revenue from prepaid calling card sales, only data from convenience stores, gas stations, and independent grocery stores were used. There were approximately 16,000 of these in the state at the time the data were gathered. But prepaid calling cards are sometimes sold in beauty salons, drug stores, dollar stores, restaurants, coffee shops, and many other types of general retail stores. This expands the number of businesses that sell the cards to more than 100,000 . It is not possible to tell if a business is reporting their calling card 
sales by reviewing their Sales and Use Tax Return. The return contains no detail. The only way to know, and therefore to enforce, the collection of tax on the sale of the cards is to audit the business or otherwise obtain records in a criminal investigation. Either solution is costly and would require personnel expansions that could not be justified from increased calling card tax revenues alone. Recall that DOR's 410 auditors carried out 3,679 audits in 2008. Resources simply do not allow auditing these 100,000 businesses to make sure they are collecting the tax on calling cards.

It has been hypothesized that a better approach to the problem might be obtaining the records of the wholesalers and tracking those sales to the retail stores to make sure the sales are reported. But many of a particular wholesaler's customers are also wholesalers, who sell to other wholesalers. Once transactions are traced through the wholesale chain to the ultimate retail dealer, the lack of detail on the Sales and Use Tax Returns submitted by the retail dealers makes it impossible to determine if the sales of the calling cards are actually included. For example, assume you trace the sales records from a wholesaler to a retailer and determine that the retailer purchased $\$ 200$ worth of calling cards for resale during the month. The retailer is a convenience store and also sells beer, cigarettes, soda, snack foods, and household items. The retailer reports $\$ 70,000$ in sales for the month. How do you determine if the $\$ 200$ of calling cards is included in the $\$ 70,000$ of sales reported? You cannot without auditing or otherwise reviewing the retailer's sales documentation to determine what is included in the $\$ 70,000$ reported. Unfortunately the card sales are individually immaterial but have cumulative potential for large revenue losses. 
While tracing the sales from wholesaler to retailer to the sales tax return will not solve the problem, an approach at the wholesale level may still be the answer. Years ago Florida had similar compliance problems with fuel taxes on the sales of gasoline. The state solved this problem in 1996, as many other states have done, by beginning to collect all taxes on fuel "at the rack." In other words, when delivery tanker trucks bring the gasoline to the retail gas station, the tax has already been paid. The dealer has no returns to file to report fuel taxes and does not need to collect the taxes from their customers since they are included in the price of a gallon of gasoline. The same could be done with respect to prepaid calling cards. If the tax is collected at the wholesale level for all calling cards distributed or recharged within Florida, the state gets its sales tax revenues and the retailers no longer have an issue with unfair competition. Auditing becomes easier because there are now only a few larger wholesale businesses collecting the tax rather than tens of thousands of smaller retail businesses.

By utilizing the expertise of employees, as in this example, and channeling that expertise into a targeted focus on the tax enforcement gap that exists between "chasing delinquencies" and full audits and investigations, the gap can be attacked using intelligence-gathering techniques and existing enforcement tools to identify issues and problems and determine the appropriate enforcement approach to use. Employees of DOR have exhibited the ability to successfully engage in this type of activity. Employees participate in discovery operations and campaigns that function in a similar manner, an example of which is the aforementioned commercial rental project that produced $\$ 30$ million in new tax revenue from unregistered landlords. In order to expand these operations sufficiently to attack the tax gap, DOR must reallocate time and resources, but 
it is unlikely that large numbers of additional employees or enforcement infrastructure expenditures will be required. Employees already have access to a wide array of intelligence tools and enforcement mechanisms and some have the expertise and experience required to perform the extended functions. The task is not one of expanding the bureaucracy, but one of re-tasking a portion of the existing enforcement capabilities of the Department to an expanded role for discovery and campaign-type operations at the local level and changing their character from one-time compliance efforts to continuous enforcement. 


\section{CHAPTER 5}

\section{RESEARCH METHODOLOGY}

The primary hypothesis in this study is that the effectiveness of compliance enforcement efforts will be improved if active, well-informed enforcement activities, characterized by substantial contact initiated by agents of the state, are substituted for passive or reactive activities. This hypothesis recognizes the very large gap in compliance that exists in the current enforcement regime as illustrated in Figure 5.1. The bulk of enforcement activities are reactive in nature: a business fails to file a return and receives a contact from a collector. Proactive discovery operations, audits, and criminal investigations constitute a minute percentage of enforcement efforts. As a result, the compliance gap has the potential to be enormous with more than 99 percent of all businesses in the category of trust without verification.

Figure 5.1 Focus of Sales Tax Enforcement Efforts in Florida

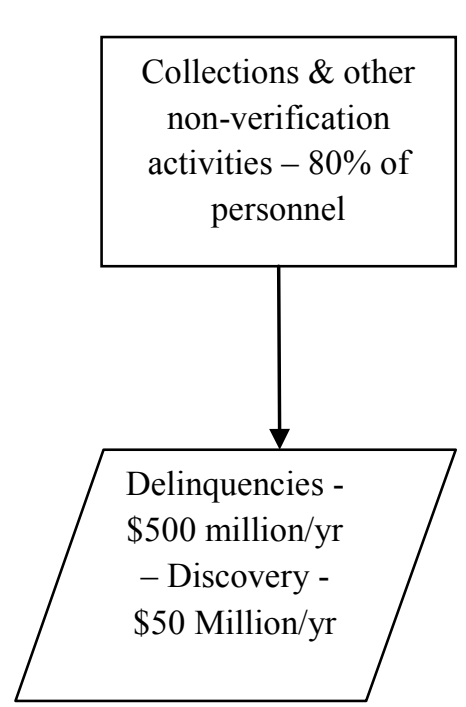

\begin{tabular}{|c|}
\hline THE GAP \\
TRUST WITHOUT \\
VERIFICATION \\
968,422 businesses out of \\
$972,977-99.53 \%$ \\
Estimated $60 \%$ of small \\
businesses noncompliant to \\
some extent \\
\end{tabular}

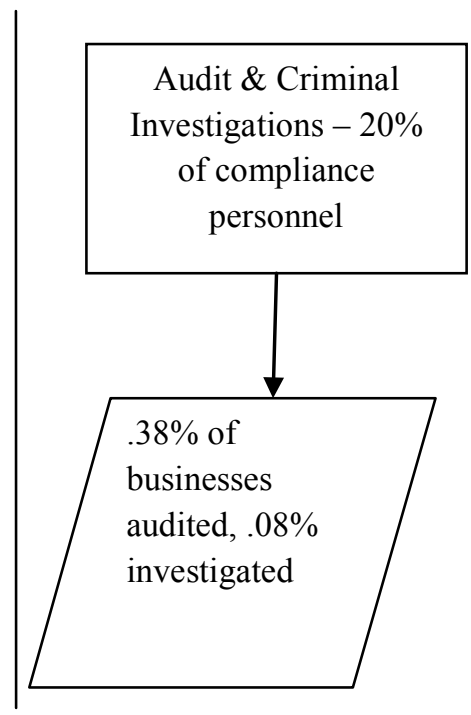


The methodology employed in this study involves a preliminary study of the current enforcement regime in Florida, which was presented in Chapter 4; followed by an analysis of two enforcement tools that the author believes are critical to the success of the design; and finally the conduct of a quasi-experimental project applying the tools and concepts of discovery operations to a targeted industry enforcement program. The proposed enforcement design is summarized in Figure 5.2.

Figure 5.2 Proposed Enforcement Design for Closing the Tax Gap

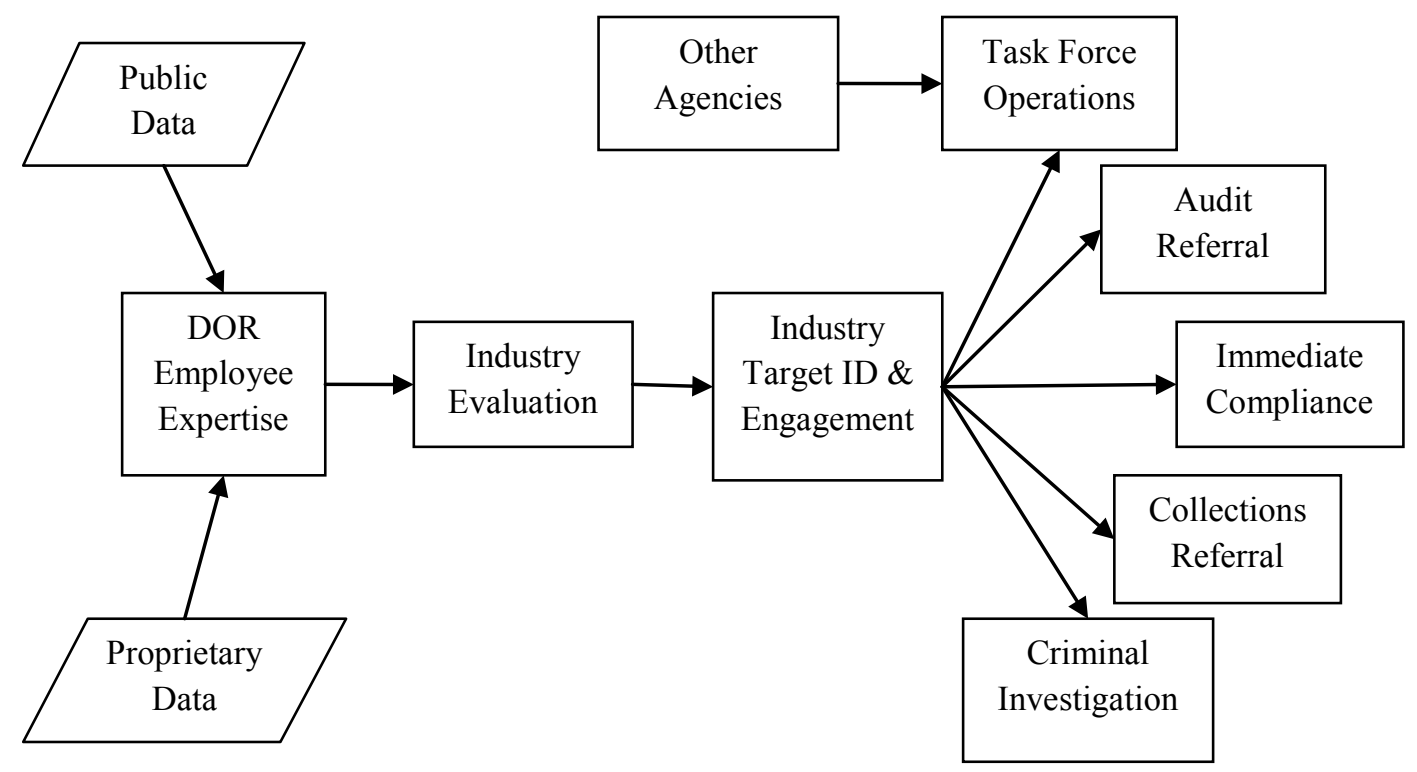

The enforcement design works as follows:

1. A DOR employee or employees with industry experience evaluate the target industry utilizing available public and proprietary databases to create a profile of the individual businesses within the industry. The data in the profile include tax filing history, property information, related businesses, rental data, location data, 
customer traffic information, and other financial and nonfinancial information related to cost and profitability.

2. On the basis of the business profiles, the employee evaluates the businesses within the industry to identify targets for possible enforcement action. For example, a business that appears to be extremely profitable but reports very low gross sales per month.

3. The employee engages the business to determine compliance. The engagement may take the form of a site visit, a letter, or a phone conversation. Multiple contacts serve the dual purpose of beginning the compliance process with respect to the individual companies contacted and alerting the industry in general that the state has the ability and the will to enforce the tax laws.

4. On the basis of the results of engagement, the employee must determine what additional action is warranted: referral for audit, referral to collections after the identification and documentation of the liability, referral for criminal investigation, or enlisting other interested agencies in a more comprehensive compliance effort if indicated. In some cases the result of engagement will be immediate compliance.

5. The evaluation and engagement cycle is continuously applied to the industry. The end result of the industry enforcement activities is assumed to be greater compliance industry-wide than what would be achieved using only traditional enforcement tools, i.e., audit and collection activities. The impact of the industry enforcement activities is reinforced as news of the enforcement activities is 
communicated through both formal and informal channels. The continuous looping of the process prevents recidivism.

This design is very similar to current discovery and campaign operations carried out by DOR. The main difference is that the proposed targeted industry enforcement program is planned and executed wholly at the local level by local employees, and is a continuous process rather than an isolated compliance exercise that may not be repeated for several years. The employee or employees given the responsibility for a particular industry will not approach their responsibility as a linear process of research, identify targets, and engage, but as one of continuous research and target identification simultaneous with engagement. The approach is one of consistent compliance pressure on the industry utilizing a minimum amount of resources prepared with the maximum amount of knowledge and information. The key is activity informed by intelligence that is accurate and actionable.

There are two tools that are indispensible to the efficient success of this process: the intuition of the employee performing the research and analysis function, and the use of task force structures to expand resources at little or no cost. The presentation of the author's proposed methodology includes an analysis of the effectiveness of task force operations; an exercise utilizing an observational survey to measure the effectiveness of intuition in identifying noncompliance; and finally, an analysis of a complete cycle of a targeted industry enforcement program. 


\section{Baseline Activities}

Interviews of DOR field personnel were conducted and current and historical management data, reports, and other relevant documents were reviewed to construct a baseline for compliance activities currently carried out by DOR personnel. This provided an understanding of the current enforcement paradigm. Much of the information contained in Chapter 4 was gleaned from these interviews and document reviews, and information from this work will be referenced throughout the discussions that follow.

\section{Analysis of the Effectiveness of Task Force Utilization}

In this section the impact of the Region 5 Investigation Unit's participation in task forces composed of multiple federal, state, and local agencies on coordinated large case efforts is evaluated. The results of task force utilization versus the results of regions that do not utilize task force operations are evaluated using descriptive statistics comparing investigative hours required to complete cases, cost to complete cases, and tax, civil liabilities, and restitution realized per case. Means, mean differences, and significance tests are presented using the Analysis of Variance (ANOVA) format. ${ }^{12}$

Investigative hours per case, cost per case, and the amount of tax, civil liabilities and criminal restitution were obtained from the Criminal Investigations Process (CIP) Case Management System for each case. Cases that are investigated as part of a task force with at least two other federal, state or local agencies are classified as task force cases, while cases that are originated in-house and worked in-house with only minor outside assistance from no more than one outside agency are classified as standard cases.

\footnotetext{
${ }^{12}$ The data gathered is an enumeration of the entire population of data rather than samples and significance testing is unnecessary. ANOVA tables are used for reporting convenience.
} 


\section{Tax Evasion Predictors from Industry Samples}

To build comfort in the level of sales reported on a sales tax return, it is possible to develop a "feel" for the business and the level of sales it should be reporting. This process is highly subjective, but could be developed into a systematic ritual for evaluation of potential sales tax theft. To test this hypothesis, I began with the data accumulated for the targeted industry enforcement study discussed in the next section. These data include reporting and compliance information for 192 used car dealers that have been identified as targets for compliance enforcement activities. Since these data included only dealers where sales tax theft was probable, an additional 238 dealers selected at random were added and any overlap with existing data was eliminated to provide the study with a number of dealers not involved in sales tax theft. An observational survey was completed for each dealer within the sample. The survey contained twenty-four characteristics designed to measure the robustness of the business environment. The survey was designed as a proxy for the judgment DOR personnel should use to identify leads when reviewing industry data. Additional data on property rentals, property ownership, community demographics, and corporate ownership was obtained from public databases and added to the data obtained through direct observation.

A dichotomous tax evasion construct was developed for use as the dependent variable in binary logistic regression analysis. Tax evasion is indicated for any dealer where the tax reported and remitted is less than 90 percent of the sales tax collected. With respect to car dealers, tax evasion at the rate of ten percent can be very substantial, and a number closer to five percent would be preferable. However, the observational 
survey as designed is a blunt instrument and is not sensitive enough to provide for a smaller threshold.

The survey responses have been operationalized as constructs representing cost structure, profit structure, and management and are the primary independent variables in my analysis. Two additional independent variables were added to measure the impact of prior participation in an amnesty program in 2003 and to test whether businesses that were chronically delinquent were higher risks for sales tax theft than those who were more compliant than chronic delinquents.

The cost structure construct is developed from the evaluation of survey responses for neighborhood type (wealthy to poor), high-rent area versus low-rent, customer activity (customer traffic) at the site, and whether they offer in-house financing. For example, a dealership near middle-class neighborhoods, in a relatively high-rent business area, with lots of customer activity, and that internally finances its sales represents a large fixed cost structure. The final independent variable for cost structure derived from the survey responses is dichotomous and is judgmentally derived from a review of observed characteristics. It indicates the extent to which the cost structure suggested by these factors is consistent with the level of sales reported on a monthly basis.

The profit structure construct is developed from the evaluation of survey responses for the condition and type of cars sold and the cleanliness and maintenance of the facility. A business selling late model cars that are in good condition from an immaculate lot indicates a profitable business. The profit structure variable is dichotomous and is judgmentally derived from a review of observed characteristics. It 
indicates the extent to which the profit structure suggested by survey responses is consistent with the level of sales reported on a monthly basis.

The management construct is developed from the evaluation of survey questions related to a history of filing sales tax returns with "round" numbers, a history of filing returns with incomplete data, and a history of late-filed sales tax returns. Historically, these are factors that have been deemed to indicate a business that is underreporting gross sales and sales tax collected. If any of these three factors is present, the variable is assigned a dichotomous value that indicates "poor reporting history," and therefore likely evasion activity.

Filers who are chronically delinquent are identified as those who were delinquent or had returned checks in more than ten percent of the periods for which returns were required of them.

Prior amnesty participants were identified through research in the System for Unified Taxation, which denotes participants but provides no additional data relating to the amnesty claim.

Binary logistic regression analysis was used to test the predictive ability of the observational survey and, by proxy, the potential value of observational judgments by Revenue employees when appropriately channeled.

\section{Targeted Industry Enforcement Program Analysis}

This section evaluates my proposed compliance enforcement design, which is supplementary to current enforcement activities. As a result of budgetary restrictions, it is necessary to find new techniques to magnify the resources available for enforcement 
and achieve more with less. One approach is to target a specific industry and focus enforcement efforts on the basis of combined intelligence from a variety of sources. This approach represents a strategy derived from the theory of planned behavior to impact the perception of behavioral control by increasing the perceived probability of being caught evading taxes. The industry targeted for this coordinated effort was the used car industry. A review of the history of collections, audit, and criminal investigations indicates that compliance in this industry has been consistently low and tax theft cases are normally large in terms of tax dollars stolen. It is notable that this is an industry regulated by another state agency that cooperatively collects data that can be used to verify whether a dealer has remitted all of the sales tax it collects. Even given this ability to check thirdparty records, my review indicates dealers still commit sales tax theft with astonishing regularity while reporting correct data to the Department of Highway Safety and Motor Vehicles. It is also notable that cross-checking methodology for this interagency data has not been automated. An important caveat to this verification process is that if this crosscheck indicates that all sales tax collected has been remitted by a dealer, it does not necessarily mean that dealer has not converted sales tax collected to personal use. It simply means that if that dealer has stolen sales tax, he or she was diligent enough to cover their tracks by making sure the amounts reported to the Department of Highway Safety and Motor Vehicles was consistent with amounts reported to the Department of Revenue, i.e., they are Proficient Evaders.

Vehicle sales transaction data are provided quarterly by the Department of Highway Safety and Motor Vehicles (DHSMV) on compact disks that include all sales transactions for which Florida titles were issued during the quarter. Currently, the 
number of transactions is approximately three million per year by more than 12,000 dealers. Since these databases include new car sales, RV sales, mobile home sales, lien maintenance transactions, and other transactions outside the scope of this study, the data have been edited and the quarterly databases compiled into a single database containing only used car transactions for the periods July 2003 through May 2008. This database contains more than 3,200,000 individual transaction records. Additionally, this new database has been divided into five separate regional databases so that analyses can be carried out on a region-by-region basis. Cross reference tables were created that match the DHSMV dealer numbers with DOR taxpayer identification numbers for Miami-Dade County dealers. Individual sales transactions and the associated sales tax collected were accumulated and the results compared with the sales tax returns filed with DOR for all dealers located in Miami-Dade County. Sales tax return data was exported from DOR's System for Unified Taxation (SUNTAX) and matched with the sales transaction data dealer-by-dealer for Miami-Dade County to identify the total amount of potential sales tax theft and the amount of potential theft by dealer. This process is diagramed in Figure 5.3 .

The potentially tax evading dealers in Miami-Dade County were selected from the analysis above. For policy reasons, companies that were currently under audit, were the subject of active collection activity, or were under criminal investigation were excluded and removed from the analysis. Companies that were closed or inactive were also removed.

Companies that exhibited very large amounts of potential sales tax theft or very high percentages of sales tax theft were segregated for full criminal investigation. These 
are companies where the discrepancy between the amount of sales tax reported to DHSMV and the amount reported to DOR was so large or so great a percentage of total taxes collected that the possibility of mistake or other good explanation would appear to be implausible. For example, the top company in this group shows possible tax theft in

Figure 5.3 The Auto Dealer Tax Return to Title Application Comparison Process

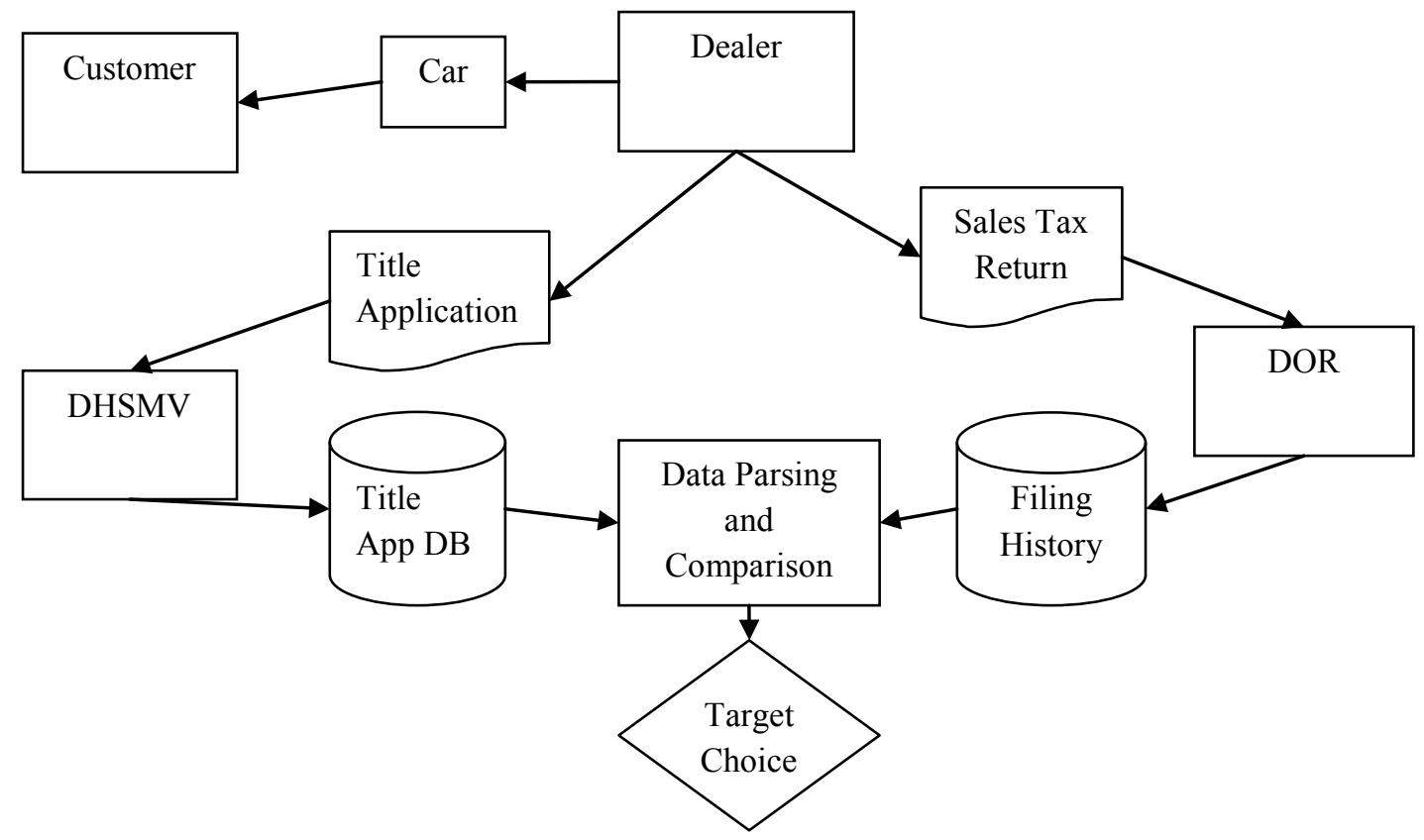

excess of $\$ 2.7$ million and actually remitted less than $\$ 1$ million of the total $\$ 3.7$ million collected. Another shows possible sales tax theft of $\$ 69,000$, but only remitted about $\$ 2,000$. These dealers were assigned to a special group designated the "Major Case" group. As noted previously, Southern Region CIP frequently participates in task force activities to leverage the resources available for criminal investigation and prosecution. The Major Case group was designated to be worked in task force fashion by combining 
forces with a South Florida task force dedicated to auto theft, dealer fraud, and similar crimes related to the auto industry. Working these cases in task force format is an extension of techniques successfully applied to large groups of related companies to large groups of similar but unrelated companies.

The remaining companies exhibit significant amounts of potential sales tax theft, but the amounts and percentage of total taxes not remitted were low enough to potentially be the result of errors, repossession credits that were not properly documented, or otherwise subject to reasonable explanation that might preclude criminal prosecution. These remaining dealers were randomly assigned to one of seven groups. Because of the nature of the subject matter and the requirements for fair application of the law, development of an experimental model for this portion of the study based on random assignment was not possible. However, the groupings were maintained to enable working with only as many entities at one time as resources would allow. The activities carried out during this phase of my study were carried out solely within CIP which, at the time of the study, had only four investigators for all of Miami-Dade County and only one that could be assigned part-time to this project.

The targeted industry enforcement program analysis was implemented as a quasiexperimental time series design involving pretesting and post-testing one group of subjects at various times to determine the effect of enforcement interventions over time. While random assignment to groups was used, the design is not experimental because the treatments between the groups could not be varied and, while a control group existed for comparison between the application of the first intervention and the first measurement date, it was not possible to shield the control group from "spillover" effects of 
enforcement activities on the first wave of interventions. The control group was also subject to interventions at a later date.

The final intervention study group was composed of 110 dealers with potential sales tax theft of $\$ 6,371,914.18$, or 22.31 percent of the total taxes collected by these companies.

The Major Case group was composed initially of 43 dealers with potential sales tax theft of $\$ 14,164,214.64$, or 60.44 percent of the total taxes collected by these companies.

There were an additional 34 dealers with total potential tax theft of $\$ 606,016$. This group was dubbed the "Low Theft" group. The amount of potential theft by each dealer was small enough that the decision was made to monitor this group throughout the study and apply interventions to them last if it appeared that the potential theft amount was growing or had not been resolved by timing differences.

Five dealers with potential tax theft of $\$ 279,167$ were removed from the study because they were identified for criminal investigation, audit, or other enforcement activities during the preparatory stages of the study.

Each of the dealers in the intervention study group was contacted by the investigator to obtain an explanation and reconciliation of the differences between the amount of sales tax reported to DHSMV and the amount reported to DOR. As a result of the serious nature of the potential tax crime being investigated, all dealers were subject to the same treatment, both because it is fair and because it is required by DOR policy. The only difference in the initial intervention approach is that dealers subsequent to the first wave received a letter that emphasized the potential criminal nature of the investigation 
because a significant number of the dealers contacted in the first wave ignored the letter. While it was done for practical reasons that had nothing to do with this study, this change did offer the opportunity to gauge the difference in response when it is made clear the potential ramifications are criminal rather than civil. The difference in response between the two treatments was analyzed using a one-way ANOVA.

An immediate indication of success of the intervention is the collection of tax evaded in prior periods as a result of the intervention, but the longer term success of the contact with the taxpayer is of equal importance. It has been hypothesized that the dealers will become newly compliant and more compliant in the future if they believe their reporting is being monitored and that the opportunity for sales tax evasion or theft is not available. The longer term success of these interventions is determined by applying repeated-measures ANOVA to measures of the amount of sales tax theft in lagging periods after the intervention. For the second wave of interventions, only one measurement period after the intervention is available at the time of this writing, so a paired samples t-test was used to evaluate the impact of the intervention at the measurement date. One would expect compliance improvement during the short term following the intervention with the possibility of a return to evasion activities in the longer term if contact is not maintained in some way. The indirect impact of interventions on companies not subject to direct intervention was also measured using paired samples t-tests.

The construct to be measured is compliance with the sales tax laws as measured by the amount of tax theft on a monthly basis by each car dealer within the study group, both before and at various points after the interventions. The monthly tax theft 
compliance measure was used as the dependent variable in the repeated-measures ANOVA and in paired samples t-tests.

The overall success of the interventions with respect to the entire pool is determined by comparing the results obtained through the application of the interventions to the proforma results had the interventions not been applied using one-way analysis of variance.

Additionally, the interactions with dealers during the intervention process have been documented and qualitatively analyzed to gain insight on the motives and needs of the dealers that led to noncompliance, attitudes with respect to compliance, and peer support structures within the industry that contribute to subjective norms.

Search warrants were drafted, approved, and executed on the companies comprising the Major Case group by a newly formed task force comprised of DOR investigators, members of the Auto Theft Task Force of the Miami-Dade Police Department, representatives from the Department of Highway Safety and Motor Vehicles, and representatives from the Miami-Dade County State Attorneys Office. The results of the handling of the Major Case group were subject to qualitative analysis regarding the efficiency of applying large related-group task force techniques to a large group of unrelated companies within the same industry.

\section{Reliability and Validity}

According to Neuman (2003), reliability and dependability are achieved when the results produced by the indicators utilized do not vary because of the characteristics of the measurement process itself. All constructs utilized in this study were clearly 
conceptualized and are easily measured and subject to precise measurement, with the exception of the observations reflected in the predictors of tax evasion survey. The survey was specifically designed to represent the judgment and analysis processes of experienced DOR personnel rather than a precise measurement of the subject matter. The measurements, computations, and tests presented in this study are easily replicable and are designed specifically with replication in mind since the methodology is intended for constant-cycle utilization in compliance enforcement operations.

Internal validity refers to the "approximate truth about inferences regarding causeeffect or causal relationships" (Trochim, 2006). Internal validity has been addressed through the use of random samples to supplement the data in the survey portion of this study and random assignment in the quasi-experimental portion of this study. Perhaps of greater importance, the subjects in this study to which interventions are applied and causal relationships are assumed represent the entire population of tax evaders within the industry chosen and not a sample. As a result, the statistics offered are descriptive of the population and threats due to sampling errors are not relevant. Social interaction threats are also not threats to validity in this study because the study relies on social interaction as part of the stimulus to achieve the desired change in behavior. The theory of planned behavior specifically includes components for social norms and attitude which are also targets of the enforcement methodology being tested here. Rather than controlling for and attempting to eliminate social interaction as a causal effect, this study attempts to exploit social interaction as a component of the compliance enforcement effort.

All access to government documents, reports and personnel required to complete this study were permitted; all data required to complete this study were made available; 
and Department of Revenue personnel were cooperative throughout. All data utilized in this study were accumulated specifically with this study in mind, so there were no issues with appropriate units of analysis, theoretical definitions, lack of control over how data were collected, or changes in definition over time. Statistical procedures were chosen based on how well they addressed the specific issues and questions under consideration and all assumptions of specific statistical procedures were met. All statistical operations were carried out using SPSS statistics software. External validity, in the sense of generalizing the results of this study to other settings, is enhanced by these same factors and by the very salient fact that the study was centered within the active enforcement operations of a state revenue agency. 


\section{CHAPTER 6}

\section{TASK FORCE UTILIZATION: FINDINGS AND ANALYSIS}

Since 2004, DOR Southern Region Investigations has been actively participating in task force operations. In this study, "task force" refers to coordinated enforcement efforts with two or more other agencies that have enforcement interests with respect to the same businesses or individuals. As homeland security issues have become more important after the events of September 11, 2001, local law enforcement agencies have been tasked with greater security and first-responder responsibilities and, likewise, have seen their budgets augmented with federal funds for homeland security that can indirectly benefit DOR's enforcement efforts. ${ }^{13}$ Further, federal agencies, primarily the Federal Bureau of Investigation (FBI), often have an interest in foreign-born U. S. businessmen who transfer or carry large sums of money from U. S. business operations out of the country, particularly when those funds are traced to locations associated with terrorist activity. The businesses or individuals who attract such interest do not do so simply because they transfer money outside the country: there are generally other factors that identify these individuals and their activities as suspicious. Immigration and Customs Enforcement (ICE) may also have an interest because workers are sometimes brought into this country illegally to work in otherwise legitimate businesses for what amounts to slave wages. While the transfer of monies overseas or using illegal immigrants to work in U. S. businesses is not within the purview of DOR employees, it has been noted that these same businesses are usually involved in sales tax theft as well. In fact, in several recent cases investigated by DOR Southern Region Investigations, a substantial portion

\footnotetext{
${ }^{13}$ As a state regulatory agency, DOR does not qualify to directly receive Homeland Security funding and grants.
} 
of the "profits" from local businesses transferred overseas was, in fact, stolen Florida sales tax. This adds a homeland security interest to sales tax enforcement. Therefore it becomes doubly important for DOR to be involved in these cases, first because significant amounts of sales taxes are being stolen through these illegal operations, and second, because stolen sales tax in these cases not only allow the illegal businesses to gain a competitive advantage over legitimate businesses, but those advantages are accruing to and financing those who seek to harm our country. It is clear that DOR has a vested interest in these cases which, in itself, is enough to justify participation. It is likewise true that other federal, state, and local agencies involved in homeland security have broad resources to bring to the table and are keenly interested in doing so. Frequently, the state tax charges are more easily proven and provide the shortest route for law enforcement to shut down these illegal operations and gain valuable insight and intelligence.

Southern Region Investigations has found that participation in these task forces leads to less expensive investigations because other agencies cover much of the cost by providing surveillance and intelligence and by paying for information obtained through third-party subpoenas. Moreover, the entities that are the targets of these investigations are generally larger and, in theory, yield much higher revenue recoveries per investigative hour than non-task force cases. On the other hand, task force cases can take longer to develop because of the diverse interests in the case. Participation requires an acknowledgement that other agencies have their own interests to pursue which may require additional time. However, in addition to cost savings and larger recoveries, task 
force participation generally allows action against much larger entities and groups of entities than DOR would otherwise be able to manage.

A recent example of this was the February 2009 execution of 30 separate search warrants, statewide and simultaneously, on a single day that involved more than 200 federal and state agents. The search warrants were part of a case that had evolved over more than a year with involvement of the FBI, ICE, the Florida Department of Law Enforcement, local State Attorneys, the Office of Statewide Prosecution, and local law enforcement agencies statewide. Other agencies assumed more than $\$ 30,000$ in direct subpoena costs, provided hundreds of hours of surveillance and intelligence gathering, and supplied the manpower that made it possible for DOR to have all 30 search warrants executed simultaneously. Working alone, DOR would have been able to execute only five of those search warrants on that one day and the other 25 targets would likely have immediately destroyed any useful records.

To determine the impact of task force participation, data from all cases statewide that were approved for prosecution over the last six years were reviewed. All cases covered by the Tax Collection Enforcement Diversion Program (TCEDP), which are essentially an extension of collection activity and are part of a program jointly managed by DOR and local participating State Attorney's Offices, were excluded. Because not all regions participate in this program and because the cases within this program are collections-oriented rather than criminal in nature, their inclusion in the analysis would skew the results. There have been 1,424 cases in this program representing $\$ 26,565,419$ 
dollars in delinquent sales tax. ${ }^{14}$ Statewide cases other than TCEDP cases approved for prosecution over the last six years are as indicated in Table 6.1. Region 5 is the Southern Region which includes task force cases.

A few definitions are required for an understanding of the data in Table 6.1. "Tax Liability Identified" is the sales tax liability only, with no interest, penalties, or investigative costs added. This is the actual amount of sales tax theft. "Total Civil Liability Identified" is the sales tax, regular late filing and late payment penalties, specific penalties for fraudulent return filing, interest, and investigative costs. "Criminal Restitution" includes the sales tax, interest, and investigative costs. ${ }^{15}$

The data in Table 6.1 shows that Region 5 had fewer prosecution cases but those cases were, on average, larger and generated greater amounts of sales tax theft, civil liabilities, and restitution identified per investigative hour. To determine how much of this difference is due to Region 5 task force participation the data for Region 5 was decomposed into non-task force and task force case data as reflected in Table 6.2.

The results of Region 5 activities were compared to Regions 1 through 4 using one-way ANOVA. ${ }^{16}$ Region 5 results showed higher civil tax theft identified $(\mathrm{M}=$ 119,406.36, $\mathrm{SD}=289,009.34)$ than Regions 1 through $4(\mathrm{M}=58,544.61, \mathrm{SD}=$ 133,373.70). This difference $(M=60,861.75)$ was significant, $F(1,721)=12.182, \mathrm{p}=$ .001 .

\footnotetext{
${ }^{14}$ This program is used for certain types of delinquency cases and is not available for cases involving sales tax theft. The program allows certain delinquent taxpayers who meet strict qualifications to make arrangements to pay their tax liabilities and avoid criminal prosecution for offenses other than theft. ${ }^{15}$ It should be noted that only about one in six criminal investigations result in referral for prosecution. The remainder may be closed, for example, with a civil collection of tax due based on a finding of no intent to commit a crime, or closed because of a finding that no tax is due and no violation was committed.

${ }^{16}$ The means and mean differences presented here are population parameters that have been evaluated using standard financial analysis techniques to compare. While significance testing is not required, it is nonetheless a familiar and convenient way to present the data.
} 
Table 6.1 Summary of DOR Criminal Prosecution Cases 2003 - 2009

\begin{tabular}{|c|c|c|c|c|c|}
\hline & Region 1 & Region 2 & Region 3 & Region 4 & Region 5 \\
\hline $\begin{array}{l}\text { Number of } \\
\text { Prosecutions } \\
\text { Approved } \\
\end{array}$ & 130 & 207 & 130 & 150 & 105 \\
\hline $\begin{array}{l}\text { Tax Liability } \\
\text { Identified }\end{array}$ & $\$ 7,884,088$ & $\$ 11,695,303$ & $\$ 6,482,774$ & $\$ 10,059,859$ & $\$ 12,537,668$ \\
\hline $\begin{array}{l}\text { Total Civil } \\
\text { Liability } \\
\text { Identified }\end{array}$ & $\$ 13,590,964$ & $\$ 22,969,254$ & $\$ 10,371,302$ & $\$ 17,417,015$ & $\$ 25,341,780$ \\
\hline $\begin{array}{l}\text { Criminal } \\
\text { Restitution }\end{array}$ & $\$ 10,329,900$ & $\$ 14,645,478$ & $\$ 8,050,095$ & $\$ 13,121,638$ & $\$ 15,561,245$ \\
\hline $\begin{array}{l}\text { Mean Tax } \\
\text { Liability } \\
\text { Identified Per } \\
\text { Case }\end{array}$ & $\$ 60,647$ & $\$ 56,499$ & $\$ 49,867$ & $\$ 67,066$ & $\$ 119,406$ \\
\hline $\begin{array}{l}\text { Mean Civil } \\
\text { Liability } \\
\text { Identified Per } \\
\text { Case }\end{array}$ & $\$ 104,546$ & $\$ 110,963$ & $\$ 79,799$ & $\$ 116,113$ & $\$ 241,350$ \\
\hline $\begin{array}{l}\text { Mean } \\
\text { Criminal } \\
\text { Restitution Per } \\
\text { Case }\end{array}$ & $\$ 79,461$ & $\$ 70,751$ & $\$ 61,924$ & $\$ 87,478$ & $\$ 148,202$ \\
\hline $\begin{array}{l}\text { Mean } \\
\text { Investigative } \\
\text { Cost Per Case }\end{array}$ & $\$ 3,928$ & $\$ 2,940$ & $\$ 2,717$ & $\$ 5,052$ & $\$ 5,155$ \\
\hline $\begin{array}{l}\text { Investigative } \\
\text { Hours Per } \\
\text { Case }\end{array}$ & 187.71 & 141.61 & 166.36 & 228.27 & 209.36 \\
\hline $\begin{array}{l}\text { Tax Liability } \\
\text { Identified Per } \\
\text { Investigative } \\
\text { Hour }\end{array}$ & $\$ 323.09$ & $\$ 398.98$ & $\$ 299.75$ & $\$ 293.80$ & $\$ 570.34$ \\
\hline $\begin{array}{l}\text { Civil Liability } \\
\text { Identified Per } \\
\text { Investigative } \\
\text { Hour }\end{array}$ & $\$ 556.95$ & $\$ 783.58$ & $\$ 479.68$ & $\$ 508.67$ & $\$ 1,152.80$ \\
\hline $\begin{array}{l}\text { Criminal } \\
\text { Restitution Per } \\
\text { Investigative } \\
\text { Hour }\end{array}$ & $\$ 423.32$ & $\$ 499.62$ & $\$ 372.23$ & $\$ 383.22$ & $\$ 707.88$ \\
\hline
\end{tabular}

Data Source: DOR Criminal Investigations Case Management System (2009) 
Table 6.2 Breakout and Analysis of Region 5 Task Force Cases and Comparison to Means for Regions 1 through 4

\begin{tabular}{|c|c|c|c|c|}
\hline & $\begin{array}{c}\text { Regions 1-4 } \\
\text { Means }\end{array}$ & $\begin{array}{c}\text { Region } 5 \\
\text { Total }\end{array}$ & $\begin{array}{c}\text { Region } 5 \\
\text { Non-Task } \\
\text { Force } \\
\end{array}$ & $\begin{array}{c}\text { Region } 5 \\
\text { Task Force }\end{array}$ \\
\hline $\begin{array}{l}\text { Number of } \\
\text { Prosecutions } \\
\text { Approved }\end{array}$ & 154 & 105 & 95 & 10 \\
\hline $\begin{array}{l}\text { Tax Liability } \\
\text { Identified }\end{array}$ & $\$ 9,030,506$ & $\$ 12,537,688$ & $\$ 5,420,588$ & $\$ 7,117,080$ \\
\hline $\begin{array}{l}\text { Total Civil Liability } \\
\text { Identified }\end{array}$ & $\$ 16,087,134$ & $\$ 25,341,780$ & $\$ 9,171,803$ & $\$ 16,169,977$ \\
\hline Criminal Restitution & $\$ 11,536,778$ & $\$ 15,561,245$ & $\$ 6,736,777$ & $\$ 8,824,468$ \\
\hline $\begin{array}{l}\text { Mean Tax Liability } \\
\text { Identified Per Case }\end{array}$ & $\$ 58,545$ & $\$ 119,406$ & $\$ 57,059$ & $\$ 711,708$ \\
\hline $\begin{array}{l}\text { Mean Civil Liability } \\
\text { Identified Per Case }\end{array}$ & $\$ 104,293$ & $\$ 241,350$ & $\$ 96,545$ & $\$ 1,616,998$ \\
\hline $\begin{array}{l}\text { Mean Criminal } \\
\text { Restitution Per Case }\end{array}$ & $\$ 74,793$ & $\$ 148,202$ & $\$ 70,913$ & $\$ 882,447$ \\
\hline $\begin{array}{l}\text { Mean Investigative } \\
\text { Cost per Case }\end{array}$ & $\$ 3,615$ & $\$ 5,155$ & $\$ 3,708$ & $\$ 15,394$ \\
\hline $\begin{array}{l}\text { Investigative Hours } \\
\text { Per Case }\end{array}$ & 180.99 & 209.36 & 159.82 & 679.98 \\
\hline $\begin{array}{l}\text { Tax Liability } \\
\text { Identified Per } \\
\text { Investigative Hour }\end{array}$ & $\$ 323.47$ & $\$ 570.34$ & $\$ 357.02$ & $\$ 1,046.66$ \\
\hline $\begin{array}{l}\text { Civil Liability } \\
\text { Identified Per } \\
\text { Investigative Hour }\end{array}$ & $\$ 576.24$ & $\$ 1,152.80$ & $\$ 604.09$ & $\$ 2,378.01$ \\
\hline $\begin{array}{l}\text { Criminal Restitution } \\
\text { Per Investigative } \\
\text { Hour }\end{array}$ & $\$ 413.25$ & $\$ 707.88$ & $\$ 443.71$ & $\$ 1,297.75$ \\
\hline
\end{tabular}

Data Source: DOR Criminal Investigations Case Management System (2009)

The Region 5 results also showed higher total civil liability identified $(\mathrm{M}=$ $241,350.29, \mathrm{SD}=716,219.10)$ than the Region 1 through 4 results $(\mathrm{M}=104,292.60, \mathrm{SD}$ $=251,986.28)$. This difference $(\mathrm{M}=137,057.69)$ was significant, $\mathrm{F}(1,721)=13.125, \mathrm{p}<$ .001 . 
The Region 5 results also showed higher restitution identified $(\mathrm{M}=148,202.33$, $\mathrm{SD}=351,639.34)$ than the Region 1 through 4 results $(\mathrm{M}=74,792.72, \mathrm{SD}=173,580.62)$. This difference $(\mathrm{M}=73,409.61)$ was significant, $\mathrm{F}(1,721)=11.081, \mathrm{p}=.001$.

The analysis presented in Table 6.2 makes it clear that task force cases in Region 5 drive the entire difference between the overall prosecution results of Region 5 activities and the other regions because:

1. The liabilities identified in the ten task force cases exceed the liabilities identified on the remaining 95 cases combined, and

2. The means for non-task force cases in Region 5 are similar to the means for Regions 1 through 4.

The clearest indication of the benefit of task force participation is the increased liability and restitution identified per investigative hour. The primary goal of criminal investigations is deterrence and not necessarily the collection of tax dollars. However, the total civil liabilities identified will nonetheless be secured by a lien against the taxpayer's property, and criminal restitution amounts will be payable under court order and, generally, as a condition of probation if such is granted. Task force participation has resulted in an additional $\$ 576.56$ per investigative hour of civil liability identified $(\$ 1,152.80$ vs. $\$ 576.24)$ and an additional $\$ 294.63$ per investigative hour of criminal restitution identified (\$707.88 vs. $\$ 413.25$ ) when compared to the means of the other regions. The more important point is that these increases are achieved at no additional cost to DOR due to the leverage obtained from utilizing the resources of other agencies.

To determine the impact of task force cases on Region 5 results it is necessary to compute proforma statistics for Region 5 activities by converting investigative hours 
spent on task force cases $(6,799.80)$ to equivalent non-task force cases at the mean rate of 159.82 hours per case. This calculation yields an additional 43 cases which are assumed to produce the same mean tax liability, civil liability, and restitution amounts as the historical non-task force cases. The summarized proforma results of investigations activities computed in this manner are presented in Table 6.3.

Results of Region 5 activities were compared to the proforma results using oneway AVOVA. ${ }^{17}$ The Region 5 results showed higher actual civil tax theft identified ( $M=$ $119,406.36, \mathrm{SD}=289,009.34)$ than the proforma results $(\mathrm{M}=57,058.88, \mathrm{SD}=$ 46,032.22). This difference $(\mathrm{M}=62,347.48)$ was significant, $\mathrm{F}(1,241)=6.223, \mathrm{p}=.013$.

The Region 5 results also showed higher total civil liability identified $(\mathrm{M}=$ $241,350.29, \mathrm{SD}=716,219.10)$ than the proforma results $(\mathrm{M}=96,545.20, \mathrm{SD}=$ 80,959.89). This difference $(M=144,805.09)$ was significant, $F(1,241)=5.555, \mathrm{p}=$ .019 .

The Region 5 results also showed higher restitution identified $(\mathrm{M}=148,202.33$, $\mathrm{SD}=351,639.34)$ than the proforma results $(\mathrm{M}=70,913.30, \mathrm{SD}=55,886.24)$. This difference $(\mathrm{M}=77,289.03)$ was significant, $\mathrm{F}(1,241)=6.461, \mathrm{p}=.012$.

The results of the proforma calculations and comparison to Region 5 historical results indicates that investigative hours devoted to task force cases yielded better results than what could have been achieved if those same resources had been applied to additional non-task force cases. It is particularly pertinent to note that while 33 additional cases could have been investigated by abandoning task force operations, total

\footnotetext{
${ }^{17}$ As noted previously, the means and mean differences presented here are population parameters that have been evaluated using standard financial analysis techniques to compare. Significance testing is not required but the ANOVA presentation provides a familiar way to present the data.
} 
Table 6.3 Summary of Region 5 Criminal Prosecution Cases 2003 - 2009 with Proforma Results Excluding Task Force Cases

\begin{tabular}{|c|c|c|c|c|}
\hline & $\begin{array}{l}\text { Region } 5 \\
\text { Actual }\end{array}$ & $\begin{array}{c}\text { Region } 5 \\
\text { Proforma } \\
\text { without } \\
\text { Tax Force }\end{array}$ & $\begin{array}{c}\text { Difference: } \\
\text { Proforma - } \\
\text { Actual }\end{array}$ & $\begin{array}{c}\text { (Memo) } \\
\text { Region } 5 \\
\text { Task Force }\end{array}$ \\
\hline $\begin{array}{l}\text { Number of Prosecutions } \\
\text { Approved }\end{array}$ & 105 & 138 & 33 & 10 \\
\hline Tax Liability Identified & $\$ 12,537,688$ & $\$ 7,848,272$ & $\$(4,689,416)$ & $\$ 7,117,080$ \\
\hline $\begin{array}{l}\text { Total Civil Liability } \\
\text { Identified }\end{array}$ & $\$ 25,341,780$ & $\$ 13,279,438$ & $\$(12,062,342)$ & $\$ 16,169,977$ \\
\hline Criminal Restitution & $\$ 15,561,245$ & $\$ 9,753,843$ & $\$(5,807,402)$ & $\$ 8,824,468$ \\
\hline $\begin{array}{l}\text { Mean Tax Liability } \\
\text { Identified Per Case }\end{array}$ & $\$ 119,406$ & $\$ 57,059$ & $\$(62,347)$ & $\$ 711,708$ \\
\hline $\begin{array}{l}\text { Mean Civil Liability } \\
\text { Identified Per Case }\end{array}$ & $\$ 241,350$ & $\$ 96,545$ & $\$(144,805)$ & $\$ 1,616,998$ \\
\hline $\begin{array}{l}\text { Mean Criminal } \\
\text { Restitution Per Case }\end{array}$ & $\$ 148,202$ & $\$ 70,913$ & $\$(77,289)$ & $\$ 882,447$ \\
\hline $\begin{array}{l}\text { Investigative Hours Per } \\
\text { Case }\end{array}$ & 209.36 & 159.82 & $(49.54)$ & 679.98 \\
\hline $\begin{array}{l}\text { Tax Liability Identified } \\
\text { Per Investigative Hour }\end{array}$ & $\$ 570.34$ & $\$ 357.02$ & $\$(213.32)$ & $\$ 1,046.66$ \\
\hline $\begin{array}{l}\text { Civil Liability Identified } \\
\text { Per Investigative Hour }\end{array}$ & $\$ 1,152.80$ & $\$ 604.09$ & $\$(548.71)$ & $\$ 2,378.01$ \\
\hline $\begin{array}{l}\text { Criminal Restitution Per } \\
\text { Investigative Hour }\end{array}$ & $\$ 707.88$ & $\$ 443.71$ & $\$(264.17)$ & $\$ 1,297.75$ \\
\hline
\end{tabular}

Data Source: DOR Criminal Investigations Case Management System (2009)

civil liability and restitution identified would have decreased by $\$ 12,062,342$ and $\$ 5,807,402$, respectively, representing a permanent loss of the potential ability to recapture that revenue. On the basis of this analysis, the null hypothesis is rejected and the alternative set forth in Chapter 3 is accepted:

$\mathbf{H}_{3}$ : Joint investigations with other federal, state, and local agencies result in improved enforcement outcomes, including greater restitution for the same level of resource output. 
The purpose of this analysis is not to suggest that DOR criminal investigations units should pursue every case in the task force format; but to suggest that where possible, and where it enhances efficiency for all agencies involved, cooperative enforcement activities allow leveraging of resources and allow DOR to expand its capabilities to larger cases that provide higher recovery per investigative hour. To date the task force methodology has been utilized for groups of companies related by common ownership, but it will be demonstrated in Chapter 8 that this concept can be expanded to include cases that are related by industry or other subject matter and not just by ownership. 


\section{CHAPTER 7}

\section{PREDICTORS OF TAX EVASION: FINDINGS AND ANALYSIS}

One of the best tools an auditor or investigator has is intuition based on experience and expertise. A tax agency employee is beset with mountains of data provided by hundreds of thousands of tax filers. Information provided on a sales tax return, unlike federal income tax returns, is minimal, providing little information to frame the data being reviewed. If business A reports $\$ 100,000$ in gross sales for the month, an agent cannot readily determine if that amount is reasonable without learning more about the business. Filing history may indicate the return is consistent with prior filings, but consistency does not equal accuracy. The majority of the enforcement employees of DOR are dedicated to resolving delinquencies: the failure to file a return or pay the tax due on the return. These employees are collections personnel, or collectors, and are not tasked with determining whether the filings are accurate, but just that they are filed. It must be stressed that verifying the correctness of returns is not in the job description for this group of employees. The assumption is that the amount the tax filer reports to the state is correct. It is left to a small group of auditors and investigators to determine if what was filed was accurate or if sales tax theft occurred. As a result, the odds of catching those filing inaccurate returns or stealing sales tax dollars are enormously against DOR with the probability of any company in Florida becoming subject to an audit or investigation equal to approximately .0046 (odds 213:1 against) ${ }^{18}$. The very real impact of this mismatch of resources is apparent in interviews during criminal

\footnotetext{
${ }^{18}$ The probability calculation is based on numbers presented in Figure 5.1 on page 77 and does not give weight to the fact that audit selection is weighted toward larger companies which tends to lower the probability of audit for those companies most likely to be involved in evasion.
} 
prosecutions of accountants and bookkeepers that occurred over the past several years. In reviewing the files, I found where one such accountant very candidly stated that he advised his clients to always file a return on time and claim some level of sales. The amount claimed does not matter, but should be somewhat consistent from month to month. He further advised them to remit whatever tax they claimed they collected, and make sure the check does not bounce. He advised his clients that if they follow these directions, they will never have a problem with the Department of Revenue, because the Department focuses on delinquencies. If you are not delinquent, you will "fly below the radar." The client that ultimately got him into trouble reported almost $\$ 6.7$ million in gross sales and more than $\$ 400,000$ in sales tax collected over an eighteen month period. On the surface, there did not appear to be anything wrong with the amounts being reported. But suspicion of money laundering attracted the attention of a Florida Department of Law Enforcement Special Agent who had previously worked for DOR. He brought DOR into the case and it was ultimately found that the business had more than $\$ 48$ million in gross sales and had stolen more than $\$ 2.3$ million in sales tax during that 18 -month period. This case illustrates that raw numbers without context are meaningless. The reporting of $\$ 6.7$ million in gross sales was substantial enough for a small business not to raise suspicion, but was less than 14 percent of the actual gross sales.

My review of some accounts yielded shocking revelations. It is relatively easy to find accounts where the business reports exactly the same amount of gross sales every month, even though they are a retail store and the odds of the sales in any two months 
being the same are microscopically small. Many stay in operation for many years and never once have monthly sales that exceed the amount of their rent.

With convenience stores it is common to see high amounts of exempt sales, much higher than supermarkets, even though their primary sales items are beer, soft drinks, and cigarettes, all taxable items. It is also not uncommon to see them claim the exact same percentage of exempt sales every single month. Sales may vary but the exempt portion is always exactly 82.00 percent, for example, each and every month.

These types of anomalies are not within the purview of the collection staff. Auditors and investigators will review only a tiny fraction of the tax filings for a given year. There are dedicated staff members who review data to identify audit or investigative leads from the data, but there are so few performing this function and so few employees investigating the leads provided that the advice of the prosecuted accountant still works quite well for the vast majority of sales tax filers. In essence, no one is looking at the information filed because most resources are devoted to delinquencies or other non-verification tasks such as taxpayer services and tax processing.

It is not the intention in the present study to indicate that delinquencies are unimportant: they represent hundreds of millions of dollars annually in lost revenue that collectors recover or secure by filing liens against estimated amounts due. My study instead asserts that delinquencies are the tip of the tax fraud iceberg. In the next chapter, 192 dealers are examined with potentially $\$ 21,421,312$ or more in theft of sales tax collected from their customers. Those 192 dealers had delinquencies booked of just over $\$ 300,000$ and most had no delinquencies. When tax filers fail to file a return, collections personnel can only estimate the amount of tax due. If the tax filer never reports the 
correct amount of tax collected, then the estimates will always be wrong. Working delinquencies recovers funds but because of the assumption that nobody steals, sales tax theft cannot be uncovered through collection activity alone.

Personnel assigned to "discovery" operations or those who develop leads for audit take a higher level look at those filing returns. They look for indicators of fraud not only in the data compiled by the Department, but by combining those data with data from other sources, such as from returns filed with the IRS, customs declarations, property records, business license filings, and similar records. Analysis of this type yields actionable results and helps to produce hundreds of millions of dollars in audit and discovery assessments every year. My study holds that the discovery model must be devolved to the local level and adapted for more widespread use if sales tax enforcement is to become more effective and efficient.

Using the data accumulated on car dealers involved in sales tax theft (next chapter), I undertook an exercise to predict sales tax theft on the basis of observation, filing data, and a minimal amount of additional information provided by public information available online. Since all of the dealers in this group were likely involved in sales tax theft, the group was supplemented with a random sample taken from the population of dealers located in Miami-Dade County. Since this random sample was chosen from the entire pool of dealers there was some overlap with the dealers already included in the theft group. Some dealers from both groups had to be excluded from this test because they had gone out of business and were no longer available for observation. The end result was a total of 369 observable dealers. 
I prepared a survey to be completed for each dealer. Survey questions were divided into three major categories: cost structure, profit structure, and management. A copy of the survey is included in Appendix 2. The idea behind the survey is to formally conceptualize a high-level review of an account by an agent supplemented by observation and readily available public data. Table 7.1 lists the categories and questions or observations included in the survey.

Each section of the survey also includes space for additional observations. The completion of a survey requires a site visit or access to pictures of the site, reference to the Miami-Dade County property records website, and reference to the Florida Department of State, Division of Corporations website. In reality, DOR employees also have access to other non-public databases for additional information but these were not used for this study. ${ }^{19}$ A single observer collected the survey data.

The results of the specific survey responses were used to make judgments and assign fraud flags to the three categories covered by the survey. The purpose was not to use the survey answers as variables, but for the answers to guide intuition about whether the answers taken as a whole raised red flags about the tax filer. For example, company number nine was a large dealer with a very large inventory of moderately expensive cars. The cars were well maintained, the premises were clean, and the business was located in a high traffic, high rent area. The average monthly sales reported meant that the business would have difficulty carrying such a large inventory and other high costs associated with the location and status of the business. Intuition led to a determination that the company

\footnotetext{
${ }^{19}$ The non-public databases could have been used for the companies suspected of sales tax theft, but could not be legally used for the companies with no theft. Therefore, these databases could not be used for any of the companies in this study.
} 
Table 7.1 Survey Questions and Observations

\begin{tabular}{|c|c|c|}
\hline Category & Question or Observation & Measurement \\
\hline \multirow[t]{7}{*}{$\begin{array}{l}\text { Cost } \\
\text { Structure }\end{array}$} & $\begin{array}{l}\text { Surrounding neighborhood type - poor to } \\
\text { wealthy }\end{array}$ & 4-point Likert scale \\
\hline & $\begin{array}{l}\text { Surrounding neighborhood type - industrial to } \\
\text { retail }\end{array}$ & 4-point Likert scale \\
\hline & $\begin{array}{l}\text { Property appearance - appears low rent to } \\
\text { appears high rent }\end{array}$ & 4-point Likert scale \\
\hline & Rent analysis & $\begin{array}{l}\text { Based on square footage from } \\
\text { property records and average rental } \\
\text { rates for area }\end{array}$ \\
\hline & Rent coverage & Sales reported divided by rent \\
\hline & Type of dealer & $\begin{array}{l}\text { Other, office/warehouse, repair } \\
\text { shop, traditional }\end{array}$ \\
\hline & Size of operation & $\begin{array}{l}\text { Small, medium, large, multi- } \\
\text { location }\end{array}$ \\
\hline \multirow[t]{10}{*}{$\begin{array}{l}\text { Profit } \\
\text { Structure }\end{array}$} & $\begin{array}{l}\text { Condition and type of cars - inexpensive to } \\
\text { expensive }\end{array}$ & 4-point Likert scale \\
\hline & Condition and type of cars & Disrepair, fair, good, excellent \\
\hline & Condition and type of cars & General, mixed, luxury, specialty \\
\hline & $\begin{array}{l}\text { Cleanliness and maintenance of facilities - } \\
\text { dirty to very clean }\end{array}$ & 4-point Likert scale \\
\hline & $\begin{array}{l}\text { Cleanliness and maintenance of facilities - } \\
\text { poorly maintained to well maintained }\end{array}$ & 4-point Likert scale \\
\hline & Location - low traffic to high traffic & 4-point Likert scale \\
\hline & $\begin{array}{l}\text { Location - difficult access and parking to easy } \\
\text { access and parking }\end{array}$ & 4-point Likert scale \\
\hline & $\begin{array}{l}\text { Location - not meant for retail to meant for } \\
\text { retail }\end{array}$ & 4-point Likert scale \\
\hline & In-house financing provided? & Yes or no \\
\hline & Inventory size & $\begin{array}{l}0-15 \text { cars; } 16-30 \text { cars; } 31-45 \text { cars; } \\
45 \text { cars or more }\end{array}$ \\
\hline \multirow[t]{7}{*}{ Management } & $\begin{array}{l}\text { Historical filing review - files returns with } \\
\text { round numbers }\end{array}$ & Yes or no \\
\hline & $\begin{array}{l}\text { Historical filing review - files incomplete } \\
\text { returns }\end{array}$ & Yes or no \\
\hline & Historical filing review - late filing & $\begin{array}{l}\text { Number of returns filed late and } \\
\text { number of months reviewed }\end{array}$ \\
\hline & Historical filing review - returned checks & $\begin{array}{l}\text { Number of returned items (bounced } \\
\text { checks, failed EFT items) }\end{array}$ \\
\hline & Historical filing review - exempt sales & Average exempt sales claimed \\
\hline & Registration status - other taxes & $\begin{array}{l}\text { Whether or not registered for other } \\
\text { taxes for which they are obligated, } \\
\text { such as corporate or documentary } \\
\text { stamp tax }\end{array}$ \\
\hline & $\begin{array}{l}\text { Churn - whether there has been a string of } \\
\text { corporations owned by the same owners or } \\
\text { related parties with corporate changes every } \\
\text { couple of years }\end{array}$ & Yes or no. \\
\hline
\end{tabular}


could not carry the cost structure observed with the sales reported so the company was flagged for potential fraud with respect to the cost structure of the company. Developed in this manner, the independent variables in this study are all based on observation and available financial data. As such they provide a basis for determining whether intuition informed by objective observation and data can be efficiently used to bolster compliance enforcement efforts. The present study also assists in determining what types of indicators are most useful in identifying potential fraud. The basis for this type of analysis is simple: if a business is to stay in operation for a long period of time, it must produce enough revenue to cover its costs and produce a profit to make operations justifiable. Further, people who do not manage their filing obligations properly may be more likely to be involved in tax evasion or fraud than those who do manage their obligations properly.

The dichotomous dependent variable was computed and set on the basis of sales tax collections not reported and remitted in excess of ten percent of the total sales tax collected. Sales tax theft has been measured in this study by comparing sales tax collections reported to the Department of Highway Safety and Motor Vehicles on title applications to the sales taxes reported to the Department of Revenue on sales tax returns. Ten percent was chosen as the cutoff for theft because timing differences in reporting can occur that create temporary but persistent differences that will not resolve until the business closes. Additionally, as mentioned previously, the survey used in this part of the study is a blunt instrument that would not be useful in identifying smaller amounts of theft. 
Of the 369 companies in the survey, 216 had sales tax theft in excess of ten percent of sales tax collected. Interestingly, only 190, or 51.5 percent, of the dealers were traditional car lots. A high percentage, 31.7 percent, operated out of office/warehouse facilities and carried little or no inventory. The remaining dealers were repair shops, used part dealers, or other businesses where car sales were more of a sideline than the main thrust of the business. Small- to medium-sized dealers accounted for 84 percent of the companies in the survey. Eighty dealers, 21.7 percent of the total, offered financing of cars directly with no lending institution involvement. These dealers are typically known as "buy here, pay here" dealers. (See Appendix 3 for case frequencies).

From the review of the survey data, the fraud flags were set for the cost structure, profit structure, and management variables. A classification table was prepared comparing these flags to the theft status of each company indicating that 244 of the 369 companies were correctly classified (66.12 percent). Of these, 185 of the companies with sales tax not remitted were identified out of 216 (85.65 percent). However, 94 companies that had no unremitted sales tax were falsely flagged out of 153 (61.44 percent). The survey flags successfully identified companies representing $\$ 15,331,235$ in sales tax theft out of the total $\$ 20,452,673$ (74.96 percent).

These results were compared to the results of using only the chronic delinquency flag to identify potential fraud. Using this greatly simplified method there were fewer false positives, only 32 out of 153 (20.92 percent), but also only 87 out of 216 companies that had unremitted sales tax (40.28 percent) were identified. More importantly, this simplified analysis only identified $\$ 6,216,452$ of the total theft of $\$ 20,452,673$ (30.39 percent). This last statistic provides a critical insight: companies that 
steal the most file their returns on time and do not submit payments with insufficient funds. Table 7.2 provides a summary of this data.

Binary logistic regression was used to further analyze the results of the survey. The dichotomous indicator for sales tax theft in excess of ten percent was used as the dependent variable. The three fraud flags for cost structure, profit structure, and management were used as the independent variables. The flag for chronic delinquencies was included as a component in the management variable. The results of this analysis are presented in Table 7.3.

The results of the regression indicate that an analysis of the cost structure and management practices of a business can provide results that are useful in identifying companies involved in fraudulent activities. Further, the independent variables used in this analysis represent value judgments by an agent rather than strict financial analysis, which extends the conclusion to indicate that the analysis can be largely based on intuition and experience. More specifically, companies that appear to have cost structures that appear to be more expensive than what their reported revenues can support are 2.64 times more likely to be involved in tax evasion than those with cost structures supported by reported revenue. Likewise, companies that indicate poor control over their operations, as identified through late reporting, writing insufficient funds checks, and not properly registering for all taxes for which they are liable, are 3.541 times more likely to be involved in tax evasion than those that are not. The profit structure variable was not significant in this analysis. 
Table 7.2 Classification Table for Survey Fraud Flag to Theft Comparisons

\begin{tabular}{|c|c|c|c|c|}
\hline $\begin{array}{r}\text { USING SURVEY DATA } \\
\end{array}$ & Number & $\begin{array}{c}\text { Theft } \\
\text { Amount }\end{array}$ & $\begin{array}{c}\text { Percent } \\
\text { Companies }\end{array}$ & $\begin{array}{c}\text { Percent } \\
\text { Theft }\end{array}$ \\
\hline Total correctly classified & 244 & $\$ 15,231,235$ & $66.12 \%$ & $74.96 \%$ \\
\hline Total cases & 369 & $\$ 20,452.673$ & & \\
\hline Total correctly identified as no theft & 59 & N/A & $38.56 \%$ & N/A \\
\hline Total with no theft & 153 & & & \\
\hline Total correctly identified with theft & 185 & $\$ 15,231,235$ & $85.65 \%$ & $74.96 \%$ \\
\hline Total with theft & 216 & $\$ 20,452,673$ & & \\
\hline False positives & 94 & & & \\
\hline Theft not identified & 31 & $\$ 5,121,438$ & & \\
\hline \multicolumn{5}{|c|}{$\begin{array}{c}\text { USING CHRONIC DELINQUENCY } \\
\text { AS INDICATOR }\end{array}$} \\
\hline Total correctly classified & 208 & $\$ 6,216,452$ & $56.37 \%$ & $30.39 \%$ \\
\hline Total cases & 369 & $\$ 20,452,673$ & & \\
\hline Total correctly identified as no theft & 121 & N/A & $79.08 \%$ & N/A \\
\hline Total with no theft & 153 & & & \\
\hline Total correctly identified with theft & 87 & $\$ 6,216,452$ & $40.28 \%$ & $30.39 \%$ \\
\hline Total with theft & 216 & $\$ 20,452,673$ & & \\
\hline False positives & 32 & & & \\
\hline Theft not identified & 129 & $\$ 14,236,221$ & & \\
\hline
\end{tabular}

Table 7.3 Results of Logistic Regression - Tax Evasion Prediction

\begin{tabular}{|l|r|r|r|r|r|r|}
\hline \multicolumn{1}{|c|}{ Variable } & & & & & & $\begin{array}{c}\text { Exp (B) } \\
\text { (Odds } \\
\text { Ratio) }\end{array}$ \\
\hline Cost Structure & B & SE & Wald & df & Sig & \multicolumn{1}{c|}{ (r) } \\
\hline Profit Structure & .971 & .308 & 9.960 & 1 & .002 & 2.640 \\
\hline Management & .313 & .295 & 1.122 & 1 & .289 & 1.367 \\
\hline Constant & 1.264 & .303 & 17.362 & 1 & .000 & 3.541 \\
\hline N=369 & -.741 & .202 & 13.452 & 1 & .000 & .477 \\
\hline $\begin{array}{l}\text { (a) Reference category is no theft. } \\
\text { (b) Nagelkerke R Square =.183 } \\
\text { (c) See Table 8 for complete analysis of prediction results. }\end{array}$ \\
\hline
\end{tabular}


The model provides a good fit to the data as evidenced by the Hosmer and Lemeshow test results $\left(x^{2}=2.069, d f=4, p=.723\right)$, where a lack of significance, i.e., p>. 05 is an indicator of model fit. However, the nonparametric correlations between the dependent variable for sales tax theft and the independent variables were not strong as is indicated in Table 7.4.

The weak correlations between the dependent and independent variables explain the large number of false positives identified through the use of the three fraud flags. The present study shows that intuitive analysis is likely to identify a large majority of sales tax cheats, but it will also result in the false identification of many non-cheating businesses as cheating businesses, leading to a waste of resources.

Table 7.4 Correlations among Theft and Fraud Flag Variables

\begin{tabular}{|l|c|c|c|c|}
\hline & Theft Indicator & Cost Structure & Profit Structure & Management \\
\hline Theft Indicator & & $.296^{* *}$ & $.246^{* *}$ & $.265^{* *}$ \\
& & $\mathrm{~N}=369$ & $\mathrm{~N}=369$ & $\mathrm{~N}=369$ \\
\hline Cost Structure & & $.653^{* *}$ & $.169^{* *}$ \\
& & $\mathrm{~N}=369$ & $\mathrm{~N}=369$ \\
\hline Profit Structure & & & $.172^{* *}$ \\
& & & $\mathrm{~N}=369$ \\
\hline ** Correlation is significant at the 0.01 level (2-tailed) \\
\hline
\end{tabular}

It is therefore necessary to expand the analysis beyond intuition. Intuition is a necessary, efficient, and effective first step (Gladwell, 2005), but cannot be the final step in target selection unless resources are plentiful. Intuition can be used to identify potential targets to subject to more detailed investigative techniques to narrow the field. 
It was also noted that profit structure and cost structure are moderately correlated. This is to be expected since cost and profit are similar measures and profit is to a large degree dependent on cost structure. The fact that cost structure is significant in the analysis and profit structure is not indicates that cost constraints on a business are more likely to create an environment where sales tax theft is likely than the simple desire to make more profit (greed). It would therefore seem appropriate to fix intuitive efforts on cost rather than profit factors.

The weak correlation between filing history and sales tax theft was expected. It was previously noted that the 192 dealers in the targeted industry enforcement program discussed in the next chapter were responsible for $\$ 21,421,312$ of sales tax theft and those same dealers had delinquencies booked of just over $\$ 300,000$, and most had no delinquencies. Most companies that are involved in the theft of large amounts of sales tax will likely be filing on time, reporting a substantial amount of sales tax collected every month, and remitting the tax without insufficient funds problems. In fact, the correlation between sales tax theft and chronic delinquency (late filing or payment in more than ten percent of filing periods $)$ is only $.204(\mathrm{~N}=369, \mathrm{p}=.001)$. These data indicate that companies most heavily involved in sales tax theft are aware of the theft and make an effort to conceal it. As an additional test of this theory an additional binary logistic regression model was developed including one additional variable identifying those members of the sample who participated in the Florida amnesty program in 2003. The results are presented in Table 7.5. 
Table 7.5 Results of Logistic Regression - Tax Evasion Prediction Flags and Amnesty

\begin{tabular}{|c|c|c|c|c|c|c|}
\hline Variable & B & SE & Wald & df & Sig & $\begin{array}{l}\text { Exp (B) } \\
\text { (Odds } \\
\text { Ratio) }\end{array}$ \\
\hline Cost Structure & 1.103 & .318 & 11.995 & 1 & .001 & 3.012 \\
\hline Profit Structure & .224 & .302 & .549 & 1 & .459 & 1.251 \\
\hline Management & 1.280 & .306 & 17.525 & 1 & .000 & 3.598 \\
\hline Amnesty Participant in 2003 & 1.925 & .805 & 5.723 & 1 & .017 & 6.856 \\
\hline Constant & -.843 & .209 & 16.257 & 1 & .000 & .477 \\
\hline \multicolumn{7}{|l|}{$\mathrm{N}=369$} \\
\hline
\end{tabular}

These results indicate that amnesty programs, while generally responsible for raising a lot of money, do not result in more compliant behavior on the part of those who participate. In this study, amnesty participants were 6.856 times more likely to be involved in sales tax theft than those members who did not participate, which is the largest indicator in the analysis by a wide margin. ${ }^{20}$

The data and analysis from this portion of this study make it clear that simply trusting businesses to remit the sales tax they collect is bad policy. My study indicates that a large percentage of companies are involved in sales tax theft. Companies that steal the most conceal the theft carefully, and may even participate in amnesty programs to provide additional cover for their illegal activities or to deter the taxing authority from taking a closer look at the business. Delinquent filers and payers, who currently receive the majority of the attention and resources of DOR, account for a very small percentage

\footnotetext{
${ }^{20}$ This statistic is problematic in that it suggests that amnesty participants should be singled out for audit or investigation. But such a response would certainly dampen taxpayer enthusiasm for participating in amnesty programs. In the author's opinion, adding more resources to enforcement activities is preferable to amnesty programs and, ultimately, more cost effective.
} 
of the theft of state funds that occurs. Intuitive analysis utilized at a lower level in the compliance enforcement process can be a critical component of improved enforcement efforts. As a result of this analysis, the alternative hypothesis set forth in chapter 3 is accepted:

$\mathbf{H}_{2}$ : Agent intuition applied to intelligence data yields effective identification of candidates for targeted enforcement efforts.

But it has also been shown that such analyses can yield a large number of false positives which have the potential to cause an enforcement agent to waste precious time and resources on nonproductive endeavors. To realize the efficiency promised by this type of analysis and minimize the waste caused by false positives, two additional requirements are necessary:

1. The time-consuming process of proving compliance must be transferred to the target by requiring the presentation of records required by law to be maintained in support of the returns filed. Businesses that are in compliance with the recordkeeping requirements of the law will be able to prove the veracity of the returns filed with little effort.

2. Informal contacts and engagement with the target are substituted, at least initially, for the more formal and structured approaches present in audits and criminal investigations.

In the next chapter the author provides an analysis of how such a program can be successfully implemented with minimal resources. 


\section{CHAPTER 8}

\section{TARGETED INDUSTRY ENFORCEMENT PROGRAMS:}

\section{FINDINGS AND ANALYSIS}

On any given day an agent with the Florida Department of Revenue may interact with owners of convenience stores, car rental companies, car sales lots, restaurants, bars, secondhand dealers, consignment shops, 99 cent stores, gas stations and every other type of business that can be imagined. Collection employees in the Service Centers are assigned by zip codes, not by business type. Audits are conducted as a result of audit case selection activities. Criminal investigations are initiated based on complaints or other leads related to fraudulent activities. While there are industry experts within DOR, none of the employees in the Service Centers specialize in any particular industry by design. Periodically, DOR does initiate enforcement programs designed to increase compliance in an industry where compliance is deemed to be low. An example of this was the commercial rental enforcement program discussed in Chapter 4. Using the data warehousing capabilities of the SUNTAX system DOR was able to identify a large number of commercial landlords that were not registered to collect and remit sales tax. This program resulted in the collection of more than $\$ 30$ million in unreported sales tax revenue. In addition, the registration of these entities provided an annuity of $\$ 10$ million per year in future revenues through the same effort. Discovery operations and campaigns generate about $\$ 50$ million on average per year. These enforcement programs are not common at the local level in the Service Centers. When they are initiated, they have largely been discovery-oriented projects run centrally out of Tallahassee with little, if any, involvement at the local level. Additionally, they normally are of limited duration. 
An opportunity arose within Southern Region Criminal Investigations for me to study the impact of targeted industry enforcement activities at the local level. As mentioned in Chapters 5 and 7, for every used car sold in the state an application for title is filed with the Department of Highway Safety and Motor Vehicles (DHSMV) to cause the transfer of title from the dealer to the purchaser of the car. Car dealers are required to include their sales tax number and the amount of sales tax collected with respect to the transaction on the title application. Sales tax data from these title applications can be accumulated and compared to amounts reported to DOR on monthly sales tax returns to identify discrepancies that need to be reconciled. (See Figure 5.2 in Chapter 5 for a diagram of this process). The data from the applications for title is provided to DOR on a quarterly basis. ${ }^{21}$ For purposes of the present study, this comparison was performed for every dealer in Miami-Dade County. The initial comparisons yielded 192 used car dealers in Miami-Dade County with potential sales tax theft of $\$ 21,421,312.22$ over the last five-year period.

On average, more than $\$ 357,000$ of the sales tax theft identified would be lost to the five-year statute of limitations for theft every month that passed. It was, therefore, important that action be taken fairly quickly. Resource limitations dictated that 192 criminal investigations, more than doubling the current case load, could not be conducted quickly enough so alternative treatments had to be found in order to address the identified

\footnotetext{
${ }^{21}$ The comparison of sales tax collected as reflected on title transfer applications to amounts reported to the Department of Revenue on monthly sales tax returns is a time-consuming, laborious task. An effort was made to match the data statewide in 2001, but only about 60 percent of the data could be matched easily because of difficulties in matching Department of Highway Safety and Motor Vehicles licensees to Department of Revenue tax accounts. As a result, no overall matching of data is performed on a regular basis. When needed, investigators accumulate and compare the data manually.
} 
potential theft through a combination of full investigations and activities designed to quickly identify those cases that did not involve criminal activity.

\section{The Interventions}

As noted in Chapter 4, the comparison of sales tax collected per the DHSMV title applications to amounts reported to DOR yields potential sales tax theft. Explanations other than theft are possible. Part of the difference is sometimes explained by timing differences. Some dealers report the sales tax collected only after the title to the car is issued, resulting in a one- or two-month delay in reporting the tax to DOR. It is not correct to report in this manner, but over time, no theft occurs. Technically the dealer owes a penalty and interest on the sales tax remitted late. Additionally, those dealers that finance car sales internally, known as "buy here pay here" dealers, usually have high numbers of repossessions, which result in credits against their sales tax liabilities. They are required to report the entire amount of sales tax collected on the date of sale. If they do not collect all the payments under a deferred payment arrangement, they are allowed a credit essentially for the tax rate times the principal amount of the sales price not collected. ${ }^{22}$ The credits taken are required to be reported on the monthly sales tax returns, but some dealers do not understand this requirement and simply report the current month sales tax collected net of any repossession credits they are due. Therefore, those companies with smaller discrepancies and those where the sales tax reported was a

\footnotetext{
${ }^{22}$ The actual calculation as set forth on Form DR-95b seems significantly more complex to most small dealers who have no training in accounting or finance. The calculation guides the dealer step by step through the process of allocating payments between principal and interest to determine the principal balance due at the date of repossession, which is simple enough conceptually, but most dealers struggle with the calculation and many claim the entire amount of sales tax originally collected as the credit amount.
} 
high percentage of the total tax collected might be companies that are reporting the sales tax when the title is actually issued and/or they may have claimed repossession credits that were not formally reported that explain the differences. Therefore, it is reasonable to handle those companies in a manner other than a full criminal investigation, and in a manner that does not pull investigative resources away from those cases where they are obviously required. It was decided to send these dealers a letter explaining the need for a reconciliation of amounts reported to the DHSMV versus the amount reported to DOR. In this manner, the companies with smaller amounts or percentages of possible theft could be handled more quickly, and those where it appeared a civil rather than criminal solution was warranted could be identified rapidly and referred to collections employees within DOR.

A review of the accounts for classification purposes identified 34 companies that could be classified in what was labeled the low-theft group, representing a total of $\$ 606,016.10$ in potential sales tax theft. Five companies were identified that were already the subject of a separate investigation, audit, or other compliance enforcement activity and were thus removed. These five companies represented $\$ 279,167.30$ in potential sales tax theft. Companies classified as having major theft probability totaled 43 and represented $\$ 14,164,214.64$ in potential sales tax theft. These companies would require full investigation. This left 110 companies representing $\$ 6,371,914.18$ in potential sales tax theft to be initially contacted via letter and asked to provide reconciliation. Table 8.1 presents a summary of the companies as classified. 
Table 8.1 Classification of Dealers with Potential Sales Tax Theft

\begin{tabular}{|l|r|r|r|r|r|}
\hline & Number & \multicolumn{1}{c|}{$\begin{array}{c}\text { Revenues } \\
\text { Reported }\end{array}$} & \multicolumn{1}{|c|}{$\begin{array}{c}\text { Sales Tax } \\
\text { Reported }\end{array}$} & \multicolumn{1}{c|}{$\begin{array}{c}\text { Potential } \\
\text { Theft }\end{array}$} & \multicolumn{1}{c|}{$\begin{array}{c}\text { Collection } \\
\text { Balance }\end{array}$} \\
\hline $\begin{array}{l}\text { Contact by } \\
\text { Letter }\end{array}$ & 110 & $\$ 486,633,327$ & $\$ 22,188,274$ & $\$ 6,371,914$ & $\$ 182,054$ \\
\hline $\begin{array}{l}\text { Criminal } \\
\text { Investigation }\end{array}$ & 43 & $\$ 339,418,780$ & $\$ 9,270,420$ & $\$ 14,164,215$ & $\$ 89,552$ \\
\hline Low Theft & 34 & $\$ 164,670,689$ & $\$ 3,717,882$ & $\$ 606,016$ & $\$ 27,456$ \\
\hline Removed & 5 & $\$ 27,323,885$ & $\$ 1,610,648$ & $\$ 279,167$ & $\$ 3,164$ \\
\hline Totals & 192 & $\$ 1,018,046,681$ & $\$ 36,787,224$ & $\$ 21,421,312$ & $\$ 302,226$ \\
\hline
\end{tabular}

The "Revenues Reported" and "Sales Tax Reported" columns in Table 8.1 are the amounts of gross sales and sales tax collected as reported on the Sales and Use Tax Returns filed by the companies. The "Potential Theft" column reflects the additional amount of sales tax reported to DHSMV on title applications over and above what was reported on the returns filed with DOR. The "Collection Balance" is the amount of delinquent taxes subject to DOR collection activities as reflected in SUNTAX and included in DOR receivables.

Note from Table 8.1 that the collection balance associated with the dealers included in this study was only $\$ 302,226$. That is the amount that the local service center collections personnel were attempting to collect from the 192 dealers included. Absent this study or the generation of other leads or complaints that might have resulted in an audit or criminal investigation of one or perhaps a few of these dealers, DOR would have recovered $\$ 302,226$ either through cash collection or through levy against a warrant or lien at some point in the future. In reality, these businesses owed $\$ 21,421,312$ in sales tax, not $\$ 302,226$. This comparison points to the very large hole in the compliance umbrella previously discussed. With collections personnel concentrating solely on delinquencies; audits or criminal investigations few and far between because of resource 
limitations; and no third-party verification of sales taxes collected by business agents of the state, the vast majority of sales tax theft goes unnoticed and unchallenged.

To facilitate the handling of and allocation of resources to the accounts to be contacted via letter, 64 dealers were selected for contact in the first mailing to gauge response and determine if any changes in procedure were needed before contacting the remainder. This mailing is designated as "Wave 1." The letter simply requested that the dealer review their records to determine why the amount of sales tax collected as reported to DHSMV differed from the amount of sales tax collected reported to DOR on monthly Sales and Use Tax Returns. To assist them with their reconciliation, the dealers were provided with a schedule listing the differences in the amount of sales tax reported to DHSMV versus the amount reported to DOR for each month over the last five years or the time during which they were in business if shorter. The dealers were also supplied with a listing of every transaction reported to DHSMV with the amount of tax reported on the title application and sufficient detail to enable them to identify the car sold and the customer to whom it was sold. With this information, the dealer could review their records transaction by transaction to determine that each transaction was indeed a sale consummated by their business and that the amount of tax reported to DHSMV was correct. They were informed that if the transactions reported to DHSMV were found to be correct, then the additional tax shown on the monthly comparison would be due and payable to DOR. There was no indication in this letter that the reconciliation being asked for was part of a criminal investigation.

Only 69 percent of the dealers contacted in the first mailing responded. Those who responded did so quickly. Many asked for additional time to complete the 
reconciliation. Carrying the analysis back five years proved a problem for some, highlighting a disconnect between the required period for maintaining records, three years, and the statute of limitations for sales tax theft which is five years. The following Table 8.2 presents the resolutions that followed the first mailing over a 12-month period of time:

Table 8.2 Resolutions from the First Mailing - Wave 1

\begin{tabular}{|c|c|c|}
\hline $\begin{array}{r}\text { Resolution } \\
\end{array}$ & Number of Dealers & Sales Tax Amount \\
\hline $\begin{array}{l}\text { Payment made or payment } \\
\text { arrangement made }\end{array}$ & 9 & $\$ 337,037$ \\
\hline $\begin{array}{l}\text { Adjustments or credits verified for } \\
\text { those dealers making payments }\end{array}$ & $\mathrm{N} / \mathrm{A}$ & $\$ 83,595$ \\
\hline $\begin{array}{l}\text { Preliminary agreement with tax due, } \\
\text { but pending completion of review }\end{array}$ & 4 & $\$ 312,275$ \\
\hline Closed business & 11 & $\$ 543,816$ \\
\hline $\begin{array}{l}\text { Provided documentary evidence that } \\
\text { filings were correct - received training } \\
\text { on proper reporting of repossession } \\
\text { credits }\end{array}$ & 8 & $\$ 562,150$ \\
\hline $\begin{array}{l}\text { Certified correct, but no verification } \\
\text { provided }\end{array}$ & 2 & $\$ 175,388$ \\
\hline Already in prosecution & 1 & $\$ 70,247$ \\
\hline Moved to full criminal investigation & 8 & $\$ 634,372$ \\
\hline Total resolved & 43 & $\$ 2,718,880$ \\
\hline Total mailings & 65 & $\$ 4,129,232$ \\
\hline Percentages resolved & $66.15 \%$ & $65.84 \%$ \\
\hline $\begin{array}{l}\text { Responded, but analysis is still } \\
\text { pending }\end{array}$ & 6 & $\$ 705,064$ \\
\hline Open dealers that did not respond & 16 & $\$ 705,288$ \\
\hline $\begin{array}{l}\text { Percent of dealers who did not respond } \\
\text { (closed and open, } 20 \text { dealers, } \$ 906,828 \\
\text { in tax) }\end{array}$ & $30.77 \%$ & $21.96 \%$ \\
\hline \multicolumn{2}{|c|}{ Time required to date to achieve indicated resolution } & 12 months \\
\hline
\end{tabular}

The non-responsive dealers, those who closed their business after receiving the inquiry and those who certified their returns were correct but provided no corroborating 
evidence will be subject to other enforcement efforts, including possible full criminal investigation or referral for audit.

The second mailing was targeted to the remaining 46 dealers in the group designated for the receipt of letters with a request for reconciliation of taxes reported to DHSMV and DOR. This mailing was designated as "Wave 2." Because of the low and slow response rate to the first letter, the letter used for the second group mailing included language making it clear that the request was being made as part of a criminal investigation, but was similar in all other substantive respects. The change in response was immediately noticeable: 85 percent of the recipients of the second letter responded within 30 days of their receipt of the letter and 91 percent eventually responded within the first four months. For the first mailing, only 57 percent responded within the first 30 days of receipt and only 69 percent responded in total over the following 12 months. This result appears to provide empirical support for the assertion that whether or not the consequences of tax evasion are criminal or not is important as per Varma and Doob (1998).

Table 8.3 presents the resolutions that followed the second mailing over a 4month period of time:

It is striking that the results of the two mailings are similar, except that virtually the same results were achieved in the second mailing in one-third of the time. The percentage of dealers who failed to respond dropped from 31 percent in the first mailing 
Table 8.3 Resolutions from Second Mailing - Wave 2

\begin{tabular}{|l|r|r|}
\hline \multicolumn{1}{|c|}{ Resolution } & Number of Dealers & Sales Tax Amount \\
\hline $\begin{array}{l}\text { Payment made or payment } \\
\text { arrangement made }\end{array}$ & 9 & $\$ 288,150$ \\
\hline $\begin{array}{l}\text { Adjustments or credits verified for } \\
\text { those dealers making payments }\end{array}$ & N/A & $\$ 94,449$ \\
\hline $\begin{array}{l}\text { Preliminary agreement with tax due, } \\
\text { but pending completion of review }\end{array}$ & 10 & $\$ 184,629$ \\
\hline Closed business & & $\$ 520,720$ \\
\hline $\begin{array}{l}\text { Verified filings were correct - } \\
\text { received training in proper reporting } \\
\text { of repossession credits }\end{array}$ & 5 & $\$ 300,486$ \\
\hline $\begin{array}{l}\text { Certified correct, but no verification } \\
\text { provided }\end{array}$ & 0 & $\$-$ \\
\hline Already in prosecution & 0 & $\$ 100,200$ \\
\hline Moved to full criminal investigation & 3 & $\$ 1,488,634$ \\
\hline Total resolved & 31 & $\$ 2,312,930$ \\
\hline Total mailings & 46 & $64.36 \%$ \\
\hline Percentages resolved & $67.39 \%$ & $\$ 632,740$ \\
\hline $\begin{array}{l}\text { Responded, but analysis is still } \\
\text { pending }\end{array}$ & 11 & $\$ 191,556$ \\
\hline Open dealers that did not respond & 4 & $8.28 \%$ \\
\hline $\begin{array}{l}\text { Percent of dealers who did not } \\
\text { respond }\end{array}$ & $8.70 \%$ & months \\
\hline Time required to achieve indicated resolutions & & \\
\hline
\end{tabular}

to nine (9) percent in the second mailing. It appears that the threat of criminal

consequences is a potent enforcement tool if used judiciously. ${ }^{23}$ These results show that enforcement operations driven by intelligence data gathered from available resources can be utilized to drive industry-wide enforcement campaigns at the local level to yield solid results with the relatively small resource commitment of one individual working on the project part time.

\footnotetext{
${ }^{23}$ Note that all of the contacts were, in fact, in connection with a criminal investigation. However, the mailings to the first wave of subjects did not stress that fact.
} 
The question now becomes: did the activities and contact with a large number of dealers over a period of time produce improved compliance overall?

\section{Tests of Compliance after Interventions}

Some of the dealers targeted either closed their businesses or greatly scaled back operations. It should be noted that causing a noncompliant business to close operations is a compliance success because it causes the sales tax theft to cease. Assuming that demand for used cars is not impacted by the closure of a dealership, it can be assumed that the customer will patronize another dealer who is compliant and remains open. This impact will be quantified in total later in this chapter.

To gauge the initial and continuing impact of the interventions, the average sales tax theft for each company in Wave $1(\mathrm{~N}=64)$ was measured, prior to the intervention and at three intervals after the intervention, as noted in Figure 8.1.

The first measurement occurred four months after the intervention; the second three months later, just before the intervention on Wave 2; and the third five months later at the first measurement date for Wave 2 interventions. Additional interventions were not applied at each measurement interval so the analysis measures the length of time the original intervention continued to have an impact on compliance.

Repeated-measures analysis of variance was used to evaluate the changes in average sales tax theft per month and to test the null hypothesis:

$\mathrm{H}_{0}$ : Any changes that occur in the mean monthly sales tax theft at the measurement dates are due to chance and not to the intervention and such differences will average to zero. 
Figure 8.1 Intervention Mailing and Measurement Timeline

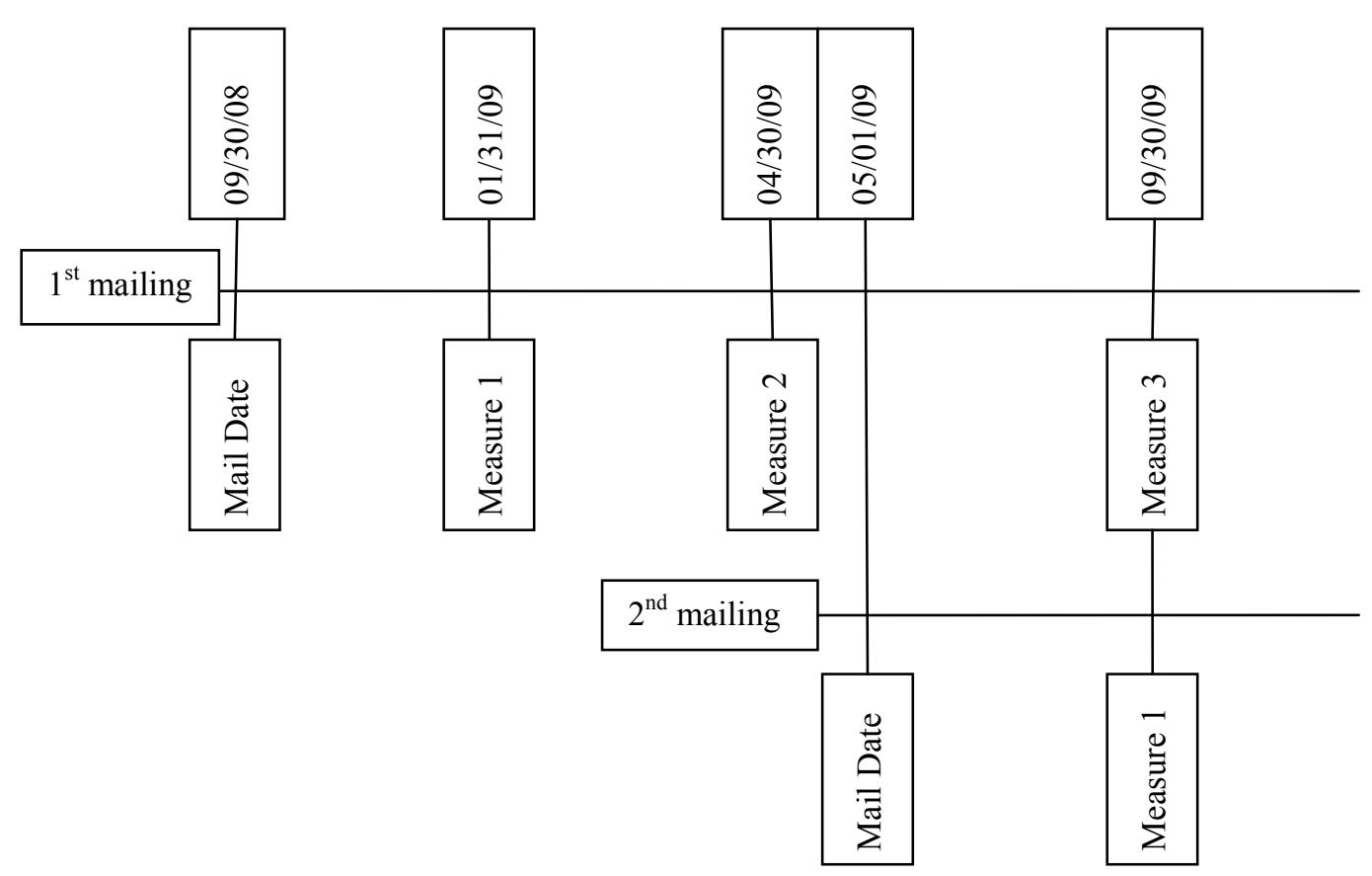

The means and standard deviations are presented in Table 8.4. The repeatedmeasures analysis of variance revealed that the intervention produced a significant decrease in sales tax theft per month over the course of this study, $F(2.219,139.779)=$ $7.73, p=.000$. The Greenhouse-Geisser epsilon estimate was used because the assumption of sphericity was not met.

Table 8.4 Average Sales Tax Theft for Wave 1 Companies at Future Measurement Dates

\begin{tabular}{|l|r|r|}
\hline & M & SD \\
\hline Prior to intervention & $1,296.61$ & $1,046.87$ \\
\hline Measurement at 4 months after intervention & 711.96 & $1,109.76$ \\
\hline Measurement at 7 months after intervention & 965.67 & $1,541.77$ \\
\hline Measurement at 12 months after intervention* & 500.92 & $1,547.42$ \\
\hline * The interventions for Wave 2 occurred at the beginning of this five-month period. \\
\hline
\end{tabular}


The analysis of variance results in a rejection of the null hypothesis and conclusion that at least one mean measured at the measurement dates is different and not due to chance. A review of pairwise comparisons of the results between periods reveals the following:

Table 8.5 Wave 1 Pairwise Comparisons of Average Sales Tax Theft at Measurement Dates

\begin{tabular}{|c|r|r|r|}
\hline Start Period & End Period & Mean Difference & \multicolumn{1}{c|}{ Significance } \\
\hline Pre-intervention & $01 / 31 / 09$ & -584.65 & $<.001$ \\
\cline { 2 - 4 } $09 / 30 / 08$ & $04 / 30 / 09$ & -330.94 & .095 \\
\cline { 2 - 4 } & $09 / 30 / 09$ & -795.69 & $<.001$ \\
\hline
\end{tabular}

The pairwise comparisons indicate that the Wave 1 interventions had a significant impact on the amount of average sales tax theft during the four-month period following the intervention. It also appears that the impact of the intervention began to wane at the second measurement date, seven months after the intervention when there was no significant difference in the amount of average sales tax theft compared to the periods prior to the intervention. The results show that the mean difference between average sales tax theft prior to the interventions and average sales tax theft one year after the interventions was again significant. It is surmised that this "renewal" of impact occurred due to the indirect impact of the interventions on Wave 2 and the effect of continued follow up with respect to those companies that had responded slowly to the initial inquiry.

In May 2009, the interventions emphasizing the connection to a criminal investigation were applied to Wave 2. The means and standard deviations prior to intervention and five months after the intervention are presented in Table 8.6. The 
average monthly sales tax theft for the companies in the second wave of interventions decreased $(\mathrm{M}=1,107.40, \mathrm{SD}=992.10)$ during the five months following the intervention applied to this second wave. Applying a paired-samples t-test it was found that this reduction was statistically significant, $\mathrm{t}(45)=7.571, \mathrm{p}<.001$.

Table 8.6 Wave 2 Monthly Sales Tax Theft Means and Standard Deviations before the Interventions and at the Five-Month Measurement Date

\begin{tabular}{|l|r|r|}
\hline & \multicolumn{1}{|c|}{ M } & \multicolumn{1}{c|}{ SD } \\
\hline Prior to intervention & $1,105.53$ & 717.63 \\
\hline Five months after intervention & -1.87 & 970.34 \\
\hline
\end{tabular}

Recall that the intervention applied to the second wave emphasized that the inquiry was in connection with a criminal investigation. A one-way ANOVA was utilized to compare the impacts between the two types of interventions applied to the two groups based on the mean tax theft per month at the first measurement date after the application of the intervention. ${ }^{24}$ The ANOVA revealed a significant difference between the two treatments, $\mathrm{F}(1,103)=10.941, \mathrm{p}=.001$. Table 8.7 presents the means and standard deviations for each intervention.

Table 8.7 Comparison of Mean Sales Tax Theft per Month between Waves 1 and 2

\begin{tabular}{|l|r|r|}
\hline & $\mathrm{M}$ & \multicolumn{1}{|c|}{ SD } \\
\hline Intervention 1 - Wave 1 $(\mathrm{N}=64)$ & 711.96 & $1,109.76$ \\
\hline Intervention 2 - Wave 2 $(\mathrm{N}=41)$ & -2.10 & $1,129.59$ \\
\hline
\end{tabular}

The comparison of mean sales tax theft per month between Waves 1 and 2 suggests that interventions that emphasize criminal consequences result in more

\footnotetext{
${ }^{24}$ The first measurement date for each intervention was used in the comparison because that is the measurement date when the intervention should have its maximum impact.
} 
compliance than interventions perceived as civil in nature in line with the findings of Varma and Doob (1998).

\section{The Indirect Impact of the Interventions}

Did the interventions have an indirect impact on companies within the study that were not directly targeted by a specific intervention? Again, monthly average sales tax theft calculated for those companies which were not directly targeted by the specific intervention was used in this analysis. With respect to the first intervention which occurred in October 2008, companies that were not subject to an intervention until the second wave in May 2009 were included in the indirect analysis along with companies that were not subject to interventions at all (the Major Case and Low Theft groups). With respect to the second intervention, only the Major Case and Low Theft groups were evaluated for indirect impact. The measurement date with respect to the first intervention was four months after the intervention, and for the second intervention, five months. A paired samples $t$ test was used to test the null hypothesis:

$\mathbf{H}_{\mathbf{0}}$ : Any changes that occur in the mean monthly sales tax theft of members of groups not subject to direct intervention are due to chance and not to the indirect effect of the intervention and such differences will average to zero.

Table 8.8 presents the means and standard deviations of the monthly tax theft before and after the interventions for companies that might have been indirectly affected by the interventions. 
Table 8.8 Monthly Sales Tax Theft Means and Standard Deviations for Indirect Effects of Interventions

\begin{tabular}{|l|l|r|r|r|}
\hline & & M & \multicolumn{1}{|c|}{ SD } & \multicolumn{1}{|c|}{ N } \\
\hline Interventions - Wave 1 & Prior to Intervention & $2,713.85$ & $5,861.50$ & 94 \\
\cline { 2 - 5 } & After Intervention & $2,486.70$ & $8,253.97$ & 94 \\
\hline Interventions - Wave 2 & Prior to Intervention & $3,496.19$ & $7,019.28$ & 53 \\
\cline { 2 - 5 } & After Intervention & $1,973.85$ & $4,164.90$ & 53 \\
\hline
\end{tabular}

With respect to the first set of interventions, monthly sales tax theft decreased (M $=227.14, \mathrm{SD}=4,172.41)$ in companies that might have been indirectly impacted by the intervention. The decrease was not statistically significant $\mathrm{t}(93)=.528, \mathrm{p}=.599$.

With respect to the second set of interventions, monthly sales tax theft decreased $(\mathrm{M}=1,522.34, \mathrm{SD}=4,449.48)$ in the companies that might have been indirectly impacted by the intervention. The analysis indicates that the decrease was significantly more than would be expected by chance, $\mathrm{t}(52)=2.491, \mathrm{p}=.016$.

On the basis of these tests, it can be inferred that direct interventions have a significant impact on monthly tax theft by the companies to which the interventions are applied. The impact is significant regardless of whether the intervention implies compliance failure will be subject to civil consequences or criminal consequences, but it appears that the impact is stronger where the implied consequences are criminal in nature. Additionally, criminal interventions have a significant indirect impact on compliance while civil interventions do not.

The implication of these results is that to control sales tax theft, non-criminal interventions must be continuous and direct. Further, interventions with implied or clearly criminal consequences do result in some indirect or "spillover" effect on companies not directly targeted by the intervention. 


\section{Enforcement and the "Major Case" Dealers}

To this point the "Major Case" dealers, the 43 dealers responsible for potential sales tax theft of $\$ 14,164,215$, have been ignored. The amount of potential sales tax theft by these dealers dictated that normal criminal investigations be carried out as opposed to some lighter form of intervention. Chapter 6 described how the Southern Region Investigations unit had increased participation in task forces with other federal, state and local agencies on large, multi-company cases where other agencies had enforcement interests that aligned with those of DOR. With respect to the Major Case car dealers, it was decided that the same approach could be used with respect to a large group of similar companies that were unrelated by ownership, but related by business type. The State Attorney's Office assigned a prosecutor to participate and provide legal assistance and expedited review of search warrant affidavits. The Special Investigations Unit of the Miami-Dade Police Department, Auto Theft Task Force, was approached for their assistance with the execution of search warrants. They indicated they held complementary interests in many of these dealers and agreed to a cooperative operation.

Fifteen of the 43 dealers in this class had closed during the months that elapsed while search warrants were being drafted and approved; one was removed and referred to another region because their operations actually existed in that other region; and five were removed to be subjected to other types of interventions based on various other criteria. This left 22 dealers to be investigated by the newly formed task force. In mid October 2009 ten search warrants were executed in a single day with two alternates executed a few days later. In early December 2009 the remaining search warrants were executed, again in a single day. Executing ten search warrants per day in this manner 
required five teams of at least five people each with two additional people "floating" for support. Each team was responsible for executing one search warrant in the morning and one in the afternoon. Since DOR Southern Region Investigations has only four agents and one support analyst to participate in search warrants, it would have been impossible to execute these warrants in such a short period of time without the task force format. The execution of DOR search warrants always requires the assistance of a law enforcement agency because DOR agents are classified as regulatory and not law enforcement. Without a task force, however, it is difficult to obtain support for multiple search warrant executions in a single day. Under ordinary circumstances these 22 search warrants would have likely been executed over the course of a year if executed singly as separate cases. By conglomerating them into a single operation, DOR was able to obtain the evidence required to document criminal cases against all 22 entities in a very compressed period of time. By the end of December, two cases had already been documented, approved, and submitted to the State Attorney's Office for potential prosecution. The State Attorney's Office had also committed to expedite the handling of all 22 cases to minimize any further losses because of expiration of the statute of limitations.

\section{Summary of the Impact of the Targeted Interventions}

Over the course of 14 months targeted interventions were applied to the used car industry in Miami-Dade County Florida. The interventions included substantial contact with targeted dealers and the execution of search warrants on those with the largest amounts of identified potential theft. The impact of these interventions is the 
identification and collection of a portion of the unremitted sales tax in the short term; longer term additional annual collections of sales tax through increased compliance; pending additional collections through continuing contact with dealers who have not completed their analysis of DOR-provided data; potential restitution from dealers identified for full investigation and potential prosecution; and reduced sales tax theft from the closure of noncompliant businesses.

The short term impact of the interventions is measured by the amount of unremitted sales tax collected, the amount under payment arrangements, plus the amount of unremitted sales tax where the liability has been admitted but payment arrangements are not complete. The short term impact measured in this manner is $\$ 1,122,090.41$. There is an additional $\$ 2,542,817.82$ of unremitted sales tax pending at this time that will likely be added to the short term impact.

The continuing monthly impact of the interventions with respect to open businesses is measured by the additional amount of monthly sales tax being remitted since the intervention by those companies that have become compliant. The monthly increase in sales tax remitted since the interventions is $\$ 157,761.02$, or $\$ 1,893,132.24$ per year. It will likely be necessary to maintain periodic contact with these businesses in order to sustain these savings.

The continuing monthly impact of the interventions with respect to closed businesses is measured by the monthly amount of sales tax no longer being stolen by these businesses. Assuming the demand for used cars is not impacted by the closure of these businesses, the closing of noncompliant businesses should result in sales being transferred to compliant businesses that will remit the sales tax collected. Therefore, the 
closure of noncompliant businesses does increase future sales tax collections. The increase in sales tax remittances by compliant businesses who inherit the sales volume of closed noncompliant businesses is $\$ 133,745.08$ per month or $\$ 1,604,940.96$ per year. Some businesses do close naturally, but the businesses in this study that closed had been in operation for more than five years indicating the intervention was likely a trigger for closing at this particular time.

There is $\$ 8,430,301.69$ of potential criminal restitution that will be collected as a result of these interventions. Of this amount, documentation supporting $\$ 7,269,212.70$ of unremitted sales tax has been obtained through the execution of search warrants. Analysis of the evidence and drafting of the probable cause affidavits for bringing criminal charges against these entities and owners is underway, with two cases already complete and submitted to the State Attorney's Office for charging. Criminal charges related to the remaining $\$ 1,161,088.99$ of potential restitution will be documented through a combination of subpoenas and the use of title applications certified by DHSMV. All criminal charges should be in place within four months of the execution of the search warrants. The State Attorney's Office has the option of negotiating payment of these liabilities, plus interest, investigative costs, and a plea to lesser charges in lieu of prosecution.

Dealers that closed during the course of the interventions owed $\$ 5,818,319.74$, with a single dealer owing $\$ 2,442,177.37$ of that amount. These dealers will be subject to a complete criminal investigation and referral for prosecution.

A total of 35 dealers have been identified for the next wave of interventions representing $\$ 1,296,174.82$ in unremitted sales tax. 
Table 8.9 summarizes the impact of these interventions at the time of this

writing.

Table 8.9 Summary of the Impact of Interventions

\begin{tabular}{|l|r|r|}
\hline \multicolumn{1}{|c|}{ Category } & Companies & \multicolumn{1}{c|}{ Amount } \\
\hline Short term collections & 26 & $\$ 1,122,090.40$ \\
\hline Pending short-term collections & 42 & $\$ 2,542,817.82$ \\
\hline $\begin{array}{l}\text { Continuing annual collections - open } \\
\text { compliant businesses }\end{array}$ & 107 & $\$ 1,893,132.24$ \\
\hline $\begin{array}{l}\text { Continuing annual collections - } \\
\text { transferred from closed noncompliant } \\
\text { to open compliant businesses }\end{array}$ & 37 & $\$ 1,604,940.96$ \\
\hline $\begin{array}{l}\text { Potential restitution - search warrants } \\
\text { executed }\end{array}$ & 22 & $\$ 7,269,212.70$ \\
\hline $\begin{array}{l}\text { Potential restitution - alternate } \\
\text { documentation }\end{array}$ & 13 & $\$ 1,161,088.99$ \\
\hline $\begin{array}{l}\text { Potential restitution - prosecutions of } \\
\text { closed businesses }\end{array}$ & 35 & $\$ 5,818,319.74$ \\
\hline Next wave of interventions & 35 & $\$ 1,296,174.82$ \\
\hline Totals & N/A due to overlaps & $\$ 22,707,777.67$ \\
\hline
\end{tabular}

As pending cases are resolved, full investigations and prosecutions proceed, and the next wave of interventions take place, the analysis of the industry will continue in a cycle designed to continuously identify potential theft and begin to intervene before the amount of theft by any given dealer becomes large enough to require a full investigation or prosecution.

You may recall the following hypothesis set forth in Chapter 3:

$\mathbf{H}_{1}$ : The effectiveness of compliance enforcement efforts will be improved if active, well-informed enforcement activities characterized by substantial contact initiated by the agents of the state are substituted for passive or reactive activities. 
To test this hypothesis the above results were compared with the results that would have been achieved without this project. Without the interventions, it is possible that the collection balances because of delinquencies would have been recovered, even though recovery from companies that closed would be unlikely. It is also possible that audits would have been performed for those companies identified in the System for Unified Taxation (SUNTAX) as audit leads, even though some of these leads had already been rejected. To be conservative, it is assumed that all collection balances would eventually be collected $(\$ 302,226.49)$ and that audits would be performed for all identified audit leads and that such audits would result in identification of the unremitted sales tax identified. There were 14 companies identified as audit leads representing $\$ 1,946,053.89$ in sales tax theft. Therefore, without the interventions it is possible that DOR would have recovered a total of $\$ 2,248,280.38$ of unremitted sales tax.

Amounts recovered as a result of the interventions are calculated excluding additional monthly sales tax in future periods or sales tax theft avoided because of closed companies and includes only theft balances that existed at the time the interventions began. This total is $\$ 19,209,704.47$. The means and standard deviations of the tax theft amounts identified with and without the interventions are presented in Table 8.10.

Table 8.10 Means and Standard Deviations of Sales Tax Theft Identified and Recoverable With and Without Interventions

\begin{tabular}{|l|r|r|}
\hline & M & \multicolumn{1}{l|}{ SD } \\
\hline Identified and recoverable through interventions & $100,050.54$ & $220,100.00$ \\
\hline Identifiable and recoverable without interventions & $11,709.79$ & $48,504.86$ \\
\hline
\end{tabular}


Using a one-way ANOVA to compare means before and after (with and without) the intervention, the interventions resulted in an increase $(M=88,340.75, \mathrm{SD}=218,997)$ in sales tax theft identified. The Brown-Forsythe F-ratio is being reported because the assumption of homogeneity of variance was violated. The increase in sales tax theft identified and recoverable was statistically significant, $F(1,209.509)=29.498, \mathrm{p}<.001$. As a result, the null hypothesis is rejected and it is concluded that the effectiveness of compliance enforcement efforts are improved by active, well informed enforcement activities characterized by substantial contact initiated by agents of the state. 


\section{CHAPTER 9}

\section{EXPLAINING SALES TAX THEFT THROUGH THE THEORY OF PLANNED BEHAVIOR AND CRESSEY'S FRAUD TRIANGLE}

It is claimed that the U. S. income tax system is built on voluntary assessment and payment (Flora v. United States, 1960). A review of the income tax return clearly illustrates it is more a case of trust but verify. An Internal Revenue Service agent reviewing an income tax return has enough financial data provided on the return itself to visualize the financial position of the individual or company and make a preliminary determination of the veracity of the income tax reported. Income tax returns provide a frame of reference because deductions are reported along with revenues. One can readily see that the amount of revenue reported supports the level of expenses claimed, or that it does not. Corporate income tax returns also include a balance sheet with supporting statements which allow a fuller financial analysis of the business. The sales tax return, on the other hand, is all trust with no verification. The return, at least in Florida, provides one line of data containing gross sales, exempt sales, taxable sales, and the sales tax collected.

Perhaps one of the most important findings in this study is that trust is misplaced in the tax environment. Remember that Martinez-Vazquez, Harwood, and Larkins (1992) found in their experiments that given the safe opportunity to evade taxes, a near-majority of people would take that chance and, if in an illiquid position, a significantly larger proportion of people would choose to evade. The findings in this study support this premise. 
The framework for this study seeks to explain sales tax theft utilizing the theory of planned behavior for analysis of the decision to evade, incorporated into Cressey's fraud triangle, and to use this framework to set forth enhanced enforcement methodologies to combat sales tax theft. My study has provided analysis to support arguments for the adoption of new methods and empirical evidence that the proposed methodology works. At this point a qualitative review of this study is appropriate to match observations to the theory underlying this study.

The theory of planned behavior posits that for an individual to perform a given behavior, it is necessary that the person be able to decide at will to perform or not perform the behavior. The theory postulates three independent determinants of intention:

- The person's attitude toward the behavior, as in whether the person has a favorable or unfavorable view of the behavior;

- Perceived social pressure to perform or not perform the behavior; and

- Perceived behavioral control: the perceived ease or difficulty of performing the behavior based on past experience and anticipated obstacles (Ajzen, 1991). Cressey's fraud triangle adds the element of need to the analysis to account for how the individual arrives at the point where the intention to steal is formed. Need is the element that leads the individual to the decision point. Need pushes the individual into the realm where intention to steal or not to steal is formed by the determinants of the theory of planned behavior. The need arises; the individual forms an intention to steal to satisfy that need.

This study provided the opportunity to meet and talk to more than 100 business owners, all of whom were under investigation for theft of state funds. Nearly all of those 
who received inquiry letters requiring a reconciliation of sales tax reported to DHSMV versus DOR and responded were extremely concerned by the inquiry and desired to resolve their tax issues expeditiously. All of them stated that if it were found they owed the taxes, they would make arrangements to pay the amount due. Indeed, several immediately paid the entire difference identified. It was clear from the responses that most knew they owed the money. One stated that he had come upon hard times and held back some of the taxes to subsidize his operations with the intention of making it up in later months, but once behind on his payments it became difficult to make good on his intentions, a Borrower in the typology of tax evaders. Twelve dealers claimed that errors had been made by employees or accountants and ten pled misunderstanding of the rules regarding the calculation and reporting of repossession credits (Incompetents in the evader typology). Ten dealers identified other individuals utilizing their DHSMV dealer number to sell cars without reporting the sales tax. Four dealers had allowed others to use their dealer number and trusted them to properly report the sales tax. These fourteen dealers were "Negligent Evaders" in the typology. Four had lost all their records and could not perform an analysis to enable a response, potential "Proficient Evaders" using the excuse of lost records to confound proving a theft case. Two dealers pointed to illness as a cause of the problem, Incompetents of the subtype citing medical problems afflicting the primarily responsible party. Ten dealers claimed to be victims of fraud perpetrated by a partner, employee, or manager of the business, "Negligent Evaders" due to lack of internal controls. One dealer was deceased and another was incarcerated in another state, confounding proper classification. As predicted by Cressey's fraud triangle, some form of need requiring retention of the state funds existed in most cases as 
evidenced either by an admission during discussions, payment difficulties evidenced in the records of DOR, or in difficulties in arranging down payments on payment plans to resolve their tax issues. Few were able to repay the tax immediately. Most cited the horrible downturn in the economy, although such excuses disregard the fact that the theft began five years prior, when the economy was booming, and further ignores the fact that sales of used cars actually increased because of the economic downturn as was evidenced by their own increased sales. These excuses appeared to be rationalizations based on generalized causes that, on the surface, made sense given the current state of the economy, but were not grounded in fact.

Some of the business owners decided to close their businesses and fade from view in order to avoid the repayment of the tax. There were 21 of these owing $\$ 1,064,536$, and these are of the "Hardcore Evader" typology progressing toward "Proficient Evader." It is curious that so many business owners would believe that closing their business would solve their tax problem. To a great degree this is because they have learned this behavior.

In Chapter 6 a task force case was mentioned where 30 search warrants were executed in a single day. One of these companies had been audited five years before and had a $\$ 146,000$ audit assessment outstanding. It had been outstanding for five years because the company purportedly closed. However, the investigation determined that the business had been transferred to a new corporation ostensibly owned by the daughter of the owner of the predecessor company. In fact, the company had not closed for a single day. It continued to operate as it had before and continued to steal sales tax during the entire period from the audit assessment to the execution of the search warrant five years hence. Failure to follow up the assessment and resulting lien with a levy and seizure of 
property resulted in the infrastructure for theft being left intact for the new straw owner. Experience shows this to be a common occurrence in Florida because the state exercises so much restraint in seizing property to satisfy levies that seizures essentially never occur. Some business owners understand this and have come to accept and rely on the state's passivity in this area. This particular evader was a "Proficient Evader" but was caught through association with "Hardcore Evader" companies who were identified through their failure to cover all indicators of fraud.

One of the accountants representing two of the car dealers who had received intervention letters mentioned that his clients had asked him what would happen if they simply ignored the letter from DOR since they were aware that some companies that received the letters were doing so, an indication that the dealers were talking among themselves. The execution of the first set of search warrants on the "Major Case" group had just been completed and a large number of boxes sealed with red evidence tape were in the author's office for review. The accountant was told that the boxes were from search warrants executed on companies that chose to ignore the letters, a fact communicated by the accountant to his clients. Not only did his clients no longer think ignoring the letters was viable, but two additional companies that had not previously responded to their letters contacted the author within 24 hours to seek guidance on how to proceed with their review.

While this evidence is merely anecdotal, these two stories illustrate an important fact that officials responsible for compliance enforcement need to understand: businesses talk to each other. They know what is happening in their industry and analyze activities to ascertain what they need to be concerned with and what can be ignored. A business 
owner is faced with a tax assessment; they close down and reopen under a relative's name; a lien is filed against the old business but the authorities never take any further enforcement action against the owners to collect. The end result is that the owners have learned how to avoid enforcement action and that knowledge is passed on to others in their industry. The author has personally witnessed this pattern repeated many times. It can be assumed that subsequent investigations of the car dealers that closed will reveal that several are still in business at a new location with a new name and with a relative or trusted associate listed as the owner. One of the dealers in the "Major Case" group has owned four previous dealerships through which she stole more than $\$ 2$ million in sales tax collections. More than one year prior to this study she was served with a subpoena for the business records of those four businesses. Her response was to close the current business and ignore the subpoena. Being aware that she had opened yet another business under her sister's name, the new business was included in the "Major Case" search warrants. Records obtained from the search warrant indicate she had stolen another $\$ 250,000$ through the new business in the course of a year. She is a prime example of a "Hardcore Evader" struggling to become "Proficient" but stymied by her prior identification as a "Hardcore Evader." True "Proficient Evaders" must learn from others before they are caught and marked, or they must be able to transfer their operations to an individual who cannot be connected to them.

While participating in the execution of search warrants on two convenience stores the author overheard a young lady outside one of the stores say "They'll just change the name," as she watched the operation unfold. She had made the connection between enforcement action and transfer of ownership. Subsequent review indicated that there 
had indeed been previous search warrants executed on companies with different names at these same locations within the past few years and that the current owners of record were related to the owners of the previous entities. ${ }^{25}$ It is unknown whether this problem is unique to Florida, but it is commonly recognized by DOR personnel as a significant problem for Florida tax enforcement.

In the case of the car dealers who received intervention letters, it was observed and heard from third parties that many of the dealers were watching and biding their time to see if DOR would actually follow through on collecting the taxes due as reflected in the letters. The execution of the search warrants on the Major Case group helped in this regard. One of the owners of a business subjected to a search warrant commented that he had received calls from "everyone I know and everybody I used to know" regarding the search warrant. He stated that "bad news travels fast" and that everyone wanted to know what he had done wrong. He stated that he had not heard from many of these people in years (Anonymous, Personal communication, 2009). The speed at which information travels in industry circles cannot be underestimated. Just as bad news travels fast, as this dealer learned, news about how to beat the system travels fast as well. An accountant who represents many car dealers was in DOR offices on another matter and mentioned to one of the investigators that the "yellow envelopes," (the mailed interventions), were now famous with local used car dealers and his clients were dreading receiving one. There are significant indications that the subjective social norms in the theory of planned behavior

\footnotetext{
${ }^{25}$ The owner was subsequently convicted on the strength of the evidence obtained in the final search warrant and sentenced to four years in prison.
} 
are at work with respect to tax enforcement in this project and that these norms are coloring individual attitudes toward compliance.

There was a distinct tendency for dealers to let deadlines slip. For example, a dealer would call and request an additional 60 days to complete their analysis because records had to be retrieved from storage. If a follow up call was not initiated at the end of the 60 days, the dealer generally would not contact the Department once the additional time granted had expired. In several cases the author waited for several weeks after the deadline passed to see if the dealer would call and they did not. They appeared to be testing their limits in their interaction with the state. Continuous and consistent follow up is critical.

So why do people steal sales tax dollars? Sales tax theft can be explained within the expanded theory of planned behavior framework presented in this study and evaders can be categorized within the evader typology set forth herein. It was noted in this study that dealers who failed to remit sales tax dollars had a need for the funds, a framework component supplied by Cressey's fraud triangle. The need was not necessarily one where the company was faced with bankruptcy absent embezzlement of the tax funds, for most of these dealers drove expensive cars, wore nice clothes and jewelry, operated wellmaintained business locations, and paid for extensive help at the car lots even though they reported few, if any, employees. Their need was for the funds required to support the lifestyle to which they had become accustomed or to which they aspired.

Information sharing between dealers with respect to this project was witnessed, as discussed above, during this project and was confirmed in interviews with DOR personnel and analysis of other DOR cases that provide evidence of the information 
sharing that occurs among industry peers specifically and taxpayers in general. This information sharing is sophisticated enough that it has become a learning system where taxpayer activities adjust constantly to enforcement efforts. Members of the investigations unit noted that as they execute search warrants on, for example, convenience store locations, which have historically low rates of compliance, and complete criminal cases against stores based on certain types of evidence, they find that the nature and quality of evidence obtained in subsequent search warrants tends to deteriorate. Several years ago an investigator could prepare a case covering several years with documentation obtained through the execution of a search warrant on a convenience store. Currently, it is difficult to get more than a month's worth of data on site because owners have learned to remove the documentation from the store premises as soon as it is no longer required there for business operations. The response was not one of becoming more compliant, but one of destroying the evidence of noncompliance. These situations constitute substantial evidence of the existence of social norms that support tax evasion and tax theft activities. They are also examples of Proficient Evaders who adjust and adapt as enforcement efforts progress, but never choose compliance as a response option.

Based on this study I conclude that businesses collecting sales tax perceive they have a high level of behavioral control with respect to the decision to retain the sales tax. They do not believe they will be caught and a shockingly high percentage of businesses make the decision to retain taxpayer funds for their personal use. Even when they are caught through audit activities many have learned that they can ignore the assessment and avoid consequences fairly easily. Few of them actually own the property from which their business is run, so a tax lien matters little. 
The final component of the theory of planned behavior as it relates to sales tax theft is the business owner's attitude toward sales tax theft. From interaction with business owners during this study the author has developed the distinct impression that most do not view their failure to remit the full amount of sales tax collected as theft of state funds. Social norms help to explain this attitude. If the circles to which business owners belong treat sales tax theft as just another governmental fee to be avoided; and if, in fact, the circles to which they belong embrace avoidance of remitting sales taxes collected and proactively share strategies that enable the businessman to avoid paying the sales tax even when assessed; then the stigma of theft does not attach to the activity. From this grows an attitude that sales tax theft is acceptable, commonplace, and not immoral.

Just as the theory of planned behavior assists in understanding sales tax theft, it can also provide the key for improved enforcement. Enforcement efforts must be brought to bear simultaneously against the business owner's perception of behavioral control and the social norms that feed the attitude that sales tax theft is acceptable. This is most readily achieved through the use of targeted industry enforcement activities informed by strategic intelligence and data analysis that result in continuous and consistent engagement with the businesses collecting taxes as an agent of the state.

It is important to make it clear that this approach is not merely better targeting of the deterrence model to evasion, but an attempt to use engagement to educate taxpayers, change attitudes, and ensure continued compliance in the future. It may appear that this study is primarily focused on increasing compliance by targeting enforcement in such a way as to preclude the assumption of behavioral control on the part of a potential evader. 
While that is certainly a major thrust of the approach, the intended impact of engagement on attitudes and subjective norms is equally as important, but more difficult to illustrate in a time-limited study. Such impacts can only be measured over time and, indeed, require much time to take effect. A single encounter with a tax enforcement agent, no matter how "pleasant" the agent attempts to make it, has little chance of completely negating the repeated government bashing and tax hate that grips a substantial portion of the population and is reinforced by some politicians. However, it is my belief that such encounters do make a difference. All of the subjects in this study and the attorneys some of them engaged indicated repeated and sometimes emotional gratitude for the professional manner in which they were treated and for the reasonableness of the approach. Most of them understood that the first encounter could have been much more confrontational, accusatory, and might have included the drafting of a probable cause affidavit for their arrest with only a single opportunity to consent to an interview, which their attorney's would have advised against anyway. All too often the first approach in enforcement is a severe one, as dictated by the still influential but often misinterpreted deterrence model, involving assessments, penalties, and fees equal to several times the amount of the tax not remitted, and sometimes being charged with a felony tax crime before any real effort is made to resolve the deficiencies. While the impact of this approach on attitudes and social norms cannot be specifically illustrated using only evidence from this study and statistical analysis, the author's interactions with these individuals provides an indication that the approach does indeed have an impact. Over time it will be possible to measure this impact if the approach is adopted more universally. 


\section{CHAPTER 10}

\section{MAKING ENFORCEMENT WORK}

The state of the compliance enforcement environment is not always as clear as it may seem. Florida reports voluntary sales tax compliance rates based solely on delinquent returns, late remittances, and audit assessments and these reported voluntary compliance rates are generally around 98 percent (Florida Department of Revenue, 2007). Other states, Washington for example (Washington Department of Revenue, 2008), follow this procedure as well. Due (1975) estimated the sales tax gap at five percent of actual collections. My study indicates these reported and estimated rates bear little resemblance to reality. There is an enormous gap in the enforcement tools currently in use that exists between the collection of delinquent taxes on one end of the spectrum and audit and investigation activities on the other. The ability to fill this gap rests on the realization that more collection efforts, more audits, and more investigations are not the answer, although more of all three are indeed needed. Filling the gap requires a new type of enforcement methodology focused on managing the principal-agent relationship between the state and the businesses that collect sales tax on behalf of the state. It is not sufficient to wait until a business is late filing a return to develop an enforcement-related relationship with that business. That business must understand that they are an agent of the state, collecting funds that become the property of the state at the moment of collection, and that representatives of the state are there to manage that agency relationship and protect the state's interest in those funds. In the present study that function was portrayed as "interventions" on the part of the state with respect to businesses identified that had collected and failed to remit sales taxes collected from their 
customers. In this case "interventions" is probably an appropriate term to use because the businesses identified had been involved in sales tax theft for five years or more. Moving forward, I think it is more appropriate to describe this relationship as one of "engagement" rather than "intervention." Engagement is possible as long as enforcement operations are proactive, as the author believes they must be.

This new enforcement methodology is based on current activities known as lead development and discovery operations. Lead development is how companies are identified for audit, the specifics of which are not well publicized, but involves analysis of data and available information to identify anomalies in reporting habits of businesses. Discovery operations are similar but are much more targeted. An industry or other grouping of businesses is targeted for enforcement operations based on evidence of noncompliance. The discovery operation is sometimes referred to as a "campaign." The targeted industry enforcement program described in Chapter 8 is similar to a discovery operation based on leads generated from a lead development program. This specialized type of discovery operation is precisely the type of enforcement operation that needs to be made a permanent part of local enforcement activities, operating constantly rather than only when a new "campaign" is deemed necessary. The targeted industry enforcement program described in Chapter 8 is the first stage of such an operation. Moving forward, it would involve constant monitoring of the industry and identification of new leads. As new leads are identified, new waves of "interventions" would be rolled out. As the industry becomes more compliant because of consistent and timely monitoring, the focus would shift to engagement, with noncompliant activities quickly identified and corrections initiated before the business finds itself mired in felonious activities far too 
deeply to be easily extracted. A relatively common comment heard from dealers during the targeted enforcement portion of this study was that they wish the discrepancies had been identified earlier instead of the problem being compounded over five years. It is far easier for a dealer to become compliant again if they are faced with unremitted taxes for three months totaling $\$ 6,000$ rather than unremitted taxes for 60 months totaling $\$ 120,000$. In ten cases the owners of the businesses were not actively involved in the day-to-day operations of the business but had a business manager or partner who handled daily activities, a not uncommon situation in business. These owners (Negligent Evaders) were shocked to learn that hundreds of thousands of dollars of sales taxes had not been remitted by their businesses. State enforcement operations could have actually provided these owners a benefit by identifying the theft earlier. Granted it is not the state's responsibility to do this, and there is no doubt that some of these absentee owners understood that sales tax theft was occurring, but from the state's standpoint, it is much harder to collect unremitted taxes that have gone unnoticed for five years. You can punish the owners at that point, but the liability has grown too large for the owners to readily repay. It is better for the owner and the state to not allow the liability to reach that level.

It may appear that this study advocates an enforcement approach that is tantamount to auditing everyone. The point was made that there are nearly 1 million businesses in Florida. How can you "engage" with all of them? Of course, you cannot. That is where intuition and strategic lead development come to bear as was indicated in Chapter 7. This study was designed to show that the solution is not as resource intensive or expensive as it might intuitively appear to be. It has taken many months to mount and 
administer the targeted enforcement project that is the subject of this study, but that is a result of having only one individual assigned to the project, part time. Additionally, because the project covered a five-year period and records are only required by law to be retained for three years, it has taken the dealers longer to analyze and reconcile their records. If such a program were instituted where an individual in each region were assigned full time to the used car dealer industry, for example, the results of this study suggest that the industry could be analyzed and brought into compliance within two years. Going forward, updating comparison data and maintaining contacts with the dealers would require less time. An additional component of this plan would be unannounced records inspections at the dealers similar to those already carried out by inspectors from DHSMV. In fact, the revenue inspections could be carried out in conjunction with those of the DHSMV.

Used auto dealers represent a fairly easy industry in which to enforce compliance. Third-party data are available for comparison and the businesses in the industry are selling fewer items at higher prices making the analysis easier to perform. Compliance has not been enforced to the extent it should only because the resources required have not been provided. The comparison of sales tax reported on title applications to DHSMV to sales tax reported to DOR should be an automated process that immediately flags problems for follow up before five years pass and dealers manage to retain $\$ 20$ million in state funds for their own use, and that from just one county. That a system has not been put in place to automate this process is probably an indication of the difficulties in obtaining approval and financing of interagency projects. The ease of identifying potential sales tax theft in this industry, by comparing information supplied to two 
separate state agencies by the subject company, is the factor that made this industry ideal for this type of project. In effect, the companies indicted themselves by supplying conflicting information regarding the same sale to two different agencies of the state. But how will such an investigative structure work in other industries?

Each industry has unique characteristics that can be used to define a fraud signature. To implement a similar compliance enforcement project in other industries, data from various sources is utilized to create the fraud signature for that industry. Data specific to individual companies can be compared to this fraud signature to identify potential targets for enforcement operations. Again, this is not unlike current lead development activities, but involves an expansion of data sources and devolution to the local level.

Simultaneous to carrying out the auto dealer project, Southern Region Investigations began developing a database for identifying fraud in another industry in Miami-Dade County that has long been known to be largely noncompliant. The industry will not be identified herein because the project is ongoing. Data were accumulated from SUNTAX and a variety of public and private databases to create a profile for every entity within this industry within Miami-Dade County. Without disclosing the details of the analysis, the data can be analyzed to, for example, look for companies reporting revenues too low to support the rent applicable to the location or companies reporting exempt sales that are out of line with standards. The database is designed to allow analysis of many factors that might indicate fraud and the assignment of relative weights to each factor to arrive at a score that functions as a fraud indicator. Using this data, 142 preliminary targets have been identified with high fraud signatures representing an estimated $\$ 17$ 
million in sales tax evasion solely from Miami-Dade County, and the database is only half complete.

The factors involved will vary industry-by-industry, but factors can be developed for every industry where sales tax theft or fraud is known to be significant. One or more individuals at the local Service Center level should be allocated to each targeted industry. While a core group of individuals could be tasked with the projects across industry lines, the author believes there is much to be gained by allowing those who perform these types of tasks to specialize by industry because the interpretation of the data is enhanced by familiarity with the industry and its standards.

From the standpoint of cost, this type of enforcement activity is low cost, high return investment. Using the used auto industry that is the subject of this study and the additional target industry mentioned above for example, the author estimates a minimum requirement of two dedicated employees allocated to each industry at a fully-loaded cost of $\$ 70,713$ each (salary, benefits, taxes, specialized database access, travel expenses, and annual training costs). This $\$ 282,850$ investment has the potential to return more than $\$ 53$ million dollars in the year of inception and safeguard $\$ 10.6$ million per year thereafter in direct impact. The recovery per hour invested is $\$ 6,395$ per hour in the initial year and $\$ 1,279$ per hour thereafter, which is a higher return than either audit or criminal investigation activities. The indirect impact of highly visible enforcement activities would augment this return. Such high returns are possible because the projects move the burden of proving compliance to the dealer by requiring the dealer to justify reporting that is out of range or not supported by known facts. The targeted enforcement structure set forth in the present study effectively closes the large enforcement gap that 
exists between collections activities and audit/investigations activities in a very costeffective manner. More importantly, this type of activity maintains enforcement contact between DOR and businesses that exhibit fraud indicators. Continuous contact attracts notice and makes it appear that the risks of being caught stealing sales tax are higher than they actually are. That continuous contact works can be seen by looking at another example from the used car industry. As noted, the potential sales tax theft by the used car dealers was identified by comparing sales tax collections reported on title applications filed with DHSMV to monthly reporting to DOR. As noted, smarter thieves tend to make sure they file the same amounts with both state agencies, but why do some dealers file accurate information with DHSMV but are comfortable underreporting to DOR? The answer involves continuous contact. Filing a false title application is a third-degree felony and can easily lead to loss of the dealer's license to sell cars. Most dealers are very sensitive to this possibility and those who steal sales tax will generally file accurate title applications even though they have no intention of remitting all the sales taxes collected. Dealers understand that at least once per year inspectors from DHSMV will perform a site inspection which will include review of randomly selected contracts for compliance. If an inspector finds a fraudulently prepared title application, the dealer understands that the loss of his or her license and livelihood is the likely outcome. The probability of getting caught falsifying a title application is much greater than getting caught underreporting sales tax. That must change. The ingredients for change have been provided in this paper.

Chapter 7 provides evidence that intuition based on good data can be used to identify fraud indicators within an industry. DOR certainly has access to sufficient data 
to enable this process for any and every industry in the state. Since the process more than pays for itself, there is little reason not to supply the resources and adopt the approach.

Chapter 8 provides a blueprint for initiating a targeted industry enforcement program within a given industry. Time must be provided at the inception of the project to properly analyze the industry and identify the initial group of companies for which contact is required. It is important to adopt an approach that requires the business to provide documentation and/or justifications in response to DOR generated concerns. Auditing or investigation requires DOR employees to do the time-consuming work. Responses to intervention-type inquiries require the business to do the time-consuming work required to respond if they have not properly maintained their support for the returns filed. It is important to understand that in all cases, the DOR representative will be asking for documentation that is already required by law to exist. Some businesses will have to put this documentation together after the fact because that is the way they customarily operate. Some file returns with little organized support for the numbers they write on the returns. For those that do get their documentation in order before filing, the DOR inquiry will cause them little additional work. Those businesses that do not prepare the documentation before filing will begin to do so after they learn that DOR does indeed monitor their reporting and expects the law regarding maintenance of books and records to support tax filings to be followed. For example, in the targeted industry enforcement project in this study, some of the targeted companies contacted were able to explain the differences between what they reported as sales tax collected to DHSMV and what they reported to DOR by repossession credits. Those companies where repossession credits explained the entire difference would not have been on the intervention list had they 
reported their repossession credits properly. Further, the law requires they maintain proper documentation related to repossessions along with a detailed calculation of the amount of the credit allowed with respect to each instance. Repossession documentation is supposed to be available whenever requested by a DOR agent. While these companies were cleared of suspicion and further action was not necessary, the contact provided the opportunity to educate the taxpayer on the proper way to report the repossession credits and the proper documentation to keep on hand supporting the credit claimed. This educational aspect was an important additional benefit of the contact.

The targeted industry enforcement program should be the primary strategic compliance enforcement tool utilized. Currently, audits are more strategic than random, but the random component will need to be increased to identify Proficient Evaders who have learned to elude strategic analysis based on fraud indicators.

The present study has concentrated on state sales tax only, but it is important to mention that this study helped identify other violations as well. During the collection of data for the survey the following additional leads were developed:

- Of the dealer locations that were rented, the landlords for 123 of the locations were found to be unregistered for commercial rental activities, representing an estimated $\$ 626,399$ in monthly rental proceeds and $\$ 43,848$ in additional monthly sales tax due to the state;

- Nineteen of the dealers were not registered for corporate income tax;

- 185 dealers were not registered for unemployment tax; and

- 62 dealers who internally financed the sale of used cars were not registered for the documentary stamp tax. 
Targeted enforcement efforts should be holistic and not be directed at a single tax. The goal is to increase compliance with respect to every tax for which a business is obligated. The identification of the unregistered commercial properties mentioned above provides an example of how targeted enforcement programs can identify leads outside of the targeted group.

Targeted enforcement projects will indentify some businesses where a full audit or full criminal investigation will be required. In order to make the process work effectively, audit and criminal investigations management must be prepared to allow audits and criminal investigations to be assigned directly from the targeted enforcement process rather than going through a centralized lead development and assignment process. Alternatively, the centralized process can be utilized, but cases identified through the targeted enforcement process must be given priority. In Florida, the ability to immediately respond with a criminal investigation already exists since that process is decentralized, but the audit process is not. Speed in response is critical.

It is also critical that those responsible for enforcement in any capacity be mindful of the benefits of task force type approaches to enforcement as analyzed in Chapter 6 . The present study has dealt solely with task force utilization in the context of criminal investigations, but it is possible to utilize this structure in civil compliance enforcement efforts as well. In Florida, there are a number of other agencies that are involved with regulation of businesses that have interests that are complementary to those of DOR, such as the Division of Corporations, the Division of Alcoholic Beverages and Tobacco, numerous subunits of the Department of Professional Regulation, and, of course, the Internal Revenue Service at the federal level. Further, Florida Statutes Section 212.19 
requires that other agencies provide any information required by DOR and needed in the enforcement of revenue laws, and Florida Statutes Section 213.053 has sufficient exceptions to the confidentiality rules to allow DOR to advise many other state regulatory agencies of noncompliant status. While it is easier to envision task force operations in a criminal investigation scenario, it is nevertheless possible to utilize this technique in civil enforcement. For example, a business that refuses to comply with Florida tax laws should not be able to register as a corporation in Florida or obtain a needed business license from the Department of Professional Regulation, or be licensed as a Lotto retailer, or be able to accept Electronic Benefit Payments (food stamps); yet noncompliant businesses are allowed to do all of those things because coordination is lacking. A task force approach to noncompliant taxpayers would make it easier to have all relevant licenses revoked unless and until the company comes into compliance with all state agencies.

The legislature has a crucial role as well. There needs to be recognition that unenforceable laws and laws that simply are not enforced as they should be affect social norms regarding sales tax compliance and help to spread a culture of noncompliance. It is understandable that legislatures have a desire to make their revenue departments more "taxpayer friendly," but elected representatives must understand that the businesses collecting sales taxes are not the taxpayer. If businesses fail to remit sales taxes collected they are stealing from the actual taxpayers the legislators were elected to protect. They are defrauding the citizens of the state by using the guise of sales tax collection to enhance their own profitability. Citizens expect their tax dollars to be used by the state to provide services, not to be redirected to the personal use of the owners of the business 
that collects the tax. If legislators truly want to be "taxpayer friendly," they will provide DOR with the tools required to enforce compliance by business agents of the state.

In summary, the tasks performed by collections personnel, auditors, and criminal investigators are critical to the mission of a revenue agency, but there remains a gap in the enforcement coverage that allows unacceptably large amounts of sales tax theft to escape detection. This gap can be effectively and efficiently bridged through the use of sustained targeted industry enforcement strategies that result in continuous engagement between revenue agency employees and the business agents who collect sales tax for the state. 


\section{CHAPTER 11}

\section{CONCLUSION AND DIRECTIONS FOR FUTURE RESEARCH}

Tax evasion has been the subject of much study over the last four decades. Since Allingham and Sandmo (1972) proposed the application of a rational choice approach to evasion many other researchers have proposed dozens of drivers of tax evasion utilizing multiple decision, choice, and behavioral theories in an attempt to explain evasion and isolate the ultimate trigger which could lead to the perfect antidote. In the midst of this struggle it appears that most researchers, other than Watrin and Ullmann (2008), assumed tax evasion was one-size-fits-all and that the solution for one type of evasion would fit other types of evasion equally well. In fact, it appears that most researchers labored under the mistaken belief that evasion does not exist with respect to consumption taxes (Watrin \& Ullmann, 2008). The present study has the distinction of firmly and completely segregating the study of sales tax evasion and theft from the study of income tax evasion and leaves little room for doubt that sales tax theft or evasion not only exists, but is a much larger problem than revenue agencies will publicly admit. It is the author's hope that this study will stimulate the same level of interest in studying sales tax theft that has existed with respect to income tax evasion. In 2008 the 45 states who administer a sales tax collected more than $\$ 240$ billion in sales tax, representing almost 31 percent of total state tax revenue (U. S. Census Bureau, 2008). The levels of sales tax theft suggested in this study combined with these figures make it clear that sales tax theft is a topic worthy of additional targeted research, particularly by state finance scholars and practitioners who have access to real time data. This study has been limited to the State of Florida but other state's approaches to enforcement are worthy of study. Additionally, 
a wealth of potential information is available from comparative studies that could be conducted. The author does not believe that Florida is unique in the enforcement problems it faces primarily because the belief that consumption taxes are evasion free is so widespread. The author particularly recommends much more quasi-experimental research, which would likely require partnerships between practitioners and academicians to maximize data access. It is critical that researchers move beyond the belief that delinquencies and audit assessments are the universe of noncompliant activity in a sales tax structure.

There are those who advocate a national retail sales tax to replace all other taxes at the federal level. Some of those advocates attempt to "sell" the idea by playing to populist anger and frustration with the income tax system generally and the Internal Revenue Service (IRS) specifically. They argue that the IRS would no longer be necessary in a sales tax regime. The author believes such arguments are disingenuous at best. As discussed previously and illustrated with data, the income tax has significant built-in protections against evasion that the sales tax does not. It is the author's opinion that a national sales tax with no enforcement body and a very high tax rate would simply be disastrous. This study has illustrated why that is the case. At best, existing IRS employees could be moved to the state level to bolster existing state tax agencies, but enforcement would still be required, likely at much higher levels. But even then, unless the enforcement paradigm is changed as indicated in this study, the result would be far more evasion and theft than is currently present with an income tax. What is surprising is that with 45 sales tax systems in existence in this country, no one advocating a national sales tax has bothered to study sales tax theft and evasion at the level necessary to support 
some of the critical assumptions inherent in such a massive tax policy shift at the federal level.

The opportunity to study sales tax theft in the field is an incredible opportunity that the author is grateful to have had. It does, however, have its limitations. Since this study involves interaction with individuals potentially facing harsh consequences and punishment it was not possible to manipulate interventions and provide alternative treatments to different groups within the study as could have been done with an experimental design. It was critical that DOR policy be followed throughout the study and that all businesses and individuals that came under scrutiny were treated similarly and fairly throughout. As a result, this study was a bit less quantitative and experimental than the author would have preferred. But the advantages of studying actual processes in the field and the access to live data far outweighed the limitations. Access to data has been a perennial problem for tax evasion researchers because of confidentiality issues and the same holds true with respect to the retail sales tax. It is difficult to acquire data that has not been summarized to the point of being useless as was noted by Alm (1991). In fact, with respect to the sales tax, the data available to the taxing authority is already summarized to the point of being useless. A state sales tax return in Florida has a single line of data reporting gross sales, exempt sales, taxable sales and sales tax collected. For this reason, even if raw sales tax data cleansed of personal and corporate identifiers were provided to researchers, it would be virtually useless because it can only be evaluated when it can be matched and compared to other data that is not available on the tax return and therefore not available under any circumstances once the identifiers required for matching are removed. This was the advantage obtained in this study and is 
the advantage of any researcher who can study from within the agency: they can match the data to outside data sources and bring observation and interaction to bear.

Additional research is needed to identify innovative approaches to enforcement adopted by other states. For example, Maryland, Massachusetts, and New York are all advanced users of data accumulated from a large number of databases in the development of enforcement leads, and Georgia has begun cross-checking sales tax filings with information obtained from outside databases. Comparative research into varying approaches to intelligence generation is of great interest to the author who believes there is much to be learned from such studies.

And finally, the author hopes that states will make a stronger effort to identify the true tax gaps that exist with respect to the sales tax. It is easier to measure, and certainly more politically expedient, to use delinquency and audit data as a measure of voluntary compliance, but as this study has shown, such estimates are a poor indicator of the true tax gap and tend to lead researchers and lawmakers to incorrect conclusions regarding compliance. It will be difficult to convince legislatures to devote more resources to enforcement efforts unless the true cost of sales tax evasion and theft is identified and reported. 


\section{LIST OF REFERENCES}

Ajzen, I. (1988). Attitudes, personality, and behavior. Chicago: Dorsey Press.

Ajzen, I. (1985). From intentions to actions: A theory of planned behavior. In I. J. (Eds.), Action-control: From cognition to behavior (pp. 11-39). Berlin: Springer-Verlag.

Ajzen, I. (1991). The theory of planned behavior. Organizational Behavior and Human Decision Processes , 179-211.

Ajzen, I., \& Fishbein, M. (1980). Understanding attitudes and predicting social behavior. Englewood Cliffs, NJ: Prentiss Hall.

Albrecht, S., \& Wernz, G. (1993). The three factors of fraud. Security Management, 9597.

Allingham, M., \& Sandmo, A. (1972). Income tax evasion: A Theoretical Analysis. Journal of Public Economics , 323-338.

Alm, J. (1991). A perspective on the experimental analysis of taxpayer reporting. The Accounting Review , 577-593.

Alm, J. (1999). Tax evasion. In J. Cordes, R. Ebel, \& J. Gravelle, The encyclopedia of tax evasion and tax policy (pp. 1-6). Washington: Urban Institute.

American Institute of Certified Public Accountants. (2002, October). Statement of Auditing Standards 99: Consideration of fraud in a financial statement audit.

American Society for Quality Research Committee (2003, September 27). State of Florida Department of Revenue Case Study. Retrieved January 19, 2010, from American Society for Quality: http://www.goalqpc.com/Media/asq/Florida\%20DOR\%20Case\%20Study.doc

Americans for Fair Taxation. (2010, February 14). About the Fairtax. Retrieved February 14, 2010, from Americans for Fair Taxation:

http://www.fairtax.org/site/PageServer?pagename=about_main

Anonymous. (2006, October 23). Personal Communication.

Anonymous. (2009, October 9). Personal communication.

Antonides, G., \& J., R. H. (1995). True positives and false alarms in the detection of tax evasion. The Journal of Economic Psychology, 617-640. 
Association of Certified Fraud Examiners. (2009). 2009 Fraud Examiners Manual. Austin: Association of Certified Fraud Examiners.

Becker, G. (1968). Crime and punishment: An economic approach. Journal of Public Economy, 169-217.

Ben-Akiva, M., McFadden, D., Garling, T., Gopinath, D., Walker, J., Bolduc, D., et al. (1999). Extended framework for modeling choice behavior. Marketing Letters , 187-203.

Blanthorne, C. M. (2000). The role of opportunity and beliefs on tax evasion: A structural equation analysis. Ph.D. dissertation Publication No. AAT 9976301 . Arizona, United States: Arizona State University.

Bobek, D., \& Hatfield, R. (2003). An investigation of the theory of planned behavior and the role of moral obligation in tax compliance. Behavioral Research in Accounting , 1338.

Bohren, O. (1998). The agent's ethics in the principal-agent model. Journal of Business Ethics , 745-755.

Carnes, G. A., \& Englebrecht, T. D. (1995). An investigation of the effect of detection risk perceptions, penalty sanctions and income visibility on tax compliance. Journal of the American Taxation Association, 26-41.

Casey, J., \& Scholtz, J. (1991). Beyond deterrence: Behavioral decision theory and tax compliance. Law and Society review, 821-843.

Chang, O., \& Schultz, J. J. (1990). The income tax withholding phenomenon: Evidence from TCMP data. Journal of the American Taxation Association, 88-93.

Chang, O., Nichols, D. R., \& Schultz, J. J. (1987). Taxpayer attitudes towards audit risk. Journal of Economic Psychology, 299-309.

Chen, A. (2005, May 23). CRM Pays Off for Florida DOR. Retrieved May 9, 2005, from eWeek.com: http://www.eweek.com/c/a/Enterprise-Applications/CRM-Pays-Off-forFlorida-DOR/

Christian, P., \& Frank, H. (2006). An empirical analysis of the impact of business environment on the incidence of tax evasion. Southeastern Conference for Public Administration. Athens, Georgia.

Collins, J. H., \& Plumlee, R. D. (1991). The taxpayer's labor and reporting decision: The effect of audit schemes. The Accounting Review, 559-576. 
Commiskey, W. J. (2010). Taking aim at tax professionals who coach their clients to cheat. Washington, D. C.: Tax Analysts.

Cressey, D. (1953). Other people's money: A study in the social psychology of embezzlement. Glencoe, Ill: Free Press Press.

Cummings, R., Martinez-Vazquez, J., McKee, M., \& Torgler, B. (2004). Effects of culture on tax compliance: A cross check of experimental and survey evidence. Working Paper 2004-13. Basel, Switzerland: Center for Research in Economics, Management, and the Arts.

DeFatta, R. (2005). The blame game and how to play it. Security Management, 89-91.

Droege, S., \& Spiller, S. (2009). Critique of a premise: Illuminating the cracks in the agency theory framework. Journal of Legal, Ethical and Regulatory Issues , 41-54.

Dubin, J. (2007). Criminal investigation enforcement activities and taxpayer noncompliance. Public Finance Review , 500-535.

Due, J. F. (1975). Evaluation of the effectiveness of state sales tax administration. National Tax Journal , 197-219.

Erard, B. (1993). Taxation with representation: An analysis of the role of tax practitioners in tax compliance. Journal of Public Economics , 163-197.

Fishbein, M., \& Ajzen, I. (1975). Belief, attitude, intention, and behavior: An introduction to theory and research. Reading, MA: Addison-Wesley Publication Company.

Flora v. United States, 362 U.S. 145 (Supreme Court 1960).

Florida Department of Revenue. (2007, June 30). annual_report0607.pdf. Retrieved August 1, 2009, from Florida Department of Revenue:

http://dor.myflorida.com/dor/report/2006_2007/pdf/annual_report0607.pdf

Florida Department of Revenue Criminal Investigations Case Management System. (2009, December 21). Criminal Prosecution Cases - Ad Hoc Reporting. Miami, Florida, Miami-Dade County.

Florida Department of Revenue. (2010, February 21). GTA Home Page. Retrieved February 21, 2010, from Department of Revenue Intranet Site: https://mydorweb.state.fl.us/gta/ 
Florida Department of Revenue. (2008). Receiveable Management Goals and Strategies. Retrieved July 15, 2009, from DORWEB - Department of Revenue Intranet: http://dorweb/gta/rec_mgmt/docs/goals_strats.xls

Florida Department of Revenue. (2010). Tax collections from July 2003. Retrieved February 20, 2010, from Florida Department of Revenue:

http://dor.myflorida.com/dor/taxes/colls_from_7_2003.html

Garner, C. A. (2005). Consumption taxes: Macroeconomic effects and policy issues.

Economic Review - Federal Reserve Bank of Kansas City, 90 (2), 5-29.

General Tax Administration. (2008). Performance and expectations. Tallahassee, Florida: Florida Department of Revenue.

Gladwell, M. (2005). Blink: The Power of Thinking Without Thinking. New York: Little, Brown and Company.

Gneezy, U., \& Rustichini, A. (2000). Pay enough or don't pay at all. The Quarterly Journal of Economics , 791-810.

Hyun, J. (2006). Tax compliance in Korea and Japan: Why are they so different? Journal of the Korean Economy, 135-153.

Internal Revenue Service. (2010, January 4). IRS proposes new registration, testing, and continuing education requirements for tax return preparers not already subject to oversight. Retrieved January 6, 2010, from Internal Revenue Service:

http://www.irs.gov/newsroom/article/0,,id=217781,00.html

Internal Revenue Service. (2006, February 14). IRS Updates Tax Gap Estimates. Retrieved April 12, 2008, from Internal Revenue Service: http://www.irs.gov/newsroom/article/0,,id=154496,00.html

Internal Revenue Service. (2007). SOI Tax Stats - Individual Income Tax Returns. Retrieved December 5, 2009, from Internal Revenue Service: http://www.irs.gov/taxstats/indtaxstats/article/0,id=133414,00.html

Jones, B. D. (2003). Bounded rationality and political science: Lessons from public administration and public policy. Journal of Public Administration Research and Theory, $395-412$.

King, S., \& Sheffrin, S. M. (2002). Tax evasion and equity theory: An investigative approach. International Tax and Public Finance, 505-521. 
Kinsey, K. A., Grasmick, H. G., \& Smith, K. W. (1991). Framing Justice: Taxpayer evaluations of personal tax burdens. Law and Society Review , 845-873.

Klepper, S., Mazur, M., \& Nagin, D. (1991). Expert intermediaries and legal compliance: The case of tax preparers. Journal of Law and Economics , 205-229.

Korobow, A., Johnson, C., \& Axtell, R. (2007). An agent-based model of tax compliance with social networks. National Tax Journal , 589-610.

Long, S., \& Swinjen, J. (1991). The conduct of tax evasion experiments: Validation, analytic methods, and experimental realism. In P. Webley, H. Robben, H. Elifers, D. Hessing, \& (Eds.), Tax evasion: An experimental approach. (pp. 128-138). New York: Cambridge University Press.

Madeo, S. A., Schepanski, A., \& Uecker, W. C. (1987). Modeling Judgments of Taxpayer Compliance. The Accounting Review, 323-342.

Martinez-Vazquez, J., Harwood, G., \& Larkins, E. (1992). Withholding position and income tax compliance: Some experimental evidence. Public Finance Quarterly, $152-$ 206.

McGee, R. (2006). Three views on the ethics of tax evasion. Journal of Business Ethics, $15-35$.

McNeal, A. (2009). What's your fraud IQ? Journal of Accountancy, 52-55.

Mikesell, J. L. (1997). The American retail sales tax: Considerations on their structure, operations, and potential as a foundation for a federal sales tax. National Tax Journal, 149-165.

Mikesell, J. L., \& Birskyte, L. (2006). Lessons of tax compliance research for lawmakers and tax administrators: Getting best returns from limited resources. In H. Frank, Public Financial Management (pp. 207-236). Boca Raton, FL: CRC Press.

Miller, G., \& Whitford, A. (2006). The principal's moral hazard: Constraints on the use of incentives in hierarchy. Journal of Public Administration Research and Theory, 213-233.

Murdock, H. (2008). The three dimensions of fraud. Internal Auditor, 81-83.

Neuman, L. W. (2003). Basics of social research: Qualiitative and quantitative approaches. Boston: Pearson Education, Inc. 
Nwogugu, M. (2005). Towards multi-factor models of decision making and risk: A critique of prospect theory and related approaches. The Journal of Risk Finance, 150162.

Palmer, J. (1977). Economic analyses of the deterrent effect of punishment: A review. Journal of Research in Crime and Delinquency, 4-21.

Ramamoorti, S. (2007). Fraud, the human factor. Financial Executive, 53-55.

Reckers, P. M., Sanders, D. L., \& Roark, S. J. (1994). The influence of ethical attitudes on taxpayer compliance. National Tax Journal , 825-836.

Robben, H. S., Webley, P., Weigel, R. H., Warneryd, K. E., Kinsey, K. A., Hessing, D. J., et al. (1990). Decision framing and opportunity as determinants of tax cheating. Journal of Economic Psychology, 341-364.

Sacchetti, M. (2005). SRC Insights. Retrieved September 7, 2006, from Federal Reserve Bank of Philadelphia: http://www.phil.frb.org/bank-resources/publications/src-insights/

Sheffrin, S., \& Triest, R. (1992). Can brute deterrence backfire? Perceptions and attitudes in taxpayer compliaince. In J. e. Slemrod, Why people pay taxes: Tax compliance and enforcement. Ann Arbor: University of Michigan Press.

Skinner, B. F. (1953). Science and Human Behavior. New York: The Free Press.

Smith, K. W., \& Kinsey, K. A. (1987). Understanding taxpaying behavior: A conceptual framework with implications for research. Law and Society Review , 639-663.

State of California Franchise Tax Board. (2007). Tax Gap News. Retrieved April 12, 2008, from California Franchise Tax Board:

http://www.ftb.ca.gov/amnesty/taxgap/index.shtml

Tait, A. A. (1988). Value Added Tax: International Practices and Problems. Washington, D.C.: International Monetary Fund.

Tanzi, V., \& Shome, P. (1993). A primer on tax evasion. New York: International Monetary Fund, IMF Staff Papers.

Thibalt, J., Fredland, N., \& Walker, L. (1974). Compliance with the rules: Some social determinants. Journal of Personality and Social Psychology, 792-801.

Torgler, B., \& Murphey, K. (2004). Tax morale in Australia. What shapes it and has it changed over time? Working Paper 2004-04. Basel, Switzerland: Center for Research in Economics, Management, and the Arts. 
Trochim, W. M. (2006, October 20). Internal Validity. Retrieved January 16, 2010, from The Research Methods Knowledge Base:

http://www.socialresearchmethods.net/kb/intval.php

U. S. Census Bureau. (2008). 2008 Annual Survey of State Government Finances.

Retrieved January 1, 2010, from U. S. Census Bureau: http://www.census.gov/govs/state/

Varma, K. N., \& Doob, A. N. (1998). Deterring economic crimes: The case of tax

evasion. Canadian Journal of Criminology, 165-184.

Washington Department of Revenue. (2008). Department of Revenue Compliance Study. Olympia, WA: Washington Department of Revenue.

Watrin, C., \& Ullmann, R. (2008). Comparing direct and indirect taxation: The influence of framing on tax compliance. The European Journal of Comparative Economics, 3356.

Weeks, D. F. (2005). Enterprise-wide performance and business process management: Learn what the Florida Department of Revenue, a large organization in the fourth most populous state, has been doing to generate business results that exceed private-sector expectations. The Public Manager, 3.

Wells, J. T. (2005). Principles of fraud examination. Hoboken, NJ: John Wiley \& Sons, Inc.

Wolfe, D., \& Hermanson, D. (2004). The fraud diamond: Considering the four elements of fraud. The CPA Journal, 38-42. 
APPENDICES 
Appendix 1 - Analysis of Income and Deduction Items on the Federal Individual Income Tax Return for Verifiability 


\section{Appendix 1}

\section{All returns, total}

Income Items:

Salaries and Wages

Taxable Interest

Ordinary Dividends

State Income Tax Refunds

Alimony Received

Business or profession net income

Business or profession net loss

Capital Gain Distributions

Taxable Net Gain

Taxable Net Loss

Sales of property other than capital assets - net gain

Sales of property other than capital assets - net loss

Taxable IRA distributions

Pensions and annuities - taxable

Rent net income

Rent net loss, including nondeductible loss

Royalty net income

Royalty net loss

Farm rental net income

Farm rental net loss

Partnership and S Corporations net income

Partnership and S Corporations net loss

Estate and Trust net income

Estate and Trust net loss

Farm net income

Farm net loss

Unemployment compensation

Social Security Benefits - Taxable

Foreign earned income exclusion

Other income - net income

Other income - net loss

Net operating loss

Gambling earnings

Cancellation of debt

Income Items Totals

Percentage of income verifiable
Total

$5,842,269,820$

268,058, 182

$237,052,127$

$27,046,648$

$8,759,334$

$334,585,650$

$-54,849,389$

$11,981,884$

$912,182,379$

$-16,508,394$

$15,112,589$

$-10,755,848$

$147,959,327$

$490,581,465$

$56,510,400$

$-74,090,927$

$17,875,464$

$-235,788$

$3,988,998$

$-587,605$

$547,401,480$

$-132,696,270$

20,612,089

$-2,505,195$

$9,931,284$

$-24,624,543$

$29,415,079$

$167,186,633$

$-19,888,233$

41,578,697

$-5,438,442$

$-86,369,141$

$30,139,091$

$1,881,848$

$8,793,560,693$

\section{Verifiable}

$5,842,269,820$

$268,058,182$

$237,052,127$

$27,046,648$

$8,759,334$

$11,981,884$

$147,959,327$

$490,581,465$

$29,415,079$

$167,186,633$

$30,139,091$

$1,881,848$

$7,262,331,438$

$82.59 \%$ 


\section{Appendix 1 (continued)}

\section{Deductions for AGI:}

IRA Payments

Student loan interest deduction

Educator expenses deduction

Tuition and fees deduction

Domestic production activities deduction

Health savings account deduction

One-half of deduction for self-employment tax

Moving expense adjustment

Payments to a KEOGH plan

Penalty on early withdrawal of savings

Alimony paid

Self-employed health insurance deduction

Medical savings account deduction

Certain business expenses of reservists, performing artists, etc.

Other Adjustments

Deductions for AGI Totals

Percentage of adjustments for AGI subject to verification

\section{Other Deductions:}

Basic standard deduction

Additional standard deduction

Total itemized deductions

Exemptions

Other Deductions Totals
Total

$12,876,504$

$7,463,755$

925,997

$10,578,961$

$6,780,483$

$1,500,881$

$24,759,998$

$2,903,022$

$22,262,415$

352,592

$9,496,674$

$21,283,306$

21,748

420,756

$1,295,091$

$122,922,183$
Verifiable

$12,876,504$

$7,463,755$

$10,578,961$

$1,500,881$

$24,759,998$

$22,262,415$

352,592

$9,496,674$

21,748

$89,313,528$

$72.66 \%$

Percentage of other deductions subject to verification

$635,824,934$

$18,356,722$

$1,333,036,542$

$943,171,372$

$2,930,389,570$
$635,824,934$

$18,356,722$

$943,171,372$

$1,597,353,028$

$54.51 \%$

Source: Internal Revenue Service. (2007). Internal

Revenue Service Source of Income Tax Statistics, Table 1, Individual Income Tax, All Returns: Sources of Income and Adjustments. Internal Revenue Service. 
Appendix 2 - Auto Dealer Survey Used in Chapter 6 - Predictors of Tax Evasion 
Auto Dealer Survey

\section{Business Name:}

Tax Number:

Address: 
Cost

Structure

1 Surrounding neighborhood type

\begin{tabular}{|l|c|c|cc|}
\hline 1 & 2 & 3 & \multicolumn{2}{c|}{ Wealthy } \\
\hline Poor & 2 & 3 & 4 & \\
\hline 1 & & & & \\
\hline
\end{tabular}

2 Property appearance

\begin{tabular}{|c|c|c|c|}
\hline 1 & 2 & 3 & 4 \\
\hline Appears low rent
\end{tabular}

Appears low rent

Appears high rent

3 Rent Analysis (In-office analysis)

Approximate square footage (Property tax records)

Approximate rental value per sf (CBRE Survey)

Approximate monthly rent

Average Monthly Sales

Sales minus rents

Rent coverage (Sales divided by rent)

(Note: Rent can be used as a proxy for mortgage payments if owned or as a proxy for asset use value.)

4 Type of dealer

\begin{tabular}{|c|c|c|c|}
\hline 1 & 2 & 3 & 4 \\
\hline Other & $\begin{array}{c}\text { Office/Ware } \\
\text { house }\end{array}$ & $\begin{array}{c}\text { Repair } \\
\text { Shop }\end{array}$ & Traditional \\
\hline
\end{tabular}

5 Size of operation

\begin{tabular}{|c|c|c|c|}
\hline 1 & 2 & 3 & 4 \\
\hline Small & lediu & Larg & Multi-location \\
\hline
\end{tabular}




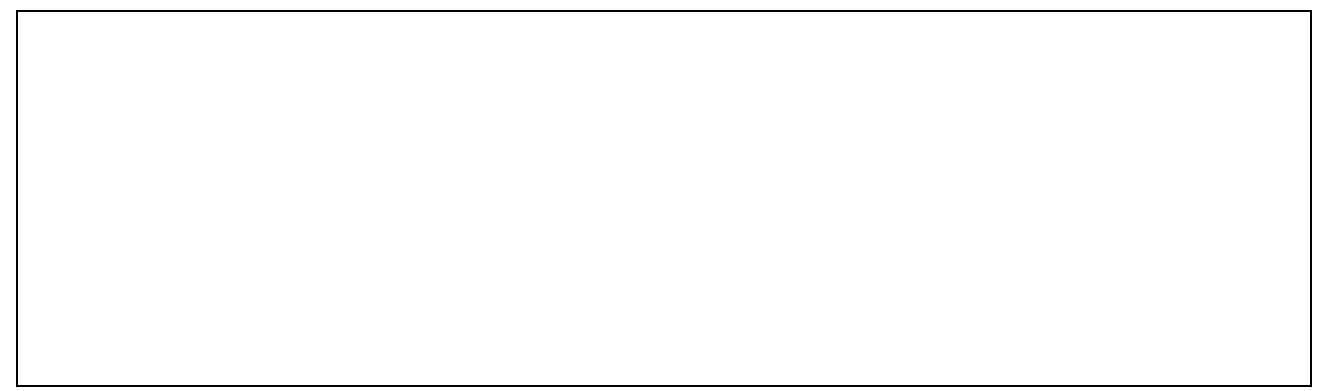

\section{Profit Structure}

1 Condition and type of cars

\begin{tabular}{|c|c|c|c|}
\hline 1 & 2 & 3 & 4 \\
\hline Inexpensive & Expensive \\
\hline
\end{tabular}

\begin{tabular}{|c|c|c|c|}
\hline 1 & 2 & 3 & 4 \\
\hline Disrepair & Fair & Good & Excellent \\
\hline
\end{tabular}

\begin{tabular}{|c|c|c|c|}
\hline 1 & 2 & 3 & 4 \\
\hline General & Mixed & Luxury & Specialty
\end{tabular}

2 Cleanliness and maintenance of facilities

\begin{tabular}{|c|c|c|c|}
\hline 1 & 2 & 3 & 4 \\
\hline Dirty & 2 & 3 & 4 \\
\hline 1 & & & \\
\hline
\end{tabular}

Poorly maintained

Well maintained

3 Location

\begin{tabular}{|c|c|c|c|}
\hline 1 & 2 & 3 & 4 \\
\hline Low traffic & \multicolumn{3}{|c|}{ High traffic } \\
\hline 1 & 2 & 3 & 4 \\
\hline
\end{tabular}

Difficult access and parking 


\begin{tabular}{|c|c|c|c|}
\hline 1 & 2 & 3 & 4 \\
\hline
\end{tabular}

4 In-house financing? (Yes/No) $1=Y ; 2=N$

5 Inventory Size

\begin{tabular}{|c|c|c|c|}
\hline 1 & 2 & 3 & \multicolumn{2}{|c|}{4} \\
\hline $0-15$ & $16-30$ & $31-45$ & $45-$ over \\
Small & & & Large
\end{tabular}

6 Observations

\section{Management}

1 Historical filing review

Files round numbers? (Yes/No)

Files incomplete returns?

(Yes/No)

(Missing signature, only taxable sales - no gross and exempt, etc) 
Number of returns filed late

Out of how many months reviewed?

Returned items? (\#)

Average exempt sales

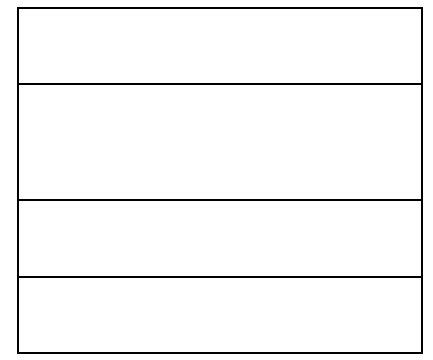

2 Not registered for other taxes they should be registered for?

( 0 = Registered; 1 = Not registered $)$

\section{Corporate}

Doc Stamps (If they provide financing)

Unemployment

Solid Waste (Sec 403.718 - New Tire Fees)

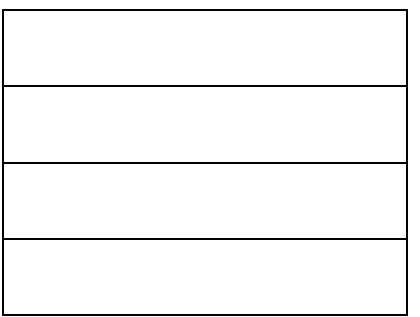

3 Observations:

\section{Churn}

1 String of corporations owned by same or related people, with ownership change or corporation change every few years? (Yes/No) 
Appendix 3 - Case Frequencies from Auto Dealer Survey 


\section{Appendix 3}

\section{Frequency Table}

Theft indicator

\begin{tabular}{|l|r|r|r|r|}
\hline & Frequency & Percent & $\begin{array}{c}\text { Valid } \\
\text { Percent }\end{array}$ & $\begin{array}{c}\text { Cumulative } \\
\text { Percent }\end{array}$ \\
\hline Valid No theft & 153 & 41.5 & 41.5 & 41.5 \\
$\begin{array}{l}\text { Theft indicated - more } \\
\text { than 10\% stolen } \\
\text { Total }\end{array}$ & 216 & 58.5 & 58.5 & 100.0 \\
\hline
\end{tabular}

Neighborhood classification

\begin{tabular}{|l|r|r|r|r|}
\hline & Frequency & Percent & Valid Percent & $\begin{array}{c}\text { Cumulative } \\
\text { Percent }\end{array}$ \\
\hline Valid Industrial & 83 & 22.5 & 22.5 & 22.5 \\
& 282 & 76.4 & 76.4 & 98.9 \\
Moderate & & & & \\
industrial & 4 & 1.1 & 1.1 & 100.0 \\
Moderate retail & 369 & 100.0 & 100.0 & \\
Total &
\end{tabular}

Neighborhood type

\begin{tabular}{|c|c|c|c|c|c|}
\hline & & Frequency & Percent & Valid Percent & $\begin{array}{c}\text { Cumulative } \\
\text { Percent }\end{array}$ \\
\hline \multirow[t]{5}{*}{ Valid } & Poor & 149 & 40.4 & 40.4 & 40.4 \\
\hline & Moderate low & 38 & 10.3 & 10.3 & 50.7 \\
\hline & Moderate high & 105 & 28.5 & 28.5 & 79.1 \\
\hline & Wealthy & 77 & 20.9 & 20.9 & 100.0 \\
\hline & Total & 369 & 100.0 & 100.0 & \\
\hline
\end{tabular}




\section{Appendix 3}

Frequency Table (continued)

\begin{tabular}{|l|r|r|r|r|}
\hline & & & & Neighborhood appearance \\
& Frequency & Percent & Valid Percent & \multicolumn{2}{c|}{\begin{tabular}{l} 
Percent \\
\hline Valid
\end{tabular} Appears low rent } & 79 & 21.4 & 21.4 & 21.4 \\
& 162 & 43.9 & 43.9 & 65.3 \\
Moderate low rent & 107 & 29.0 & 29.0 & 94.3 \\
Moderate high rent & 21 & 5.7 & 5.7 & 100.0 \\
High rent & 369 & 100.0 & 100.0 & \\
Total & & & &
\end{tabular}

\section{Dealer type}

\begin{tabular}{|l|r|r|r|r|}
\hline & Frequency & Percent & Valid Percent & $\begin{array}{c}\text { Cumulative } \\
\text { Percent }\end{array}$ \\
\hline Valid Other & 38 & 10.3 & 10.3 & 10.3 \\
& 117 & 31.7 & 31.7 & 42.0 \\
Office/warehouse & 24 & 6.5 & 6.5 & 48.5 \\
Repair Shop & 190 & 51.5 & 51.5 & 100.0 \\
Traditional sales lot & 369 & 100.0 & 100.0 & \\
Total & & &
\end{tabular}

Size of dealer operation

\begin{tabular}{|ll|r|r|r|r|}
\hline & Frequency & Percent & Valid Percent & $\begin{array}{c}\text { Cumulative } \\
\text { Percent }\end{array}$ \\
\hline Valid Small & 228 & 61.8 & 61.8 & 61.8 \\
& 82 & 22.2 & 22.2 & 84.0 \\
Medium & 52 & 14.1 & 14.1 & 98.1 \\
Large & 7 & 1.9 & 1.9 & 100.0 \\
Multi-location & 369 & 100.0 & 100.0 & \\
Total & & &
\end{tabular}




\section{Appendix 3}

Frequency Table (continued)

Price range of cars on the lot

\begin{tabular}{|ll|r|r|r|r|}
\hline & & & & \multicolumn{2}{c|}{$\begin{array}{c}\text { Cumulative } \\
\text { Percent }\end{array}$} \\
\hline Valid & Inexpensive & 111 & 30.1 & 50.5 & 50.5 \\
& Moderate low & 81 & 22.0 & 36.8 & 87.3 \\
& Moderate high & 16 & 4.3 & 7.3 & 94.5 \\
Expensive & 12 & 3.3 & 5.5 & 100.0 \\
Total & 220 & 59.6 & 100.0 & \\
Missing & 149 & 40.4 & & \\
& Total & 369 & 100.0 & & \\
\hline
\end{tabular}

State of cars on the lot

\begin{tabular}{|ll|r|r|r|r|}
\hline & Frequency & Percent & Valid Percent & Cumulative Percent \\
\hline Valid & Disrepair & 3 & .8 & 1.4 & 1.4 \\
& Fair & 34 & 9.2 & 15.5 & 16.9 \\
Good & 166 & 45.0 & 75.8 & 92.7 \\
Excellent & 16 & 4.3 & 7.3 & 100.0 \\
Total & 219 & 59.3 & 100.0 & \\
Missing & 150 & 40.7 & & \\
Total & 369 & 100.0 & & \\
\hline
\end{tabular}

Type of cars sold

\begin{tabular}{|ll|r|r|r|r|}
\hline & & & & \\
\hline Valid & General & 139 & 37.7 & 63.5 & Cumulative Percent \\
& Mixed & 54 & 14.6 & 24.7 & 63.5 \\
& Luxury & 8 & 2.2 & 3.7 & 88.1 \\
& Specialty & 18 & 4.9 & 8.2 & 91.8 \\
Total & 219 & 59.3 & 100.0 & 100.0 \\
Missing & 150 & 40.7 & & \\
& Total & 369 & 100.0 & & \\
\hline
\end{tabular}


Appendix 3

Frequency Table (continued)

Cleanliness of premises

\begin{tabular}{|ll|r|r|r|r|}
\hline & Frequency & Percent & $\begin{array}{c}\text { Valid } \\
\text { Percent }\end{array}$ & $\begin{array}{c}\text { Cumulative } \\
\text { Percent }\end{array}$ \\
\hline Valid Dirty & 36 & 9.8 & 9.8 & 9.8 \\
Fair & 89 & 24.1 & 24.1 & 33.9 \\
Clean & 139 & 37.7 & 37.7 & 71.5 \\
Very clean & 105 & 28.5 & 28.5 & 100.0 \\
Total & 369 & 100.0 & 100.0 & \\
\hline
\end{tabular}

Maintenance status of premises

\begin{tabular}{|l|r|r|r|r|}
\hline & Frequency & Percent & $\begin{array}{c}\text { Valid } \\
\text { Percent }\end{array}$ & $\begin{array}{c}\text { Cumulative } \\
\text { Percent }\end{array}$ \\
\hline Valid Poorly maintained & 29 & 7.9 & 7.9 & 7.9 \\
$\begin{array}{l}\text { Moderate low } \\
\text { maintenance }\end{array}$ & 95 & 25.7 & 25.7 & 33.6 \\
$\begin{array}{l}\text { Moderate high } \\
\text { maintenance }\end{array}$ & 140 & 37.9 & 37.9 & 71.5 \\
Well maintained & 105 & 28.5 & 28.5 & 100.0 \\
Total & 369 & 100.0 & 100.0 & \\
\hline
\end{tabular}

\section{Customer traffic}

\begin{tabular}{|l|r|r|r|r|}
\hline & Frequency & Percent & $\begin{array}{c}\text { Valid } \\
\text { Percent }\end{array}$ & $\begin{array}{c}\text { Cumulative } \\
\text { Percent }\end{array}$ \\
\hline Valid Low traffic & 110 & 29.8 & 29.8 & 29.8 \\
Moderately low traffic & 45 & 12.2 & 12.2 & 42.0 \\
Moderately high traffic & 37 & 10.0 & 10.0 & 52.0 \\
High traffic & 177 & 48.0 & 48.0 & 100.0 \\
Total & 369 & 100.0 & 100.0 & \\
\hline
\end{tabular}




\section{Appendix 3}

Frequency Table (continued)

\begin{tabular}{|l|r|r|r|r|}
\hline \multicolumn{1}{|c|}{ Access to premises } \\
\hline & Frequency & Percent & $\begin{array}{c}\text { Valid } \\
\text { Percent }\end{array}$ & $\begin{array}{c}\text { Cumulative } \\
\text { Percent }\end{array}$ \\
\hline Valid $\begin{array}{l}\text { Difficult access and } \\
\text { parking }\end{array}$ & 8 & 2.2 & 2.2 & 2.2 \\
$\begin{array}{l}\text { Moderately difficult } \\
\text { access and parking }\end{array}$ & 54 & 14.6 & 14.6 & 16.8 \\
$\begin{array}{l}\text { Moderately easy access } \\
\text { and parking }\end{array}$ & 149 & 40.4 & 40.4 & 57.2 \\
$\begin{array}{l}\text { Easy access and } \\
\text { parking }\end{array}$ & 158 & 42.8 & 42.8 & 100.0 \\
Total & 369 & 100.0 & 100.0 & \\
\hline
\end{tabular}

\begin{tabular}{|l|r|r|r|r|}
\hline \multicolumn{1}{|c|}{ Retail location indicator } \\
\hline & Frequency & Percent & $\begin{array}{c}\text { Valid } \\
\text { Percent }\end{array}$ & $\begin{array}{c}\text { Cumulative } \\
\text { Percent }\end{array}$ \\
\hline Valid Not meant for retail & 123 & 33.3 & 33.3 & 33.3 \\
Retail possible but not & 29 & 7.9 & 7.9 & 41.2 \\
relied on & 19 & 5.1 & 5.1 & 46.3 \\
Retail encouraged & 198 & 53.7 & 53.7 & 100.0 \\
Full retail & 369 & 100.0 & 100.0 & \\
Total & & & & \\
\hline
\end{tabular}

Buy Here Pay Here lot

\begin{tabular}{|ll|r|r|r|r|}
\hline & Frequency & Percent & $\begin{array}{c}\text { Valid } \\
\text { Percent }\end{array}$ & $\begin{array}{c}\text { Cumulative } \\
\text { Percent }\end{array}$ \\
\hline Valid No & 289 & 78.3 & 78.3 & 78.3 \\
& Yes & 80 & 21.7 & 21.7 & 100.0 \\
Total & 369 & 100.0 & 100.0 & \\
\hline
\end{tabular}




\section{Appendix 3}

Frequency Table (continued)

\begin{tabular}{|c|c|c|c|c|c|}
\hline \multicolumn{6}{|c|}{ Inventory size } \\
\hline & & Frequency & Percent & Valid Percent & $\begin{array}{c}\text { Cumulative } \\
\text { Percent }\end{array}$ \\
\hline \multirow[t]{5}{*}{ Valid } & Small 0 to 15 & 68 & 18.4 & 31.8 & 31.8 \\
\hline & Moderate 15 to 30 & 65 & 17.6 & 30.4 & 62.1 \\
\hline & Moderate 31 to 45 & 42 & 11.4 & 19.6 & 81.8 \\
\hline & Large over 45 & 39 & 10.6 & 18.2 & 100.0 \\
\hline & Total & 214 & 58.0 & 100.0 & \\
\hline \multirow[t]{2}{*}{ Missing } & 0 & 155 & 42.0 & & \\
\hline & Total & 369 & 100.0 & & \\
\hline
\end{tabular}

\section{Registered for corporate tax}

\begin{tabular}{|ll|r|r|r|r|}
\hline & Frequency & Percent & Valid Percent & $\begin{array}{c}\text { Cumulative } \\
\text { Percent }\end{array}$ \\
\hline Valid & Yes & 350 & 94.9 & 94.9 & 94.9 \\
& No & 19 & 5.1 & 5.1 & 100.0 \\
& Total & 369 & 100.0 & 100.0 & \\
\hline
\end{tabular}

In-house financing offered

\begin{tabular}{|ll|r|r|r|r|}
\hline & & & & \multicolumn{2}{c|}{$\begin{array}{c}\text { Cumulative } \\
\text { Percent }\end{array}$} \\
\hline Valid & No & 289 & 78.3 & 78.3 & 78.3 \\
& Yes & 80 & 21.7 & 21.7 & 100.0 \\
& Total & 369 & 100.0 & 100.0 & \\
\hline
\end{tabular}


Appendix 3

Frequency Table (continued)

Registered for documentary stamp tax

\begin{tabular}{|l|r|r|r|r|}
\hline & & & & \multicolumn{2}{c|}{$\begin{array}{c}\text { Cumulative } \\
\text { Percent }\end{array}$} \\
\hline Valid Yes & Frequency & Percent & Valid Percent & 11.4 \\
& 42 & 11.4 & 11.4 & 100.0 \\
No & 327 & 88.6 & 88.6 & \\
Total & 369 & 100.0 & 100.0 & \\
\hline
\end{tabular}

Registered for unemployment compensation tax

\begin{tabular}{|c|c|c|c|c|c|}
\hline & & Frequency & Percent & Valid Percent & $\begin{array}{c}\text { Cumulative } \\
\text { Percent }\end{array}$ \\
\hline \multirow[t]{3}{*}{ Valid } & Yes & 184 & 49.9 & 49.9 & 49.9 \\
\hline & No & 185 & 50.1 & 50.1 & 100.0 \\
\hline & Total & 369 & 100.0 & 100.0 & \\
\hline
\end{tabular}


VITA

\section{PHILIP CARY CHRISTIAN}

February 22, 1956

May, 1979

June 1979 - September 1990

March 1981

October 1990 - December 1993

January 1994 - December 1996

January 1997 - June 2002

July 2002 - present

May 2010

May 2010 - present
Born, Bluefield, West Virginia

B.S. Business Administration

Concord University

Athens, West Virginia

Accountant, Certified Public Accountant, Tax Manager

Arthur Andersen \& Co.

Miami, Florida

Certified Public Accountant

State of Florida

Managing Partner

Christian, Pringle \& Lecusay, P.A.

Miami, Florida

Partner in Charge of Taxation and Systems

Consultation

Silver and Company, P.A.

Miami, Florida

Director, Senior Project Manager and

Systems Architect

Peak Consulting, Inc.

Miami, Florida

Revenue Investigator - Criminal

Enforcement and Digital Forensics

Examiner

Florida Department of Revenue

Miami, Florida

Masters in Public Administration

Florida International University

Miami, Florida

Adjunct Faculty - Public Administration Florida International University

Miami, Florida 


\section{PUBLICATIONS AND PRESENTATIONS}

"When Public Information Systems Become a Crime Scene: An Overview of Forensic Considerations in Incident Response," Book Chapter, in Christopher Shea, editor, Handbook of Public Information Systems, Third Edition, New York: CRC Press, 2010 (forthcoming).

"Generating the Public Financial Management Knowledge Base: Analyzing Method and Direction as a Sub-Discipline of Public Administration," (with Howard Frank and Gina Scutelnicu) Journal of Public Budgeting, Accounting, and Financial Management, Volume 21, No. 2, Summer 2009, pp. 223-246.

"An Empirical Analysis of the Impact of Business Environment on the Incidence of Tax Evasion," (with Howard Frank), presented at the Southeastern Conference for Public Administration in Athens, Georgia, September 27 - 30, 2006.

"Generating the Public Financial Management Knowledge Base: Analyzing Method and Direction as a Sub-Discipline of Public Administration," (with Howard Frank and Gina Scutelnicu), presented at the Southeastern Conference for Public Administration in Athens, Georgia, September 27 - 30, 2006.

"Affordability of State Debt Revisited: Alternative Strategies for Measurement and Analysis," (with Nadine Wedderburn, Yongfeng Zhao, and Yong Zhaun), presented at the Southeastern Conference for Public Administration in Little Rock, Arkansas, October $5-8,2005$. 